Argonne

ANL-06/14

\title{
Development of Materials Resistant to Metal Dusting Degradation
}

Annual Report for Calendar Year 2005

Energy Technology Division 


\section{About Argonne National Laboratory}

Argonne is a U.S. Department of Energy laboratory managed by The University of Chicago

under contract W-31-109-Eng-38. The Laboratory's main facility is outside Chicago, at

9700 South Cass Avenue, Argonne, Illinois 60439. For information about Argonne,

see www.anl.gov.

\section{Availability of This Report}

This report is available, at no cost, at http://www.osti.gov/bridge. It is also available

on paper to the U.S. Department of Energy and its contractors, for a processing fee, from:

U.S. Department of Energy

Office of Scientific and Technical Information

P.O. Box 62

Oak Ridge, TN 37831-0062

phone (865) 576-8401

fax (865) 576-5728

reports@adonis.osti.gov

\section{Disclaimer}

This report was prepared as an account of work sponsored by an agency of the United States Government. Neither the United States Government nor any agency thereof, nor The University of Chicago, nor any of their employees or officers, makes any warranty, express or implied, or assumes any legal liability or responsibility for the accuracy, completeness, or usefulness of any information, apparatus, product, or process disclosed, or represents that its use would not infringe privately owned rights. Reference herein to any specific commercial product, process, or service by trade name, trademark, manufacturer, or otherwise, does not necessarily constitute or imply its endorsement, recommendation, or favoring by the United States Government or any agency thereof. The views and opinions of document authors expressed herein do not necessarily state or reflect those of the United States Government or any agency thereof, Argonne National Laboratory, or The University of Chicago. 


\section{Development of Materials Resistant to Metal Dusting Degradation}

by

K. Natesan and Z. Zeng

Energy Technology Division, Argonne National Laboratory

March 2006

work supported by

The U.S. Department of Energy

Office of Industrial Technologies

Project Manager: S. Dillich 


\section{CONTENTS}

ABSTRACT

PROJECT DESCRIPTION.

BACKGROUND

ECONOMIC BENEFIT

OBJECTIVES

STEERING GROUP AND MTI PROJECT MEETINGS

PROJECT TASKS

1. GAS CHEMISTRY AND CARBON ACTIVITY

2. EXPERIMENTAL PROGRAM

2.1 Description of Reactor Systems

2.2 Surface Profiler to Measure Depth of Metal Dusting Pits

2.3 Materials

2.4 Specimen Preparation.

2.5 Post-exposure Analysis of Specimens

2.6 Metal Dusting Experiments

3. TEST RESULTS AND DISCUSSION

3.1 Weight Loss Data for Ni-Base Alloys at Carbon Activity of 31

3.2 Characterization of Pits on Ni-Base Alloys at Carbon Activity of 31

3.3 Pit Diameter and Density in Ni-Base Alloys

3.4 Correlation between Pit Growth Rate and Weight Loss.

3.5 Effect of System Pressure on Metal Dusting Corrosion of Ni-base Alloys

3.6 Pre-pitting Experiment.

3.7 Approach to Mitigate Metal Dusting Corrosion 
3.8 Effect of Carbon Activity on Metal Dusting Corrosion

4. ANALYSIS OF METAL DUSTING FAILURES

5. PERFORMANCE OF WELDMENTS

6. SUMMARY

ACKNOWLEDGMENTS

REFERENCES 


\section{FIGURES}

1.1 Chemical composition and carbon activity for gas mixtures used in metal dusting study

1.2 Carbon activities of Gas 18 as a function of temperature at $1 \mathrm{~atm}$

1.3 Carbon activities of Gas 18 as a function of temperature at $30 \mathrm{~atm}$.

1.4 Carbon activities of Gas 19 as a function of temperature at $25 \mathrm{~atm}$.

1.5 Carbon activities of Gas 21 as a function of temperature at $1 \mathrm{~atm}$.

2.1 Schematic of three atmospheric test facilities used for metal dusting experiments.

2.2 Schematic of furnace assembly and gas flow arrangement used for metal dusting experiments

2.3 Schematic of steam and gas flow scheme used for metal dusting experiments.

2.4. Schematic of quartz specimen holder and test coupon arrangement used for metal dusting experiments.

2.5. Schematic of high-pressure, high-temperature system for metal dusting experiments.

2.6. Magnified view of the high-pressure region of the system shown in Fig. 2.5 .

2.7 Schematic for MicroXAM surface profiler.

2.8 Example of a profile map measured by MicroXAM surface profiler.

3.1 Weight loss data for Ni-base alloys that were exposed in Gas 10 at $593^{\circ} \mathrm{C}$ and $14.3 \mathrm{~atm}$

3.2 SEM photo-micrographs of surfaces of several Ni-base alloys after exposure to metal dusting environment

3.3 Pit morphology as a function of time for Alloy 601 exposed to Gas 10 at $593^{\circ} \mathrm{C}$ and $14.3 \mathrm{~atm}$

3.4 Pit morphology as a function of time for Alloy 690 exposed to Gas 10 at $593^{\circ} \mathrm{C}$ and $14.3 \mathrm{~atm}$. 
3.5 Pit morphology as a function of time for Alloy 617 exposed to Gas 10 at $593^{\circ} \mathrm{C}$ and $14.3 \mathrm{~atm}$

3.6 Pit morphology as a function of time for Alloy 602CA exposed to Gas 10 at $593^{\circ} \mathrm{C}$ and $14.3 \mathrm{~atm}$

3.7 Pit morphology as a function of time for Alloy 45TM exposed to Gas 10 at $593^{\circ} \mathrm{C}$ and $14.3 \mathrm{~atm}$

3.8 Pit morphology as a function of time for Alloy HR160 exposed to Gas 10 at $593^{\circ} \mathrm{C}$ and $14.3 \mathrm{~atm}$

3.9 Pit morphology as a function of time for Alloy 214 exposed to Gas 10 at $593^{\circ} \mathrm{C}$ and $14.3 \mathrm{~atm}$

3.10 Pit morphology for Alloy 693 after $9300-\mathrm{h}$ exposure to Gas 10 at $593^{\circ} \mathrm{C}$ and $14.3 \mathrm{~atm}$

3.11 Pit diameter and density for Alloy 601 as a function of exposure time in Gas 10 at $593^{\circ} \mathrm{C}$ and $14.3 \mathrm{~atm}$

3.12 Pit diameter and density for Alloy 690 as a function of exposure time in Gas 10 at $593^{\circ} \mathrm{C}$ and $14.3 \mathrm{~atm}$

3.13 Pit diameter and density for Alloy 617 as a function of exposure time in Gas 10 at $593^{\circ} \mathrm{C}$ and $14.3 \mathrm{~atm}$

3.14 Pit diameter and density for Alloy 602CA as a function of exposure time in Gas 10 at $593^{\circ} \mathrm{C}$ and $14.3 \mathrm{~atm}$

3.15 Pit diameter and density for Alloy 214 as a function of exposure time in Gas 10 at $593^{\circ} \mathrm{C}$ and $14.3 \mathrm{~atm}$

3.16 Pit diameter and density for Alloy 45TM as a function of exposure time in Gas 10 at $593^{\circ} \mathrm{C}$ and $14.3 \mathrm{~atm}$

3.17 Pit diameter and density for Alloy HR160 as a function of exposure time in Gas 10 at $593^{\circ} \mathrm{C}$ and $14.3 \mathrm{~atm}$

3.18 3-D profile map of Ni-base alloys after 9700-h exposure in Gas 10 at $593^{\circ} \mathrm{C}$ and $14.3 \mathrm{~atm}$

3.19 Correlation between weight loss and variation in size of single pit on surface of various alloys as a function of exposure time at $593^{\circ} \mathrm{C}$ in Run $59 \mathrm{HP}$

3.20 Weight loss for Ni-base alloys at system pressures of 1 and $14.3 \mathrm{~atm}$, a carbon activity of $\approx 31$, and temperature of $593^{\circ} \mathrm{C}$ 
3.21 Metal dusting pits on the edges of Alloy 800 and Type 321 stainless steel.

3.22 Schematic of scale cracking at the corner of the alloy

3.23 Alloy 800 scratched by an engraver with a carbide-tipped point

3.24 Metal dusting pits on Alloy 800 after 6-day exposure to a flowing carburizing atmosphere consisting of $72.2 \% \quad \mathrm{H}_{2}-8.3 \% \mathrm{CO}_{2}-17.6 \% \mathrm{CO}-1.96 \% \mathrm{H}_{2} \mathrm{O}$ at $593^{\circ} \mathrm{C}$.

3.25 Metal dusting pits on Alloy $9 \mathrm{Cr}-1 \mathrm{Mo}$ after 2-day exposure to a flowing carburizing atmosphere consisting of $72.2 \% \mathrm{H}_{2}-8.3 \% \mathrm{CO}_{2}-17.6 \% \mathrm{CO}-1.96 \%$ $\mathrm{H}_{2} \mathrm{O}$ at $593^{\circ} \mathrm{C}$

3.26 Metal dusting pits on Alloy 9Cr-1Mo after 4-day exposure to a flowing carburizing atmosphere consisting of $72.2 \% \mathrm{H}_{2}-8.3 \% \mathrm{CO}_{2}-17.6 \% \mathrm{CO}-1.96 \%$ $\mathrm{H}_{2} \mathrm{O}$ at $593^{\circ} \mathrm{C}$.

3.27 Metal dusting pits on Alloy $9 \mathrm{Cr}-1 \mathrm{Mo}$ after 6-day exposure to a flowing carburizing atmosphere consisting of $72.2 \% \mathrm{H}_{2}-8.3 \% \mathrm{CO}_{2}-17.6 \% \mathrm{CO}-1.96 \%$ $\mathrm{H}_{2} \mathrm{O}$ at $593^{\circ} \mathrm{C}$.

3.28 Model of possible carbon-transferring channel.

3.29 Device for electrochemical deposition of copper.

3.30 SEM micrograph of Alloy 800 after exposure to a carburizing atmosphere

3.31 SEM micrograph of Alloy $9 \mathrm{Cr}-1 \mathrm{Mo}$ after exposure to a carburizing atmosphere

3.32 SEM micrograph of Alloy 800 after exposure to a carburizing atmosphere..

3.33 SEM micrographs of Alloy 601 after 500-h exposure to a carburizing gas consisting of $50 \% \mathrm{H}_{2}$ and $50 \% \mathrm{CO}$ at 593 and $704^{\circ} \mathrm{C}$

3.34 Surface profile of Alloy 601 after $500-\mathrm{h}$ exposure to a carburizing gas consisting of $50 \% \mathrm{H}_{2}$ and $50 \% \mathrm{CO}$ at 593 and $704^{\circ} \mathrm{C}$

3.35 SEM photomicrographs of Alloy 617 after 500-h exposure to a carburizing gas consisting of $50 \% \mathrm{H}_{2}$ and $50 \% \mathrm{CO}$ at 593 and $704^{\circ} \mathrm{C}$

3.36 Profile map of Alloy 602CA exposed to a carburizing gas consisting of $50 \%$ $\mathrm{H}_{2}-50 \% \mathrm{CO}$ at $704^{\circ} \mathrm{C}$ for $500 \mathrm{~h}$

3.37 Profile map of Alloy 602CA exposed to a carburizing gas consisting of $50 \% \mathrm{H}_{2}-50 \% \mathrm{CO}$ at $593^{\circ} \mathrm{C}$ for $500 \mathrm{~h}$ 
3.38 SEM photomicrographs of Alloy 214 exposed to a carburizing gas consisting of $50 \% \mathrm{H}_{2}-50 \% \mathrm{CO}$ at 593 and $704^{\circ} \mathrm{C}$ for $500 \mathrm{~h}$

3.39 Schematic of a model for initiation of a metal dusting pit

3.40 Schematic of carbon transfer channels in a pit

3.41 Metal dusting pit on Alloy 800 after 5-day exposure to a carburizing atmosphere consisting of $72.2 \% \mathrm{H}_{2}-8.3 \% \mathrm{CO}_{2}-17.6 \% \mathrm{CO}-1.96 \% \mathrm{H}_{2} \mathrm{O}$ at $593^{\circ} \mathrm{C}$.

3.42 The specimen shown in Fig. 3.41 after exposure to $72.2 \% \mathrm{H}_{2}-8.3 \% \mathrm{CO}_{2}$ $17.6 \% \mathrm{CO}-1.96 \% \mathrm{H}_{2} \mathrm{O}$ at $593^{\circ} \mathrm{C}$ for 4 days and 6 days

3.43 Another metal dusting pit on Alloy 800 after exposure to carburizing atmosphere consisting of $72.2 \% \quad \mathrm{H}_{2}-8.3 \% \mathrm{CO}_{2}-17.6 \% \mathrm{CO}-1.96 \% \mathrm{H}_{2} \mathrm{O}$ at $593^{\circ} \mathrm{C}$ for 5 days

3.44 Specimen shown in Fig. 3.43 after further exposure to the carburizing atmosphere for 4 and 6 days

3.45 Third pit on Alloy 800 after exposure to carburizing atmosphere consisting of $72.2 \% \mathrm{H}_{2}-8.3 \% \mathrm{CO}_{2}-17.6 \% \mathrm{CO}-1.96 \% \mathrm{H}_{2} \mathrm{O}$ at $593^{\circ} \mathrm{C}$ for 5 days

3.46 Schematic of a model for the blocking action of oxide layer after intermediate oxidation of metal dusted alloy....

3.47 Weight loss of Ni-based alloys after 5839-h exposure to Gas 21 at $593^{\circ} \mathrm{C}$ and $1 \mathrm{~atm}$

3.48 Pit size in Ni-based alloys after $5839-\mathrm{h}$ exposure to Gas 21 at $593^{\circ} \mathrm{C}$ and 1 atm.

4.1. A pipe and a plate obtained from a syngas plant.

4.2. Cross section of the Alloy $800 \mathrm{HT}$ pipe

4.3 EDX map of the cross section of the pipe from a syngas plant

4.4 EDX line scanning of the cross section of the thick part of the pipe.

4.5 Weight change data for several spinels during exposure in Gas 2 at $593^{\circ} \mathrm{C}$.

4.6 Spectra from the cross section of thick part of the pipe for Raman shift of $400-750 \mathrm{~cm}^{-1}$. 
4.7 Spectra from the cross section of thick part of the pipe for Raman shift of $1200-1700 \mathrm{~cm}^{-1}$.

4.8 EDX line scanning of the cross section of Alloy 45TM after 3700-h exposure to $\mathrm{Gas} 10$ at $593^{\circ} \mathrm{C}$ and $14.3 \mathrm{~atm}$

5.1 Macrophotograph of weldment and corresponding base metal specimens after $3114 \mathrm{~h}$ exposure at $593^{\circ} \mathrm{C}$ and $1 \mathrm{~atm}$ in a gas mixture with a carbon activity of 104

5.2 Weight loss data for weldment specimens and corresponding base alloys after $3114 \mathrm{~h}$ exposure at $593^{\circ} \mathrm{C}$ and $1 \mathrm{~atm}$ in a gas mixture with a carbon activity of 104

5.3 Three-dimension profile mapping of weld materials.

5.4 Pits at the weld area of weldment W7

5.5 Photomicrograph of Weldment W7 showing pits in the weld zone 


\section{TABLES}

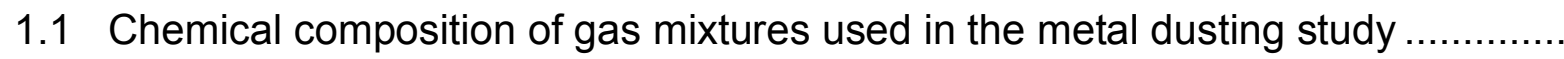

2.1 Specification for MicroXAM surface profiler

2.2. Chemical composition of alloys selected for evaluation

2.3 List of weldment details

2.4 Experimental conditions for laboratory runs.

3.1 Surface Characteristics of alloys after 246-h exposure at 1, 14.3, and 40.8 atm and $593^{\circ} \mathrm{C}$

3.2 Maximum pit size and weight loss for alloys after 9700-h exposure in Run $59 \mathrm{HP}$

5.1 Weldments of Ni-base alloys used in the study 


\begin{abstract}
Metal dusting corrosion has been a serious problem in the petroleum and petrochemical industries, such as reforming and syngas production systems. This form of deterioration has led to worldwide material loss for 50 years. For the past three years, we have studied the mechanism of metal dusting for Fe- and Ni-base alloys. In this report, we present a correlation between the weight loss and depth of pits that form in Ni-base alloys. Nickel-base alloys were also tested at 1 and 14.8 atm (210 psi), in a high carbon activity environment. Higher system pressure was found to accelerate corrosion in most Ni-base alloys. To reduce testing time, a pre-pitting method was developed. Mechanical scratches on the alloy surface led to fast metal dusting corrosion. We have also developed preliminary data on the performance of weldments of several Ni-base alloys in a metal dusting environment. Finally, Alloy 800 tubes and plates used in a reformer plant were examined by scanning electron microscopy, energy dispersive X-ray, and Raman spectroscopy. The oxide scale on the surface of the Alloy 800 primarily consists of $\mathrm{Fe}_{1+\mathrm{x}} \mathrm{Cr}_{2-\mathrm{x}} \mathrm{O}_{4}$ spinel phase with high $\mathrm{Fe}$ content. Carbon can diffuse through this oxide scale. It was discovered that the growth of metal dusting pits could be stopped by means of a slightly oxidized alloy surface. This leads to a new way to solve metal dusting problem.
\end{abstract}

\title{
PROJECT DESCRIPTION
}

The current project, funded by the U.S. Department of Energy (DOE), Idaho Operations Office, involves research and development of materials and processing methods, in accordance with the Program Plan for the Industrial Materials for the Future (IMF) subprogram. Consistent with the mission of the DOE Energy Efficiency and Renewable Energy (EERE) Industrial Technologies Program (OIT), the mission of the IMF subprogram is to lead a national effort to research, design, engineer, and test new and improved materials, as well as more profitable uses of existing materials, for the Industries of the Future (IOF).

Degradation of metallic structural components by metal dusting is a major concern in several IOFs. It is a major issue in plants used in the production of hydrogen, ammonia synthesis processes, methanol-reformer systems, and syngas $\left(\mathrm{H}_{2} / \mathrm{CO}\right.$ mixtures) systems that are pertinent to chemical and petrochemical industries. Metal dusting is experienced at high temperatures in oxidizing-carburizing environments that are prevalent in heat-treating industry. The gases used in heat-treating operations mix with oil residue on the work pieces to form gases that are kinetically favorable for metal dusting attack. Petroleum refineries experience metal dusting attack in processes that involve hydro-dealkylation and catalyst re-generation. In the steel sector, metal dusting is an issue in iron-making blast furnaces in steel plants and in processes, such as Nucor, that involve direct reduction of ores to form iron. Metal dusting also occurs with processes that handle carbon dioxide for cooling, the recycle-gas loop equipment of coal gasification units, fired heaters handling hydrocarbons at elevated temperatures, and metallic interconnects used in solid oxide fuel cells. Currently, the industrial sectors circumvent metal dusting attack by cooling the gas to temperatures low enough to avoid 
the problem but pay a penalty in the form of lower efficiency, wastage of energy, and decrease in product yield.

The current project is aimed at development of metallic alloys and surface engineering of commercial alloys to mitigate metal dusting degradation. The alloys will have an improved corrosion resistance and will also possess adequate mechanical properties at temperatures up to $816^{\circ} \mathrm{C}\left(1500^{\circ} \mathrm{F}\right)$. The project will involve exposure of candidate alloys and surface-engineered materials to metal dusting environments that simulate the temperatures, pressures, and gas chemistry prevalent in hydrogen and ammonia reformers and in syngas systems. The project will also develop a database on metal dusting degradation from the standpoint of incubation time, general corrosion, pitting attack, pitting rate, and size for the candidate alloys as a function of the process variables.

\section{BACKGROUND}

Carbon activity $\left(\mathrm{a}_{\mathrm{C}}\right)$ reflects the potential of carbon to deposit from carbonbearing gases. When $\mathrm{a}_{\mathrm{c}}>1$, carbon can deposit as a solid phase that is usually called "coke." In many industries, metallic alloys are used as structural components at elevated temperature in high carbon activity environment. For example, in hydrogen and syngas plants, methane and various other hydrocarbons are reformed or partially oxidized to produce hydrogen and carbon monoxide. When those carbon-bearing gases are catalyzed at elevated temperature, carbon will deposit on the surface of alloys that constitute vessels, gas-transfer pipes, and other equipment. Interactions between carbon and alloys lead to disintegration of the alloys into fine particles that can be carried away by the flowing gas. In the metal wastage process, pits form on the surface of alloys accompanied by the formation of a fine powder of carbide or pure metal and carbon dust. This metal wastage process, called "metal dusting," is a much more severe problem than regular carburization since the equipment or pipes will be totally destroyed after alloys become fine powder.

Three possible steps can contribute to degradation of material by metal dusting process. The first step is deposition of carbon from a multicomponent gas phase onto the surface of alloys. In typical carbonaceous environments, three potential reactions can lead to carbon deposition:

$$
\begin{array}{ll}
\mathrm{H}_{2}+\mathrm{CO}=\mathrm{C}+\mathrm{H}_{2} \mathrm{O} & \mathrm{a}_{\mathrm{C}}=\mathrm{K} \cdot \mathrm{P}_{\mathrm{H} 2} \cdot \mathrm{P}_{\mathrm{CO}} / \mathrm{P}_{\mathrm{H} 2 \mathrm{O}} \\
2 \mathrm{CO}=\mathrm{C}+\mathrm{CO}_{2} & \mathrm{a}_{\mathrm{C}}=\mathrm{K} \cdot \mathrm{P}_{\mathrm{CO}}{ }^{2} / \mathrm{P}_{\mathrm{CO} 2} \\
\mathrm{CH}_{4}=\mathrm{C}+2 \mathrm{H}_{2} & \mathrm{a}_{\mathrm{C}}=\mathrm{K} \cdot \mathrm{P}_{\mathrm{CH} 4} / \mathrm{P}_{\mathrm{H} 2}{ }^{2}
\end{array}
$$

The first reaction is the fastest and plays a major role in carbon deposition. High carbon activity is the driving force for the first step. In the second step, carbon atoms dissolve and diffuse into the alloys. The second step is driven by the concentration gradient of carbon. In the third step, graphite particles develop and lead to the separation of metal grains and/or carbide particles. Even though the third step leads to catastrophic attack, the driving force for this step had not been clear for a long time. 
For iron-base alloys, it was proposed that metal dusting occurs because of the following: (a) carbon deposits on the metal surface and dissolves in the metal, (b) $\mathrm{Fe}_{3} \mathrm{C}$ forms as carbon diffuses into the iron and the metal becomes oversaturated, and (c) metastable $\mathrm{Fe}_{3} \mathrm{C}$ decomposes to $\mathrm{Fe}$ and graphite. According to this mechanism, the final product is graphite and iron. However, there is no conclusive evidence that the iron phase is present in every case of metal dusting. It is not clear what drives the formation and decomposition of $\mathrm{Fe}_{3} \mathrm{C}$ under the same conditions of temperature, pressure, and composition. Clearly, graphite crystallizes from a supersaturated solution. Nevertheless, it is doubtful that its crystallization also causes $\mathrm{Fe}_{3} \mathrm{C}$ to decompose. The formation and decomposition of chemical bonds in the carbide phase require a sizable free energy change.

Recently, in research conducted at Argonne under the sponsorship of DOE/OIT, we proposed a new mechanism for metal dusting based on the crystallinity of carbon obtained by X-ray diffraction and Raman spectroscopy. Metal dusting in iron-base alloys is considered to be a process of catalytic crystallization of carbon with participation by iron. The difference in the free energy of poorly crystallized carbon and well-crystallized graphite is a driving force for crystallization of carbon. However, this process cannot occur at low temperature because the $\mathrm{C}-\mathrm{C}$ bonds are too strong to allow movement of carbon atoms. $\mathrm{Fe}_{3} \mathrm{C}$ and iron act as catalysts in the carbon crystallizing process in a manner that tends to improve the crystallinity of the carbon since $\mathrm{Fe}_{3} \mathrm{C}$ and iron have a suitable lattice plane, which has diffraction parameters similar to those of graphite. This lattice plane works as a template for the crystallization of carbon. At the same time, fine iron or $\mathrm{Fe}_{3} \mathrm{C}$ particles are liberated from the pure metal or alloys. Carbon filaments grow when carbon continues to diffuse through $\mathrm{Fe}_{3} \mathrm{C}$ and precipitate at one preferred side of the particles. Although the driving force is small, it results in severe corrosion over the long term. This mechanism successfully explains not only why the metal dusting products are carbon and $\mathrm{Fe}_{3} \mathrm{C}$ instead of iron, but also why carbon filaments are accompanied in the metal dusting process. The mechanism of metal dusting for Ni-base alloys is similar to that for Fe-base alloys, although $\mathrm{no} \mathrm{Ni}_{3} \mathrm{C}$ is formed in the process. The lattice of nickel metal can also work as a template to aid the crystallization of carbon. Since metal dusting process involves catalytic crystallization instead of a regular chemical reaction, metal dusting should be defined as a metal wastage process instead of regular corrosion, although the outcome of metal dusting is similar to corrosion. This metal wastage process is unique and is, generally, not uniform but initiates as pits at several sites on the metal surface and eventually propagates into the substrate.

According to the new mechanism of metal dusting, two methods could be used to stop the driving force for carbon ingress and minimize metal dusting attack. First is to build a barrier to stop carbon diffusion into alloys. A perfect oxide scale can act as a protective layer on the alloy surface since the diffusion rate of carbon in oxide, especially at low temperatures, is almost zero. Therefore, alloys that can form a stable, defect-free oxide layer in the metal dusting environment would be desirable. The current project focuses on the phase composition of oxide scales on the surface of alloys, the effect of alloy composition on the metal dusting rate, and the effect of gas 
and alloy composition on phases that form in the oxide scale. Second, if carbon cannot find a suitable lattice plane in alloys, then the alloys may not act as a catalyst to aid in the crystallization of carbon and may not disintegrate in the catalytic carbon crystallization. Therefore, the approach in the current project is to use the mechanistic knowledge developed thus far in developing new alloys and surface engineering currently available alloys, so that they do not act as a catalyst to assist in the crystallization of carbon.

\section{ECONOMIC BENEFIT}

The economic benefit to the industrial sector can be significant, if the development of new alloys and surface engineering approaches proposed in this program succeeds. The following assumptions and calculations are made for the benefits that can be realized in the chemical and petrochemical sectors. Similar calculations can be performed for the petroleum, steel, and heat treatment sectors, but are not made in this report.

A typical hydrogen reformer recovers heat at $\approx 400^{\circ} \mathrm{C}$ rather than at $800^{\circ} \mathrm{C}$ and generates excess steam. This excess steam represents about $125 \mathrm{BTU} /$ \{standard cubic foot of hydrogen (scfh)\}, which could be saved if $800^{\circ} \mathrm{C}$ heat could be used directly in hydrogen plants. In the year 2000 , about 3.8 billion scfh/d was produced in the U.S. This value translates into 475 billion BTU/d that could be saved if the metal dusting issue were solved and the $800^{\circ} \mathrm{C}$ heat could be used directly. This value is equivalent to a saving of 475 million scf of natural gas per day. Realistically, if half this amount were saved, the savings for the U.S. hydrogen industry will be $\$ 0.6-0.8$ million/day or $\$ 220-290$ million per year for the hydrogen industry alone. Since several hydrogen plants have been built since 2000 , the savings would be even greater. As the U.S. and the world moves toward a hydrogen economy, the production of hydrogen is expected to increase exponentially over time, and any improvement in the design and operation of the new plants will accelerate the economic benefit.

The gas-to-liquids (GTL) industry is in its infancy. One operating plant produces about 21,000 barrels of product per day (bpd) from 160 million standard cubic feet per day (MMscfd) of natural gas. GTL plants will operate with even lower steam/carbon ratio, with a potential for more severe metal dusting attack than in current reformer systems. Some estimates suggest that several 100,000-bpd plants will be built in the next ten years. This translates into 4,800 MMscfd of natural gas usage in year 10 . Calculations show that a plant designed for high-temperature heat transfer can realize a $6 \%$ savings in natural gas. This amounts to $9.6 \mathrm{MMscfd}$ of natural gas per plant or 274 MMscfd at year 10. The average over ten years would be a savings of natural gas of about 137 MMscfd. The cost of natural gas is variable in that some of it is now flared and considered of no value. There are known reserves of natural gas that will only come to the market if GTL becomes viable. Nonetheless, estimates indicate that overcoming the metal dusting problem would reduce the cost of a typical 100,000-bpd plant from \$2B to $\$ 1.8 \mathrm{~B}$. 
Since the reformer industry is primarily based on conversion of fossil fuels (carbon-containing fuels) such as natural gas, methanol, and other hydrocarbons, any improvement in process efficiency, energy savings, and product yield can result in less consumption of hydrocarbon-containing feedstock for a given output. Since the generation of greenhouse gas $\left(\mathrm{CO}_{2}\right)$ emissions is directly related to the use of fossil fuel feedstock, the development and application of new materials (from this project) would lead to less consumption of C-containing feedstock for a given unit of product output, and this will reduce greenhouse gas emission.

\section{OBJECTIVES}

The primary objective of the current project is to mitigate metal dusting degradation of metallic structural alloys by (a) development of alternative structural alloys with improved corrosion resistance and with adequate mechanical properties at temperatures up to $816^{\circ} \mathrm{C}\left(1500^{\circ} \mathrm{F}\right)$ and (b) surface modification of currently available commercial Fe- and Ni-base structural alloys. The study conducted at Argonne in recent years has clearly established the mechanisms for metal dusting in $\mathrm{Fe}$ - and $\mathrm{Ni}$ base alloys, and the results from this study form the basis for the ongoing project. The project involves laboratory testing of $\mathrm{Fe}$ - and $\mathrm{Ni}$-base commercial alloys, weldments of these alloys, and newly developed materials to establish their metal dusting rates as a function of key process variables. The project also includes establishment of procedures for surface modification of candidate alloys to resist metal dusting.

The better performing alloys in the laboratory tests will be produced and tested in simulated metal dusting environments in the laboratory and in commercial process systems. In addition, a user-friendly knowledge base on materials/wastage information will be developed from an analysis of pit size, distribution, depth, and volume as a function of temperature, pressure, gas chemistry, and alloy chemistry for application in chemical and petrochemical industries.

\section{STEERING GROUP AND MTI PROJECT MEETINGS}

The organizations that are involved in the current project include the Materials Technology Institute (MTI) of the Chemical Process Industries, Air Products and Chemicals Inc., ConocoPhillps, Hader Topsoe, Air Liquide, DuPont Chemical Company, Haynes International, Special Metals, Spectrum Metals, Krupp VDM, and Sandvik Steel.

A list of Steering Committee meetings, MTI meetings, and Project Assessment meetings, in which the current project was discussed, is given below:

October, 18, 2004

October, 18, 2004

February 22, 2005

April 3-7, 2005
Steering Committee meeting at Argonne National Laboratory

MTI meeting at Houston, TX

MTI meeting, Tampa, FL

NACE meeting, Houston, TX 
May 31-June 3, 2005 Industrial Technology Program Materials Project and Portfolio Review meeting, Chicago, IL

June 6-8, 2005

MTI meeting, Kansas City, MO

October 24, 2005

Steering Committee and MTI meetings, Pittsburgh, PA

\section{PROJECT TASKS}

The project research focused on the following tasks:

- $\quad$ Procure materials, fabricate specimens, and perform metal dusting experiments with off-the-shelf Ni-base alloys in simulated reformer effluent gas chemistry at temperatures in the range $450-700^{\circ} \mathrm{C}$ at both atmospheric and at high pressures..

- Develop surface engineered specimens of Ni-base alloys, such as alumina, chromia, and/or silica surface layers, and evaluate their susceptibility to coking, carbon deposition, and metal dusting attack in simulated reformer effluent chemistry at atmospheric and high pressures.

- $\quad$ Fabricate Fe- and Ni-base alloy weldments and evaluate their performance in metal dusting environments.

- Develop a pre-pitting procedure to study pit growth kinetics after an incubation period.

- Develop and fabricate alternative alloys with adequate mechanical strength and prepare specimens for exposure in metal dusting experiments.

- Develop procedures that are feasible in plant operation to mitigate metal dusting degradation. 


\section{GAS CHEMISTRY AND CARBON ACTIVITY}

Gaseous environments that are prevalent in chemical process industries were characterized by computer modeling of gas-phase reactions under both equilibrium and nonequilibrium conditions (Natesan et al. 2001, Natesan 2002, Natesan and Zeng 2003). To evaluate the role of gas composition on the metal dusting rate of alloys, specimens were exposed to gas mixtures (see Table 1.1) of varying composition that encompassed the environments that are anticipated in industrial processes. In all, we have used 21 gas compositions in our experimental program. Figure 1.1 shows these compositions in terms of $\mathrm{CO} / \mathrm{CO}_{2}$ and $\mathrm{H}_{2} \mathrm{O} / \mathrm{H}_{2}$ ratios.

The carbon activities were calculated for different gas mixtures as a function of temperature at atmospheric pressure (14.7 psia) and at plant system pressures. The carbon deposition process can be influenced by two possible reactions:

$$
\begin{aligned}
& \mathrm{CO}(\mathrm{g})+\mathrm{H}_{2}(\mathrm{~g})=\mathrm{C}+\mathrm{H}_{2} \mathrm{O}(\mathrm{g}) \\
& 2 \mathrm{CO}(\mathrm{g})=\mathrm{C}+\mathrm{CO}_{2}(\mathrm{~g})
\end{aligned}
$$

Since the gas composition is maintained fairly constant during the passage through the waste-heat boiler, either Reaction 1 or Reaction 2 may dictate the carbon activity in the stream at different temperatures. If Reaction 1 determines carbon activity, it will be directly proportional to $\mathrm{H}_{2}$ and $\mathrm{CO}$ partial pressures and inversely proportional to $\mathrm{H}_{2} \mathrm{O}$ partial pressure. On the other hand, if Reaction 2 determines carbon activity, then it will be directly proportional to the square of the $\mathrm{CO}$ partial pressure and inversely proportional to $\mathrm{CO}_{2}$ partial pressure. In addition, if gas phase equilibrium does prevail, albeit at high temperatures and/or for long residence times, then the calculated carbon activity value will be the same (i.e., irrespective of Reaction 1 or 2) since, thermodynamically, the gas composition will adjust to give the most stable (lowest free energy) composition. Therefore, carbon activity was calculated as a function of temperature from $496^{\circ} \mathrm{C}\left(925^{\circ} \mathrm{F}\right)$ to the maximum test temperature and for $1 \mathrm{~atm}$ to the maximum test pressure for various gas mixtures based on Reaction 1, Reaction 2, and thermodynamic equilibrium.

Carbon activities were calculated for several of the gas mixtures and their impact on metal dusting was reported earlier (Natesan 2002). Carbon activity calculated using Reactions 1 and 2 decreases with increasing temperature but increases with an increase in system pressure. Carbon activities of gases 1 to 17 have been reported earlier (Natesan 2002). Figures 1.2 to 1.5 show the carbon activity as a function of temperature for gas mixtures 18,19 , and 21 . Ga compositions 2, 4-6, 8-11, 13-18, and 21 have been used in metal dusting experiments as reported in Sec. 2.6. 
Table 1.1 Chemical composition (in mole \%) of gas mixtures used in the metal dusting study.

\begin{tabular}{ccccccc}
\hline Gas & $\mathrm{H}_{2}$ & $\mathrm{CO}$ & $\mathrm{CO}_{2}$ & $\mathrm{H}_{2} \mathrm{O}$ & $\mathrm{CH}_{4}$ & $\mathrm{~N}_{2}$ \\
\hline 1 & 43.8 & 7.2 & 5.7 & 39.2 & 4.1 & - \\
& 52 & 18 & 5.6 & 23 & 1.1 & - \\
2 & & & & & & \\
$2 \mathrm{~b}$ & 66.2 & 23 & 7.1 & 2.3 & 1.4 & - \\
3 & 36.3 & 8.4 & 5.6 & 35 & 0.2 & 15 \\
4 & 74.2 & 17.5 & 8.3 & 0 & - & - \\
5 & 72.2 & 17.6 & 8.3 & 2.0 & - & - \\
6 & 77.2 & 12.7 & 10.1 & 0 & - & - \\
7 & 25.3 & 70 & 4 & 0.01 & - & - \\
8 & 71.4 & 11.3 & 17.4 & 0 & - & - \\
9 & 71 & 11.7 & 17.3 & 0 & - & - \\
10 & 53.4 & 18.4 & 5.7 & 22.5 & - & - \\
11 & 79.5 & 18.2 & - & 2.3 & - & - \\
12 & 75.4 & 6.2 & 18.4 & - & - & - \\
13 & 71.0 & 2.6 & 26.4 & - & - & - \\
14 & 40 & 45 & 5 & 10 & - & - \\
15 & 20 & 65 & 5 & 10 & - & - \\
16 & 40 & 25 & 25 & 10 & - & - \\
17 & 20 & 74.5 & 5 & 0.5 & - & - \\
18 & 54.6 & 23.2 & 4 & 18.2 & - & - \\
19 & 47.4 & 15.5 & 6.2 & 30.9 & - & - \\
20 & 40.5 & 19.9 & - & - & 0.5 & 39.6 \\
21 & 65.1 & 30 & 0.9 & 4 & - & - \\
\hline
\end{tabular}

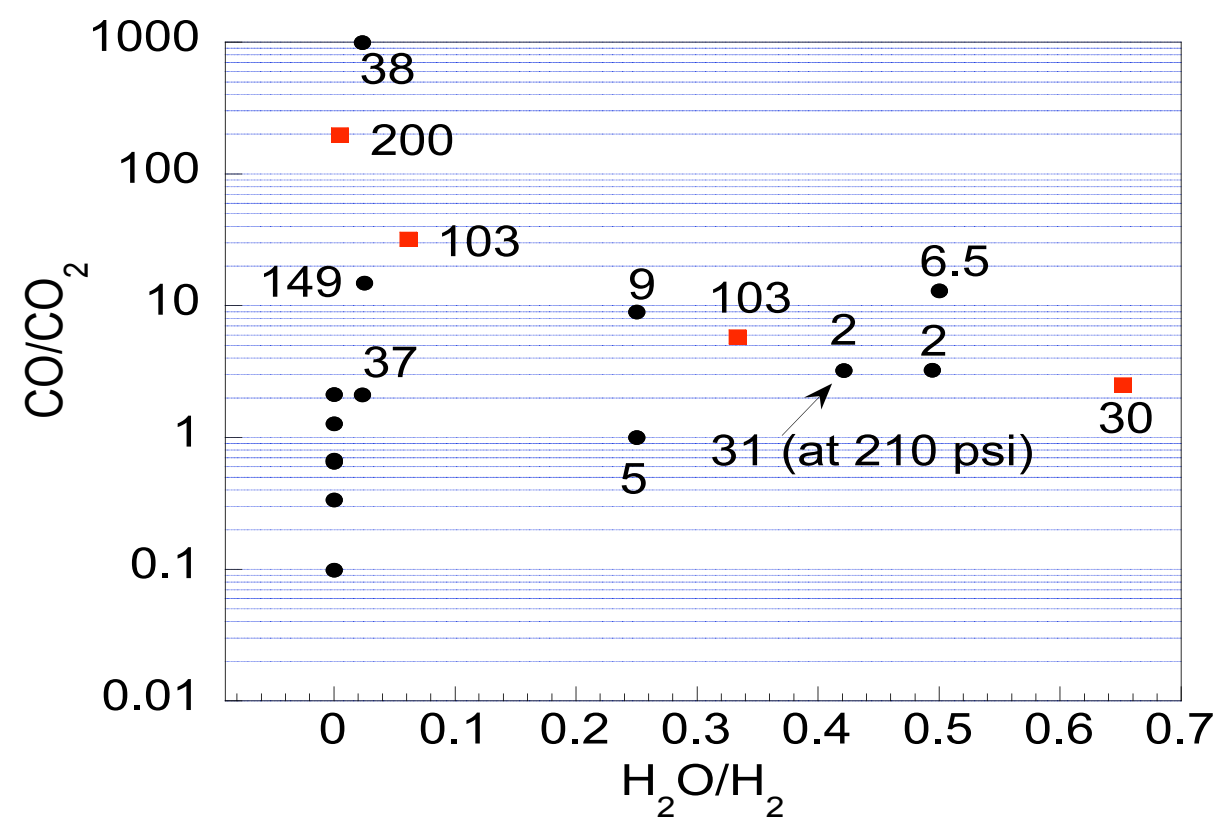

Figure 1.1. Chemical composition and carbon activity for gas mixtures used in metal dusting study. Carbon activity was calculated from the 
reaction $\mathrm{CO}(\mathrm{g})+\mathrm{H}_{2}(\mathrm{~g})=\mathrm{C}+\mathrm{H}_{2} \mathrm{O}(\mathrm{g})$ at $593^{\circ} \mathrm{C}$. The number in the indicates the carbon activity of the gas mixture.

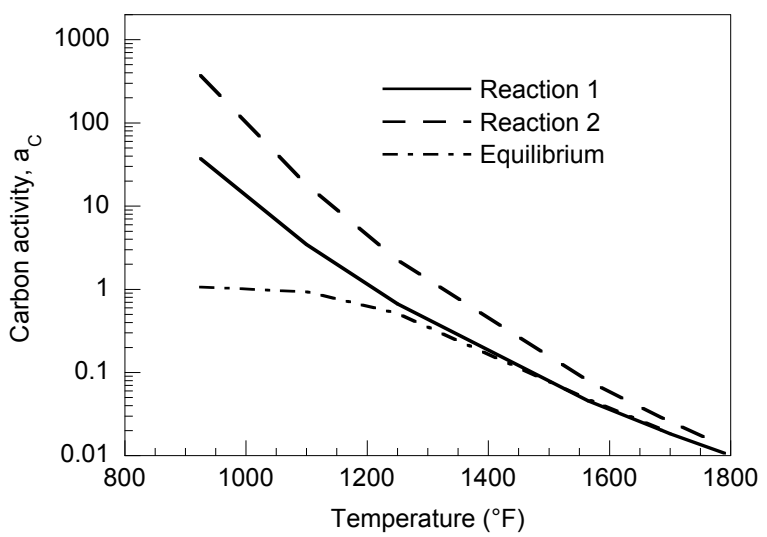

Figure 1.2. Carbon activity of Gas 18 as function of temperature at $1 \mathrm{~atm}$.

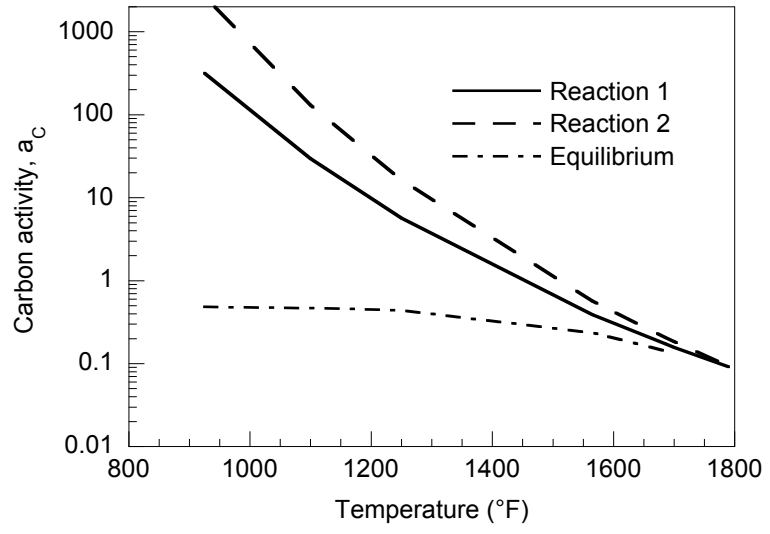

Figure 1.4. Carbon activities of Gas 19 as function of temperature at $25 \mathrm{~atm}$.

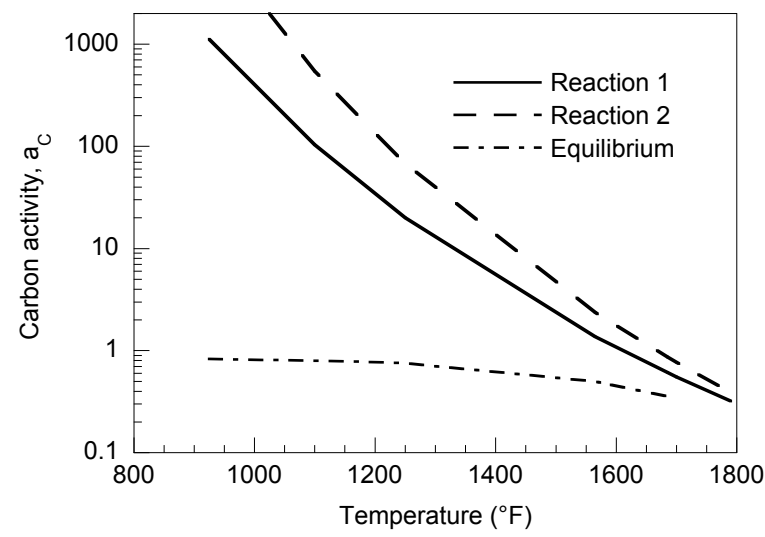

Figure 1.3 Carbon activity of Gas 18 as function of temperature at $30 \mathrm{~atm}$.

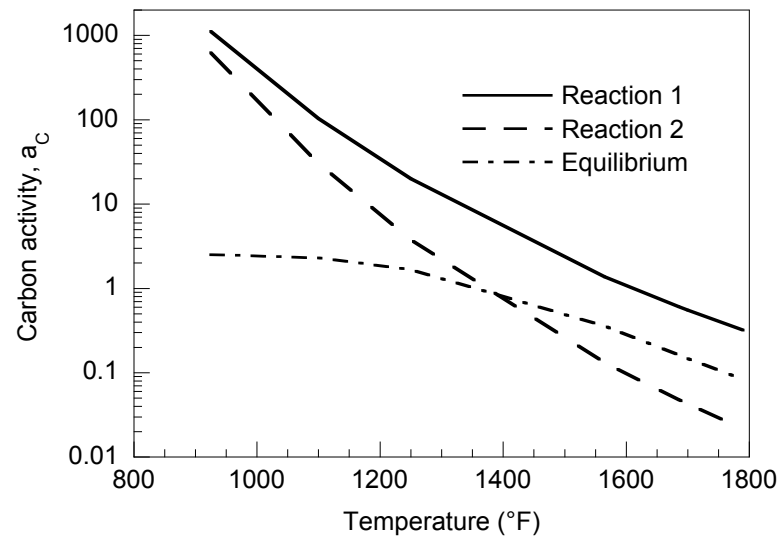

Figure 1.5. Carbon activities of Gas 21 as function of temperature at $1 \mathrm{~atm}$. 


\section{EXPERIMENTAL PROGRAM}

\subsection{Description of Reactor Systems}

Five experimental systems were used in the metal dusting experiments (Natesan 2002, Natesan and Zeng 2003). Two existing systems at ANL were modified to accommodate the requirements of the program. Each of the modified systems consisted of a horizontal, tubular, high-temperature furnace capable of operation up to $900^{\circ} \mathrm{C}$. The reaction chamber, with gas inlet/outlet fittings, was fabricated from quartz and positioned within the furnace chamber. The ends of the reaction chamber had specially designed flanges with O-ring seals. A chromel-alumel thermocouple, inserted from one end of the reaction chamber, was used to monitor the specimen temperature. Specimens were suspended from quartz rods held on the top of a high-purity alumina boat. The specimens and the boat were positioned in the constant-temperature section of the reaction chamber. High-purity gases such as $\mathrm{CO}, \mathrm{CO}_{2}, \mathrm{CH}_{4}$, and $\mathrm{H}_{2}$ were procured and piped into the reaction chamber through flow meters to obtain the desired composition. In some experiments, $\mathrm{H}_{2}$ gas was bubbled through a water bath to saturate the $\mathrm{H}_{2}$ with water prior to entering the reaction chamber. Upon completion of the experiments, the specimens and the carbon accumulated on the specimens and in the boat were removed for detailed microstructural, X-ray, and Raman analysis.

While the two systems described above enabled study of the key variables in metal dusting research, additional facilities were needed for long-term testing of metallic alloys, surface-engineered materials, and coatings. For this purpose, three new systems were designed and assembled in a metal dusting research laboratory. Figure 2.1 shows a schematic diagram for the three test facilities set up for metal dusting experiments. The three environmental exposure test fixtures were positioned horizontally on a laboratory bench top in a staggered linear arrangement with a common gas supply. Each test fixture consisted of a quartz retort chamber $(74-\mathrm{cm}$ length, $5-\mathrm{cm}$ OD, $0.32-\mathrm{cm}$ thick), which was centered in a $30-\mathrm{cm}$-diameter resistive heating furnace. A Barber-Coleman Model 560 three-mode controller was used to control the furnace temperature. Type 316 stainless steel (SS) flange caps with an O-ring seal were used to close the ends of the quartz retort tube. The flange caps provided port fittings for the gas flow, steam/vapor preheater, and ceramic thermowells used for measurements of specimen temperature. Figure 2.2 shows a schematic diagram for the furnace assembly and gas flow arrangement used for the metal experiments.

The gas that flowed through the retort chamber had various ratios of $\mathrm{H}_{2}, \mathrm{CH}_{4}$, $\mathrm{CO}, \mathrm{CO}_{2}$, and steam/water vapor. Laboratory-grade compressed gases were supplied from AGA Gas Co. in industry standard 1A size (136 atm and $4.3 \mathrm{~m}^{3}$ internal volume) cylinders. Each gas was piped to the reaction chamber through a low-pressure manifold line that is fed from a two-stage, gas-pressure-reducing regulator with a flash arrestor and a solenoid shut-off valve. The solenoid valves were controlled by a gasleak detection system manufactured by International Sensor Technology Co. Overhead sensors that are selective to $\mathrm{H}_{2}, \mathrm{CH}_{4}$, and $\mathrm{CO}$ gases were used to detect gas leaks. In 
the event of a leak detected above a user-selected threshold by any of the sensed gases, the detection system closed the solenoid valves for all gases.

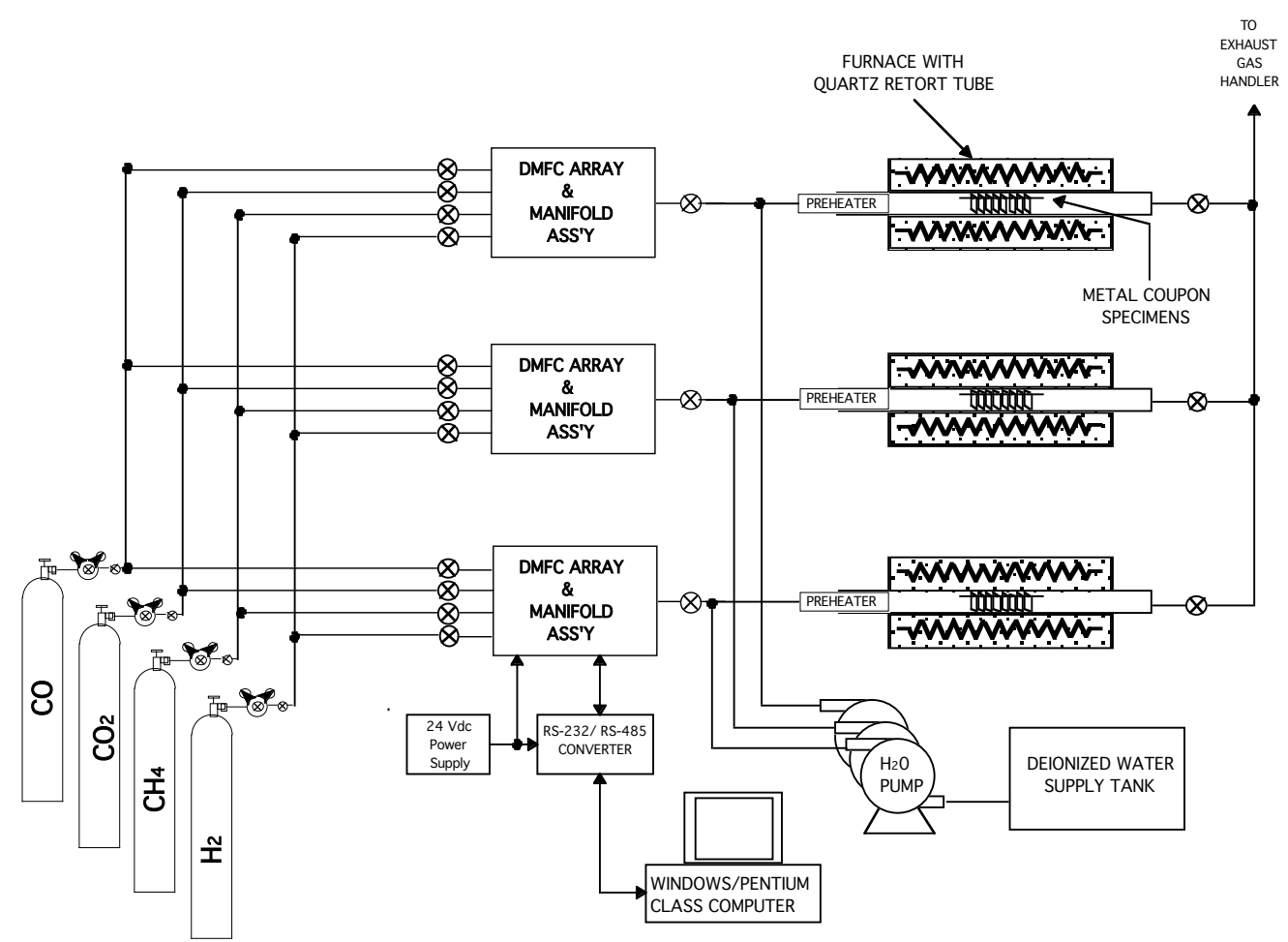

Figure 2.1 Schematic of three atmospheric test facilities used for metal dusting experiments.

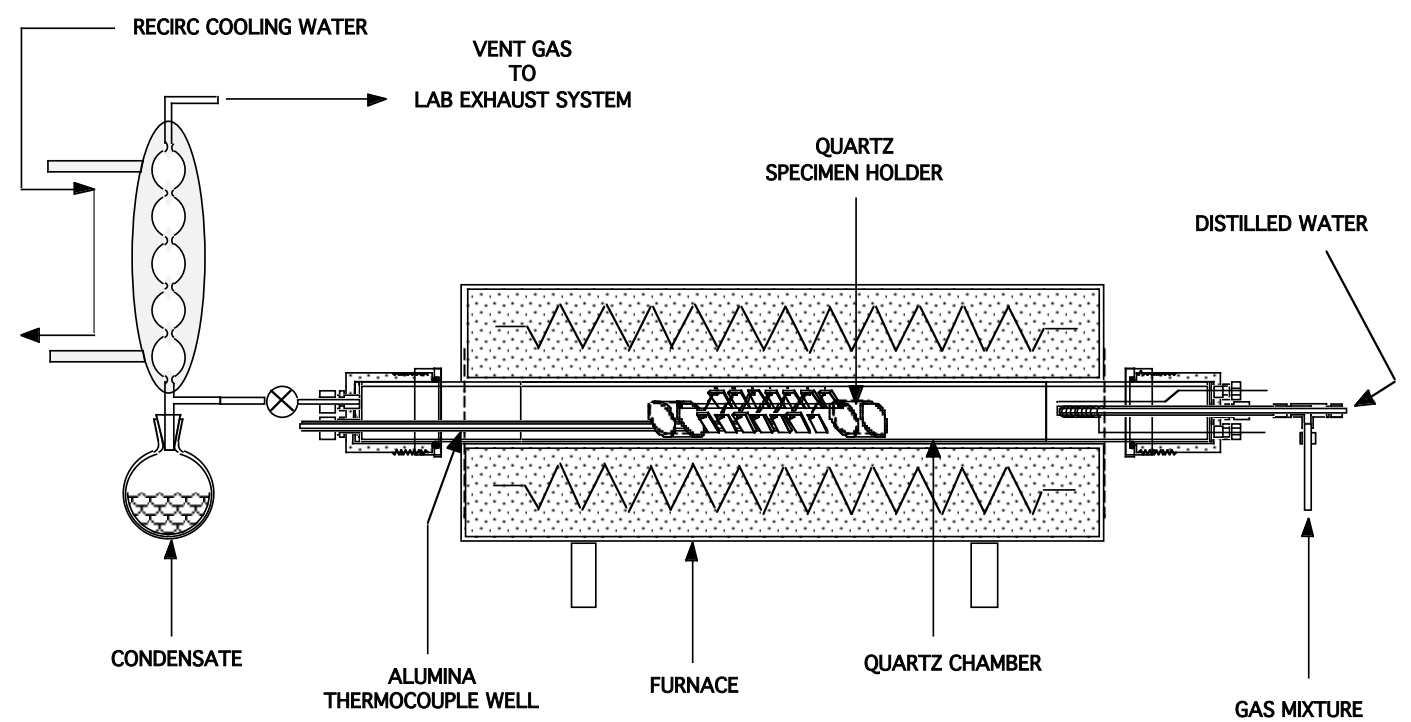

Figure 2.2. Schematic of furnace assembly and gas flow arrangement used for metal dusting experiments. 
Gases from the low-pressure manifold lines were supplied to respective Brooks model 5850 s digital mass flow control (DMFC) valves. Figure 2.3 shows a schematic diagram of the steam and gas flow scheme used. The output from each mass flow controller combined into a central manifold tube that connects to the steam/vapor preheater assembly at the input cover flange for the retort tube. The steam/vapor preheater had a coaxial-design mixing chamber enabling the water vapor to be entrained by the flowing gas mixture prior to passing the preheat element. The gas mixture flow rate was typically $200-400 \mathrm{~cm}^{3} / \mathrm{min}$ (STP), and the water flow rate was $1-5$ $\mathrm{cm}^{3} / \mathrm{h}$. The preheat temperature was maintained with a Love Controls Model $16 \mathrm{~A}$ three-mode process controller. Distilled water was supplied to the preheat mixing chamber by a Watson-Marlow Model MPL micro-metering pump that was fed from a 20$\mathrm{L}$ polycarbonate carboy. The micro-metering pump was based on peristaltic action, and the flow rate was adjusted by varying the rotational speed of the roller cam and/or the diameter of the flexible tubing. The gas-steam mixture flowed past the alloy test specimens to the exit port at the rear flange cap. After the gas-steam mixture exited the retort, it was passed through a chilled water pyrex condenser to collect water vapor for future measurement, while the remaining gas mixture was vented to a room exhaust vent handler.

Alloy test specimens were mounted on a quartz specimen tree (see Fig. 2.4) that was centered in the heat zone of the retort chamber. Metal-dusting experiments were conducted under isothermal conditions at temperatures between 427 and $704^{\circ} \mathrm{C}(800$ and $1300^{\circ} \mathrm{F}$ ). A chromel-alumel thermocouple controlled the furnace temperature. The test temperature and the precision of its control are important to the reproducibility and usefulness of the results. An indicating controller calibrated for the control thermocouple maintained the furnace temperature. Specimen temperature was monitored with a second, sheathed chromel-alumel thermocouple inserted into the reaction chamber in the vicinity of the specimens. The outputs of the monitoring and control thermocouples were calibrated over the temperature range of interest, so that if the monitoring thermocouple became inoperative due to corrosion, the control thermocouple was used during continuation of the test. The multicomponent gas environment for the metal dusting program consisted of $\mathrm{CO}, \mathrm{CO}_{2}, \mathrm{H}_{2}, \mathrm{CH}_{4}$, and $\mathrm{H}_{2} \mathrm{O}$. The actual composition of the gas mixture had a wide enough range to establish carbon activity of $\approx 0.5$ to $\approx 100$ at the temperatures and pressures of interest. The exposure time periods in different experiments ranged between 5 and $1000 \mathrm{~h}$, depending on the objective of the test.

Figure 2.5 shows a system that was built to conduct experiments at system pressures up to $40.8 \mathrm{~atm}$ (600 psi). The system consisted of a horizontal, tubular, hightemperature furnace capable of operation up to $900^{\circ} \mathrm{C}$. The reaction chamber, with gas inlet/outlet fittings, fabricated from alumina and/or quartz was positioned within a pressure vessel made of a high-temperature heat-resistant alloy (16-mm ID, 50-mm OD, 500-mm long). A chromel-alumel thermocouple was inserted into the pressure 


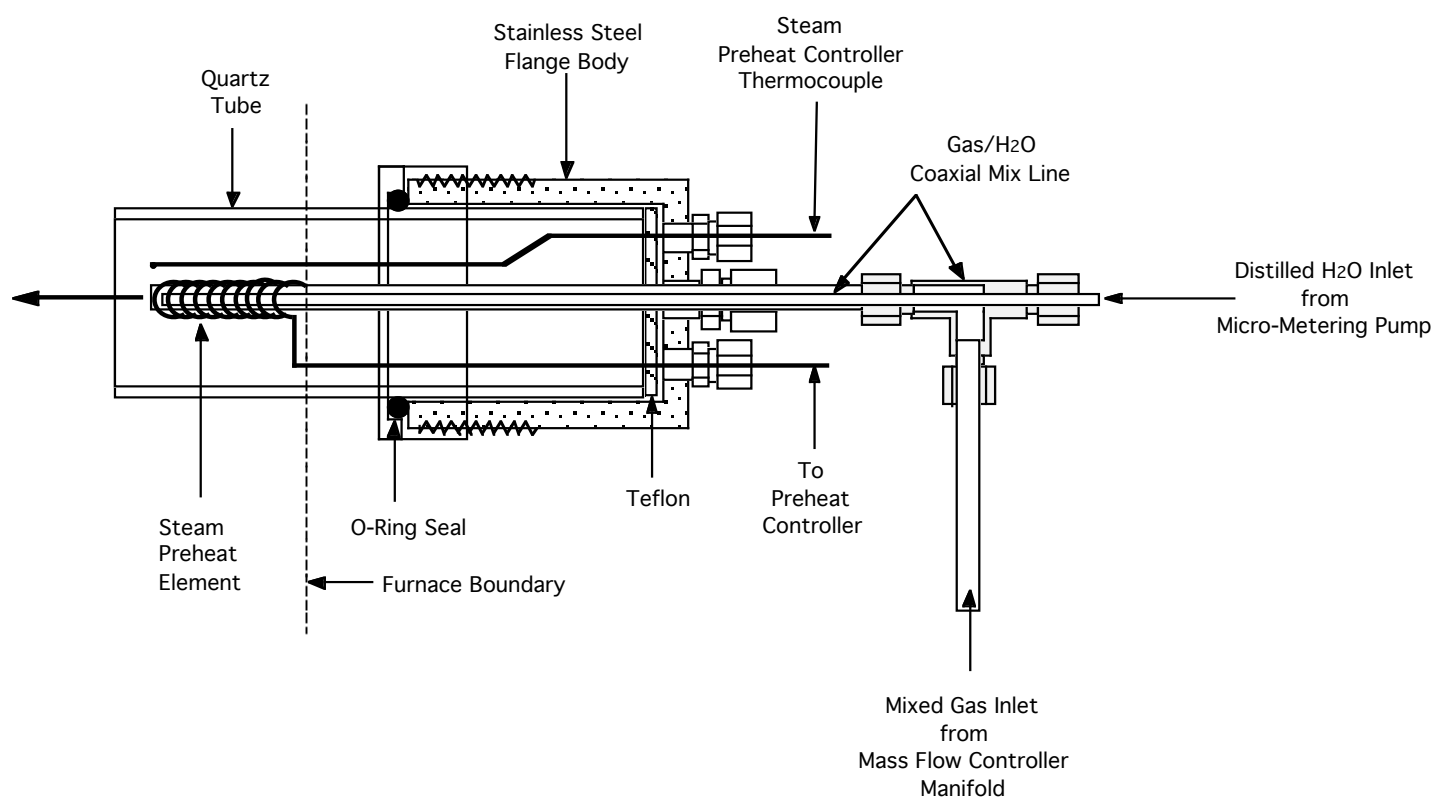

Figure 2.3. Schematic of steam and gas flow scheme used for metal dusting experiments.

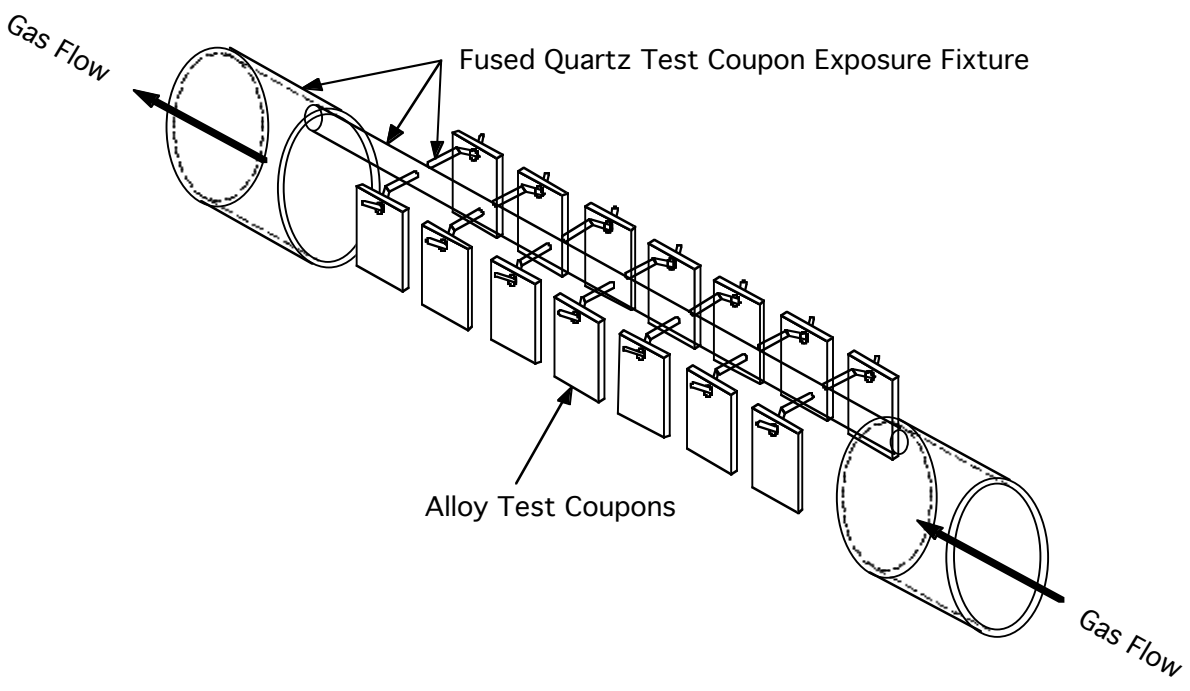

Figure 2.4. Schematic of quartz specimen holder and test coupon arrangement used for metal dusting experiments.

vessel to monitor the specimen temperature. Specimens were suspended from an alumina rod and were positioned in the constant-temperature section of the tubular furnace. High-purity gases such as $\mathrm{CO}, \mathrm{CO}_{2}, \mathrm{CH}_{4}$, and $\mathrm{H}_{2}$, were piped into the reaction chamber through flow meters to obtain the desired composition. To include steam in the exposure environment, water was pumped from a water pump, converted to steam, pressurized, and inserted along with the gas mixture. The effluent from the reactor 
chamber was condensed to remove the water prior to exhaust. Figure 2.6 shows a magnified view of the high-pressure parts of the system described in Fig. 2.5.

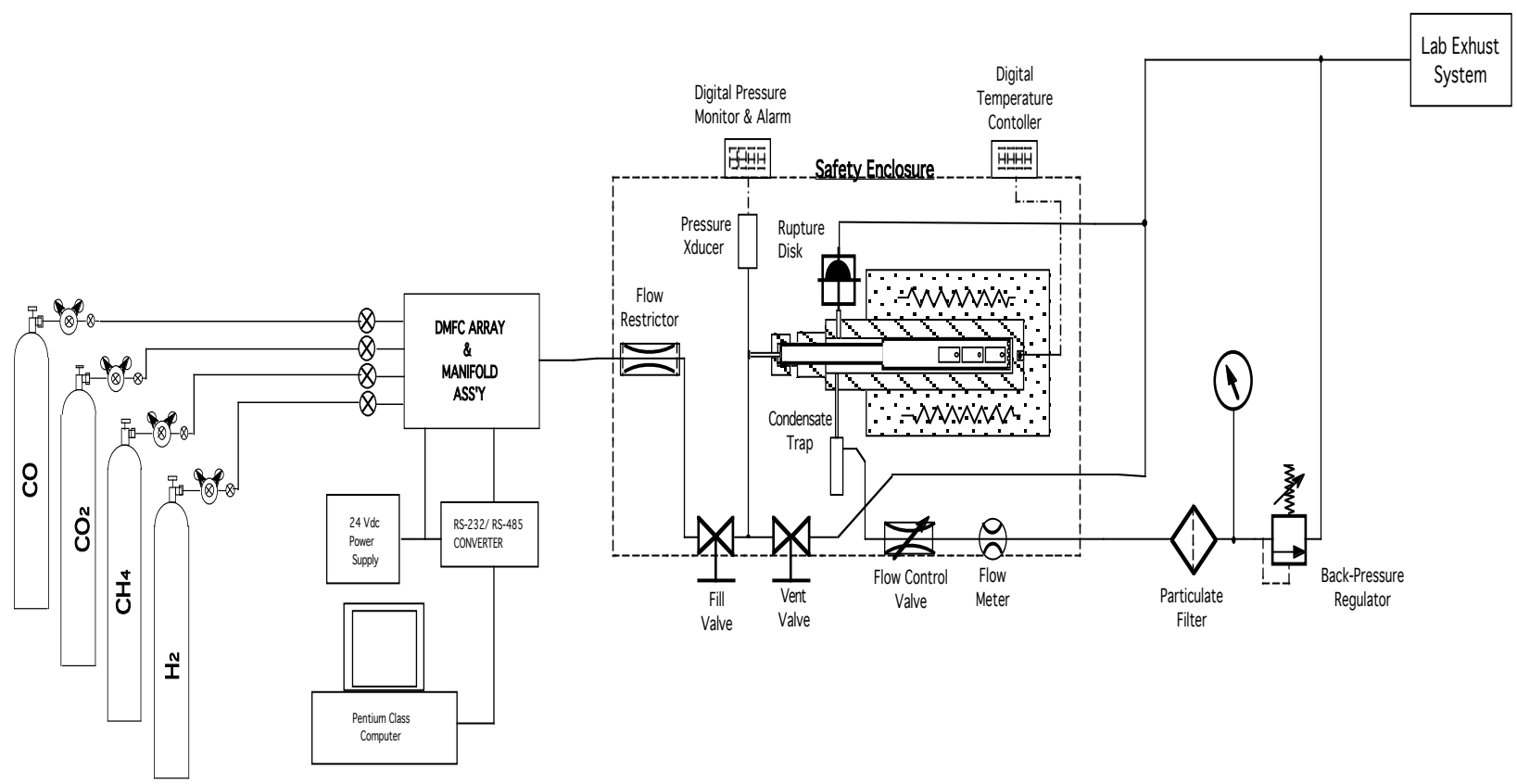

Figure 2.5. Schematic of high-pressure, high-temperature system for metal dusting experiments.

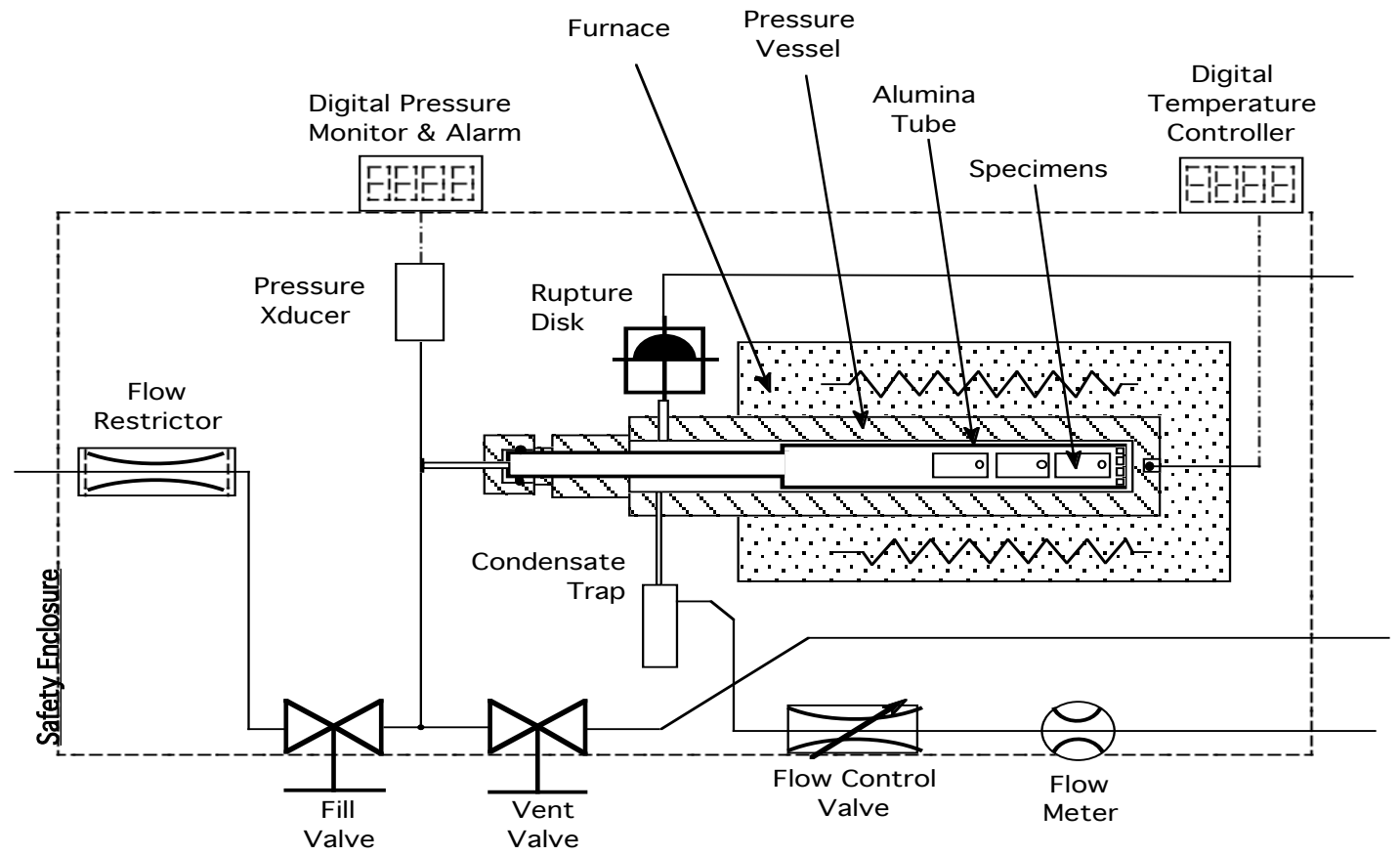

Figure 2.6. Magnified view of the high-pressure region of the system shown in Fig. 2.5 . 


\subsection{Surface Profiler to Measure Depth of Metal Dusting Pits}

In several recent steering committee meetings, extensive discussions were held on the importance of key variables in understanding the metal dusting degradation of metallic structural materials. In addition, discussions on the posttest analysis of specimens identified the necessity of understanding the pit nucleation and growth (in particular, the pit geometry including diameter, depth, and shape), distribution, and density as a function of process variables such as temperature, gas chemistry, system pressure, and exposure time.

Later in 2005, we procured a surface profiler unit with a capability to measure the depth of pits in a nondestructive fashion so that we could measure and correlate the pit depth as a function of time after repeated exposures of a given specimen to the metal dusting environment. The surface profiler, procured from ADE Phase Shift, is equipped with a MicroXAM surface measurement system comprising a non-contact optical profiler. The surface roughness (and pit depth) of the alloys was measured by using a white light beam. Figure 2.7 shows a schematic of the profilometer system. Table 2.1 shows a listing of operational and performance specifications for the unit. The profilometer can measure pit depth up to $10 \mathrm{~mm}$ with a resolution of $0.92 \mu \mathrm{m}$. The measurement area is $\approx 0.8 \times 0.6 \mathrm{~mm}^{2}$ for a single scanning. However, the equipment can theoretically measure the entire area of the sample by stitching each small piece together with MapVue AE software. Figure 2.8 shows pits on a metallic specimen and typical size (diameter and depth) measurements made using the profilometer.

Table 2.1 Specification for MicroXAM surface profiler

\begin{tabular}{|c|c|c|c|c|c|}
\hline Objective magnification & $50 X$ & $20 x$ & $10 X$ & $5 X$ & $2.5 X$ \\
\hline Numerical aperture & 0.55 & 0.40 & 0.30 & 0.13 & 0.075 \\
\hline Measurement area $(\mu \mathrm{m})$ & $165 \times 125$ & $413 \times 313$ & $827 \times 626$ & $1654 \times 1253$ & $3308 \times 2506$ \\
\hline Spatial sapling $(\mu \mathrm{m})$ & $0.22 \times 0.26$ & $0.55 \times 0.65$ & $1.1 \times 1.3$ & $2.2 \times 2.6$ & $4.4 \times 5.2$ \\
\hline Optical resolution @ 550 nm $(\mu \mathrm{m})$ & 0.50 & 0.69 & 0.92 & 2.12 & 3.67 \\
\hline Working distance (mm) & 3.4 & 4.7 & 7.4 & 9.3 & 10.3 \\
\hline Depth of focus @ 550 nm $(\mu \mathrm{m})$ & 1.16 & 2.19 & 3.89 & 20.72 & 62.25 \\
\hline $\begin{array}{l}\text { Degress of maximum surface } \\
\text { slope (EX mode) }\end{array}$ & 22.6 & 9.5 & 4.8 & 2.4 & 1.2 \\
\hline \multicolumn{6}{|l|}{ Performance } \\
\hline \multicolumn{2}{|c|}{ RMS repeatability (standard mode: $1 \mathrm{~nm}$} & \multicolumn{4}{|c|}{ Lateral surface sampling: 0.11 to $8.8 \mu \mathrm{m}$} \\
\hline \multicolumn{2}{|c|}{ RMS repeatability (standard mode: $1 \mathrm{~nm}$} & \multicolumn{4}{|c|}{ Field of view: .084 x .063 mm @ 100X } \\
\hline \multicolumn{2}{|c|}{ RMS repeatability (standard mode: $1 \mathrm{~nm}$} & \multicolumn{4}{|c|}{ Maximum slope: 40 to 3.2 degrees } \\
\hline \multicolumn{2}{|c|}{ Vertical scan range: 30,100 , or $5000 \mu \mathrm{m}$} & \multicolumn{4}{|c|}{ Reflectivity: 1 to $100 \%$} \\
\hline \multicolumn{2}{|l|}{ Data acquisition time: up to $7.2 \mu \mathrm{m} / \mathrm{s}$} & & & & \\
\hline
\end{tabular}




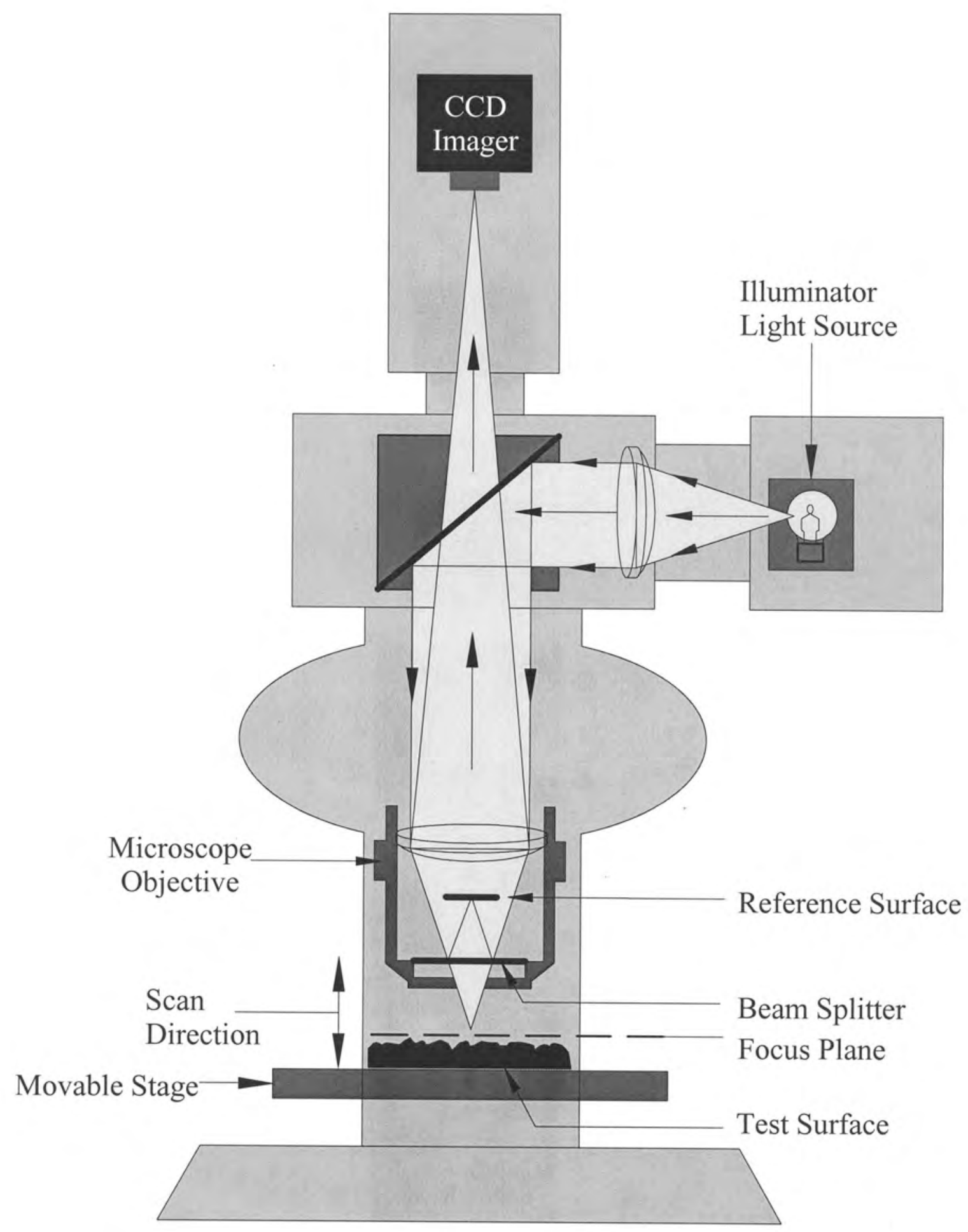

Figure 2.7. Schematic for MicroXAM surface profiler. 


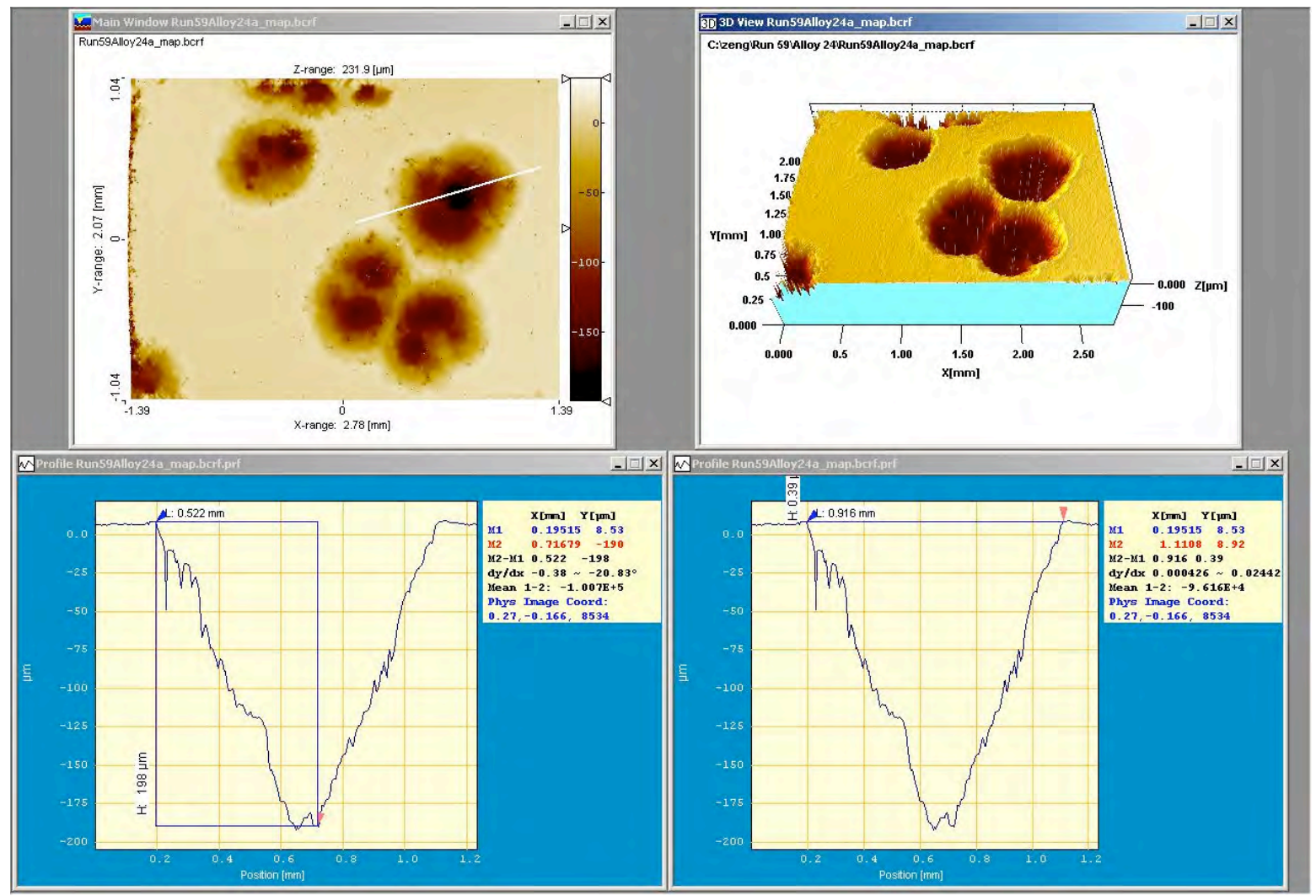

Figure 2.8. Example of a profile map measured by MicroXAM surface profilometer.

\subsection{Materials}

The test program included fourteen Fe-base and eleven Ni-base alloys, predominantly those commercially available, selected on the basis of Steering Committee discussions. Table 2.2 lists the nominal chemical compositions of the alloys selected for evaluation in the program. Heat analysis of all the alloys, provided by the alloy supplier, was maintained at Argonne National Laboratory. In addition, several surface-engineered alloy specimens (including surface coatings) were evaluated in the program. Only wrought alloys were evaluated.

The Fe-base alloys included a low-Cr ferritic steel (T22), an intermediate-Cr ferritic steel (T91), and several high-Cr ferritic and austenitic steels and other alloys. The $\mathrm{Cr}$ content of the latter alloys ranged between 17.3 and $26.7 \mathrm{wt} \%$. The Ni content of the high-Cr alloys ranged between 9.3 and $36.6 \mathrm{wt} \%$, except for alloys MA 956 and APMT, which contained no nickel. Several of the Fe-base alloys contained a third element such as $\mathrm{Al}$ or $\mathrm{Si}$, which has a high affinity for $\mathrm{O}$. For example, MA956 and APMT contained 4.5 and $4.9 \mathrm{wt} \% \mathrm{Al}$, respectively. Alloys 153MA, 253MA, and 353MA contained $\mathrm{Si}$ in a range of 1.3-1.6 wt.\%, whereas Alloy 38815 contained 5.8 wt. \% Si.

Generally, the Ni-base alloys had a much more complex chemical composition since they contained $\mathrm{Cr}$ (in a range of 15.4-28 wt.\%) and several other elements, such as Mo (Alloys 617 and 625), Al (601, 617, 602CA, 214, and 693), and Si (45TM and HR 
160). Further, several alloys contained $\mathrm{Nb}, \mathrm{W}$, and $\mathrm{Co}$, which can also influence the oxidation behavior of the alloys and their resistance to metal dusting attack.

In addition to commercial $\mathrm{Fe}$ - and $\mathrm{Ni}$-base alloys, a select number of alloys were selected for fabricating weldments for evaluation in metal dusting environments. Table 2.3 lists the weldment alloys, filler metals, and supplier organization. Six Ni-base alloys and four Fe-base alloys were used for the fabrication of weld specimens. Weldments of Type 347 and 310 stainless steels were prepared by electron beam (e-beam) and gas tungsten arc weld (GTAW) approaches.

Table 2.2 Chemical composition (in wt.\%) of alloys selected for evaluation.

\begin{tabular}{|c|c|c|c|c|c|c|c|c|c|}
\hline Material & C & $\mathrm{Cr}$ & $\mathrm{Ni}$ & $\mathrm{Mn}$ & $\mathrm{Si}$ & Mo & Al & $\mathrm{Fe}$ & Other \\
\hline \multicolumn{10}{|c|}{ Fe-base alloys } \\
\hline T22 & 0.20 & 2.3 & - & 0.6 & 0.5 & 1.0 & - & Bal & - \\
\hline T91 & 0.08 & 8.6 & 0.1 & 0.5 & 0.4 & 1.0 & - & Bal & $\mathrm{N} 0.05, \mathrm{Nb} 0.07, \mathrm{~V} 0.2$ \\
\hline 153MA & 0.05 & 18.4 & 9.5 & 0.6 & 1.4 & 0.2 & - & Bal & N 0.15, Ce 0.04 \\
\hline 253MA & 0.09 & 20.9 & 10.9 & 0.6 & 1.6 & 0.3 & - & Bal & N 0.19, Ce 0.04 \\
\hline 353MA & 0.05 & 24.4 & 34.7 & 1.4 & 1.3 & 0.1 & - & Bal & N 0.18, V 0.06 \\
\hline 321L & 0.02 & 17.4 & 9.3 & 1.8 & 0.5 & - & - & Bal & N 0.02, Ti 0.3 \\
\hline 310 & 0.03 & 25.5 & 19.5 & 1.7 & 0.7 & - & - & Bal & - \\
\hline 800 & 0.08 & 20.1 & 31.7 & 1.0 & 0.2 & 0.3 & 0.4 & Bal & Ti 0.31 \\
\hline 803 & 0.08 & 25.6 & 36.6 & 0.9 & 0.7 & 0.2 & 0.5 & 34.6 & Ti 0.6 \\
\hline 38815 & 0.01 & 13.9 & 15.3 & 0.6 & 5.8 & 1.0 & 0.13 & Bal & - \\
\hline MA956 & - & 20.0 & - & - & - & - & 4.5 & Bal & $\mathrm{Ti} 0.5, \mathrm{Y}_{2} \mathrm{O}_{3} 0.6$ \\
\hline 321 & 0.04 & 17.3 & 10.3 & 1.2 & 0.4 & - & - & Bal & Ti 0.4, N 0.01 \\
\hline APMT & 0.04 & 21.7 & - & 0.1 & 0.6 & 2.8 & 4.9 & Bal & - \\
\hline $4 C 54$ & 0.17 & 26.7 & 0.3 & 0.7 & 0.5 & - & - & Bal & N 0.19 \\
\hline \multicolumn{10}{|c|}{ Ni-base alloys } \\
\hline 600 & 0.04 & 15.4 & Bal & 0.2 & 0.1 & - & - & 9.7 & - \\
\hline 601 & 0.03 & 21.9 & 61.8 & 0.2 & 0.2 & 0.1 & 1.4 & 14.5 & Ti $0.3, \mathrm{Nb} 0.1$ \\
\hline 690 & 0.01 & 27.2 & 61.4 & 0.2 & 0.1 & 0.1 & 0.2 & 10.2 & Ti 0.3 \\
\hline 617 & 0.08 & 21.6 & 53.6 & 0.1 & 0.1 & 9.5 & 1.2 & 0.9 & Co 12.5 , Ti 0.3 \\
\hline 625 & 0.05 & 21.5 & Bal & 0.3 & 0.3 & 9.0 & 0.2 & 2.5 & $\mathrm{Nb} 3.7, \mathrm{Ti} 0.2$ \\
\hline $602 \mathrm{CA}$ & 0.19 & 25.1 & 62.6 & 0.1 & 0.1 & - & 2.3 & 9.3 & Ti 0.13, Zr 0.19, Y 0.1 \\
\hline 214 & 0.04 & 15.9 & Bal & 0.2 & 0.1 & 0.5 & 3.7 & 2.5 & Zr 0.01, Y 0.006 \\
\hline 230 & 0.11 & 21.7 & 60.4 & 0.5 & 0.4 & 1.4 & 0.3 & 1.2 & W 14, La 0.015 \\
\hline 45TM & 0.08 & 27.4 & 46.4 & 0.4 & 2.7 & - & - & 26.7 & RE 0.07 \\
\hline HR 160 & 0.05 & 28.0 & Bal & 0.5 & 2.8 & 0.1 & 0.2 & 4.0 & Co 30.0 \\
\hline 693 & 0.02 & 28.8 & Bal & 0.2 & - & 0.1 & 3.3 & 5.8 & $\mathrm{Nb} 0.7, \mathrm{Ti} 0.4, \mathrm{Zr} 0.03$ \\
\hline
\end{tabular}


Table 2.3 List of weldment details.

\begin{tabular}{cccc}
\hline $\begin{array}{c}\text { Weldment } \\
\text { designation }\end{array}$ & $\begin{array}{c}\text { Base } \\
\text { alloy }\end{array}$ & $\begin{array}{c}\text { Filler metal/Welding } \\
\text { procedure }\end{array}$ & Supplier organization \\
\hline \multicolumn{2}{l}{ Ni-base alloy } & weldments \\
W1 & 602 CA & S 6025/GTAW & Krupp VDM \\
W2 & 230 & 230W/GTAW & Haynes International \\
W3 & HR160 & HR160/GTAW & Haynes International \\
W5 & 690 & FM52/GTAW & Special Metals \\
W6 & 693 & 53MD/GTAW & Special Metals \\
W7 & 601 & 601/GTAW & Special Metals
\end{tabular}

Fe-base alloy weldment

$\begin{array}{cccc}\text { W4 } & 803 & \text { 617/GTAW } & \text { Special Metals } \\ \text { W8 } & 347 & \text { No filler, e-beam } & \text { Argonne National Laboratory } \\ \text { W9 } & 310 & \text { No filler, e-beam } & \text { Argonne National Laboratory } \\ \text { W10 } & 353 \mathrm{MA} & 353 \mathrm{MA} / \mathrm{GTAW} & \text { Outokumpu } \\ \text { W11 } & 310 & \text { ER310/ GTAW } & \text { Allegheny Ludlum } \\ \text { W12 } & 347 & 347 / \text { GTAW } & \text { Allegheny Ludlum }\end{array}$

\subsection{Specimen Preparation}

The samples were flat coupons with approximate dimensions of $12 \times 20 \times 1$ to 2 $\mathrm{mm}$. They were sheared slightly oversize, and their edges were milled to remove cut edges and reduce the coupons to final size. A standard surface finish was used for all alloy specimens. The finish involved a final wet grinding with 400-grit SiC paper. The surface-engineered specimens were used in the as-fabricated condition. In the tests to evaluate the effect of surface preparation on metal dusting, specimen surfaces were prepared by electropolishing, mill annealing, shot peening, etc. Stenciling or electric engraving at the corner of the coupons identified all of the specimens. Prior to testing, specimens were thoroughly degreased in clean acetone, rinsed in water, and dried. The specimen dimensions were measured to $\pm 0.02 \mathrm{~mm}$, and the total exposed surface area, including edges, was calculated. The specimens were weighed to an accuracy of $0.1 \mathrm{mg}$. All the weldments were tested in the as-welded condition.

\subsection{Post-exposure Analysis of Specimens}

Several analytical approaches and techniques were used to evaluate the tested specimens. These included metal weight gain/loss in as-exposed and cleaned conditions, pitting size and density (pits per unit area of surface), pit depth (average 
depth over significant number of pits), and substrate penetration as determined by metallographic examination. After the specimens were weighed in the as-exposed condition, deposits on the specimens were mechanically removed with a soft brush, and the deposit material was analyzed for metal content, if warranted. The brushed specimens were cleaned ultrasonically to remove residual deposits and then washed in water and dried. Subsequently, the specimens were weighed, and the weight gain/loss was noted. The cleaned specimens were examined for surface pits by optical microscopy. This procedure allowed determination of the number of pits present in different regions of the specimen and the pit density. In addition, the sizes of several pits were measured and averaged to establish an average pit size. Surface profiler measurements were made to determine the pit size, including depth. This nondestructive approach in characterizing the pits enabled monitoring the pit growth as a function of exposure time.

At the end of a given run, several of the cleaned specimens (after weighing and pit measurement) were cut and mounted on the cut faces for metallographic polishing and examination in the as-polished condition (with chemical etching, if needed) by optical and/or scanning electron microscopy. Pit depth and substrate penetration thickness were measured in all the exposed specimens. The remaining good metal was calculated as the difference between the original thickness and the thickness unaffected by substrate penetration after exposure.

Raman spectra were excited with $60 \mathrm{~mW}$ of $476-\mathrm{nm}$ radiation from a $\mathrm{Kr}$-ion laser. The scattered light was analyzed with a triple Jobin-Yvon grating spectrometer. All of our spectra were acquired in $300 \mathrm{sec}$ at room temperature.

\subsection{Metal Dusting Experiments}

Table 2.4 lists the experimental conditions used for the various metal dusting runs. The list includes the test temperature, system pressure, gas chemistry, exposure time, alloys tested, and the purpose for conducting these experiments. The specimens from Runs 1-32 were extensively analyzed, and the results were discussed in the last annual report and in several publications (Natesan 2002; Natesan and Zeng 2003; Natesan et al. 2001; Zeng and Natesan 2003; Zeng et al. 2001, 2002, 2004). Several conclusions were drawn from the study:

- One of the major consequences of carbon deposition is the degradation of structural materials by a phenomenon known as "metal dusting." There are two major issues of importance in metal dusting. First is formation of carbon from the gas mixture and subsequent deposition of carbon on metallic materials. Second is the initiation of metal dusting in the alloy and subsequent propagation of the degradation. The first is influenced by the $a_{C}$ in the gas mixture and the availability of the catalytic surface for carbon-producing reactions to proceed. There may be a threshold in $a_{C}(>>1)$ for carbon deposition. Metal dusting of the alloy in the reformer environments is determined by a competition between the oxide scale development and access of the virgin metal surface to the carbon deposit. 
- A new metal dusting mechanism was proposed in this study. Mechanisms for degradation of both $\mathrm{Fe}$ - and $\mathrm{Ni}$-base alloys are related to the catalytic crystallization of carbon that deposits from the gaseous environment. The only difference is that iron carbide acts as a catalyst in Fe-base alloys, whereas nickel metal instead of nickel carbide (which is thermodynamically not stable) acts as a catalyst in Ni-base alloys. To achieve good crystallinity, carbon dissolves, diffuses through the alloy, and precipitates at defects of iron carbide or nickel metal. The accumulation of carbon leads to separation of carbide or nickel grains into nano-size particles. The free energy difference between poorly and well crystalline carbon is the driving force for both metal dusting and the growth of carbon nano-filaments. We believe that the proposed mechanism can explain more of the experimental observations made regarding $\mathrm{Fe}$ - and $\mathrm{Ni}$-base alloys subjected to metal dusting degradation.

- Tests were conducted on several alloys at 482,593 , and $704^{\circ} \mathrm{C}$. The metal dusting rate at $593^{\circ} \mathrm{C}$ was the highest. However, further study was needed to establish the temperature dependence of metal-dusting rates in different alloys and to relate the metal wastage rates to the carbon activity in the exposure environment, including system pressure and temperature.

- The local nature of dusting (initiated by pits on the alloy surface) on structural alloys showed that defects in the oxide scales play a large role in initiation. Oxide scaling may not occur if $\mathrm{a}_{\mathrm{C}}$ is $>>1$ and/or if the $\mathrm{H}_{2} \mathrm{O}$ content in the environment is very low. Laboratory experiments have clearly indicated the effect of gas chemistry (in particular, $\mathrm{H}_{2} \mathrm{O}$ content) in the scaling, carbon deposition, and dusting initiation. The environment in reformers is high enough in $\mathrm{pO}_{2}$ that a Cr-rich alloy can develop a chromia scale (given enough exposure time) before carbon deposition. The presence of an oxide scale may not prevent metal dusting but can delay its initiation, thereby slowing the overall attack.

- Raman spectra showed the existence of spinel, $\mathrm{Cr}_{2} \mathrm{O}_{3}$, and disordered chromium oxide in the scale grown on high-chromium Fe-base alloys. All three phases act, to different degrees, as protective layers to prevent alloys from metal dusting corrosion. The spinel phase is not as stable as $\mathrm{Cr}_{2} \mathrm{O}_{3}$ and could be reduced by the deposited carbon, and metal dusting corrosion would initiate from these locations.

- The phase composition of the oxide scale is important in metal dusting corrosion. $\mathrm{Cr}_{2} \mathrm{O}_{3}$ is a better phase than spinel to resist metal dusting since spinel can be reduced. If alloys can generate more $\mathrm{Cr}_{2} \mathrm{O}_{3}$ phase and less spinel phase on the alloy surface, their abilities to resist metal dusting will increase. Therefore, alloys with more $\mathrm{Cr}$ and less $\mathrm{Fe}$ content performed well in a carburizing atmosphere. The phase composition of the oxide scale changes with exposure time: spinel phase content increases and chromium oxide phase content decreases. Therefore, alloys are easily attacked by metal dusting after long time exposure since spinel phase content increases.

- Metal dusting degradation involves two steps, namely, incubation and propagation. The incubation period is determined by the carbon activity in the gas phase, alloy 
chemistry, system pressure, and probably the exposure temperature. For the same exposure conditions, the incubation period for the onset of metal dusting is significantly greater for the Ni-base alloys than that for Fe-base alloys.

- Higher carbon activity may lead to higher metal loss rate, since higher carbon activity provides higher driving force to form highly disordered carbon on the metal surface.

- High system pressure not only increases the carbon activity but also seems to accelerate the carbon transport into the alloy and to reduce the incubation time for onset of metal dusting.

- Both aluminum and silicon additions increased the ability of alloys to resist metal dusting. However, silicon addition failed to protect alloys from metal dusting at high pressure, although it was beneficial at 1 -atm pressure tests. High $\mathrm{Cr}$ content in alloys is necessary but not sufficient to resist metal dusting. Iron content (especially in Ni-base) in the alloy is detrimental and should be maintained as low as possible to extend the life of the alloy. Cobalt addition is not beneficial in resisting metal dusting.

- MA956, APMT, and 4C54 are the best three Fe-base alloys to resist metal dusting. Two of the three alloys contain Al (4.5\% in MA956 and $4.9 \%$ in APMT). Alloy 4C54 contains the highest $\mathrm{Cr}$ level of $26.7 \%$.

- Ni-base alloys performed better than Fe-base alloys when exposed to similar atmospheres. Among the Ni-base materials, Alloy 693 was the best, which can be attributed to its high $\mathrm{Cr}$ and $\mathrm{Al}$ contents. Alloy 602CA was good in most of the tests, but it was attacked in high-carbon-activity Gas 17.

- Surface modification (by preoxidation and/or coatings) and alternative materials are being examined at ANL to alleviate the metal dusting problem. The advantage of oxide coatings is that they can minimize carbon-producing reactions (by reducing the availability of catalytic surface) and can also act as a barrier to minimize carbon ingress and pitting of the substrate alloy. Preliminary tests showed a beneficial effect, but long-term tests are needed to substantiate the results.

- We have examined in-situ development of oxide scales as a means to prevent or minimize metal dusting attack. Preliminary tests showed that the performance of pre-oxidized samples was worse than the samples without pre-oxidation. More spinel phase was found on the surface of alloys that were pre-oxidized. The spinel phase, especially if it contained a high Fe content, was detrimental and led to an increase in metal dusting corrosion.

During the course of the past year, we have developed a substantial body of information on both $\mathrm{Fe}$ - and $\mathrm{Ni}$-base alloys upon exposures to gas mixtures that encompass a wide range of compositions and carbon activity. Data were also developed on the long-term performance of the alloys in environments that simulate the 
reformer effluent at atmospheric and high pressures. Since the initiation time for the Nibase alloys is fairly large, we have developed pre-pitting approaches to shorten the initiation period and expedite the study of pit propagation and growth in these alloys. Furthermore, we have developed methods to mitigate metal dusting by intermediate oxidation of the partially metal dusted alloys. During the past year, we have also developed several alloys, the compositions of which were based on our fundamental understanding of metal dusting initiation and propagation. These alloys were fabricated into coupons and are being tested in simulated metal dusting environments, and their performance will be compared with that of other commercial alloys. The information on these various aspects of the project will be discussed in subsequent sections of this report.

Table 2.4 Experimental conditions for laboratory runs.

\begin{tabular}{cccc}
\hline $\begin{array}{c}\text { Run } \\
\text { Number }\end{array}$ & $\begin{array}{c}\text { Experimental } \\
\text { conditions }\end{array}$ & Gas mixture \# & Objective \\
\hline 1 & $593^{\circ} \mathrm{C}, 1 \mathrm{~atm}, 48 \mathrm{~h}$ & 6 & Program start \\
2 & $593^{\circ} \mathrm{C}, 1 \mathrm{~atm}, 100 \mathrm{~h}$ & 4 & No water \\
3 & $593^{\circ} \mathrm{C}, 1 \mathrm{~atm}, 100 \mathrm{~h}$ & 5 & 2 vol. $\% \mathrm{H}_{2} \mathrm{O}$ \\
4 & $704^{\circ} \mathrm{C}, 1 \mathrm{~atm}, 100 \mathrm{~h}$ & 4 & Effect of temperature, $\mathrm{H}_{2} \mathrm{O}$ \\
5 & $704^{\circ} \mathrm{C}, 1 \mathrm{~atm}, 100 \mathrm{~h}$ & 5 & $"$ \\
6 & $593^{\circ} \mathrm{C}, 1 \mathrm{~atm}, 5 \mathrm{~h}$ & 5 & Effect of time, $\mathrm{H}_{2} \mathrm{O}$ \\
7 & $593^{\circ} \mathrm{C}, 1 \mathrm{~atm}, 5 \mathrm{~h}$ & 4 & $"$ \\
8 & $593^{\circ} \mathrm{C}, 1 \mathrm{~atm}, 72 \mathrm{~h}$ & 4 & Ceramics only (no catalysis) \\
9 & $593^{\circ} \mathrm{C}, 1 \mathrm{~atm}, 72 \mathrm{~h}$ & 5 & " \\
10 & $593^{\circ} \mathrm{C}, 1 \mathrm{~atm}, 90 \mathrm{~h}$ & 4 & New system validation \\
11 & $593^{\circ} \mathrm{C}, 1 \mathrm{~atm}, 115 \mathrm{~h}$ & 4 & Fe specimen only \\
12 & $593^{\circ} \mathrm{C}, 1 \mathrm{~atm}, 115 \mathrm{~h}$ & Gas $4+\mathrm{H}_{2} \mathrm{O}$ & Fe specimen only \\
13 & $593^{\circ} \mathrm{C}, 1 \mathrm{~atm}, 100 \mathrm{~h}$ & Gas $4+\mathrm{H}_{2} \mathrm{O}$ & Ni specimen only \\
14 & $593^{\circ} \mathrm{C}, 1 \mathrm{~atm}, 100 \mathrm{~h}$ & 4 & Ni specimen only \\
15 & $593^{\circ} \mathrm{C}, 1 \mathrm{~atm}, 1000 \mathrm{~h}$ & 2 & Fe-base alloys \\
16 & $593^{\circ} \mathrm{C}, 1 \mathrm{~atm}, 1000 \mathrm{~h}$ & 2 & Ni-base alloys \\
17 & $482^{\circ} \mathrm{C}, 1 \mathrm{~atm}, 100 \mathrm{~h}$ & 2 & Fe specimen only \\
18 & $482^{\circ} \mathrm{C}, 1 \mathrm{~atm}, 100 \mathrm{~h}$ & 2 & Ni specimen only \\
19 & $593^{\circ} \mathrm{C}, 1 \mathrm{~atm}, 1000 \mathrm{~h}$ & Gas 2, low H $\mathrm{HO}$ & Fe-base alloys \\
20 & $482^{\circ} \mathrm{C}, 1 \mathrm{~atm}, 1000 \mathrm{~h}$ & 2 & Fe-base alloys \\
21 & $482^{\circ} \mathrm{C}, 1 \mathrm{~atm}, 1000 \mathrm{~h}$ & 2 & Ni-base alloys \\
22 & $704^{\circ} \mathrm{C}, 1 \mathrm{~atm}, 98 \mathrm{~h}$ & High CO Gas & Fe, T91, 304 \\
23 & $704^{\circ} \mathrm{C}, 1 \mathrm{~atm}, 98 \mathrm{~h}$ & $"$ & Ni, Ni-base alloys \\
24 & $704^{\circ} \mathrm{C}, 1 \mathrm{~atm}, 102 \mathrm{~h}$ & No water & Ni, Ni-base alloys \\
25 & $593^{\circ} \mathrm{C}, 1 \mathrm{~atm}, 1000 \mathrm{~h}$ & 2 & Fe-base alloys, preoxidized at \\
\hline
\end{tabular}




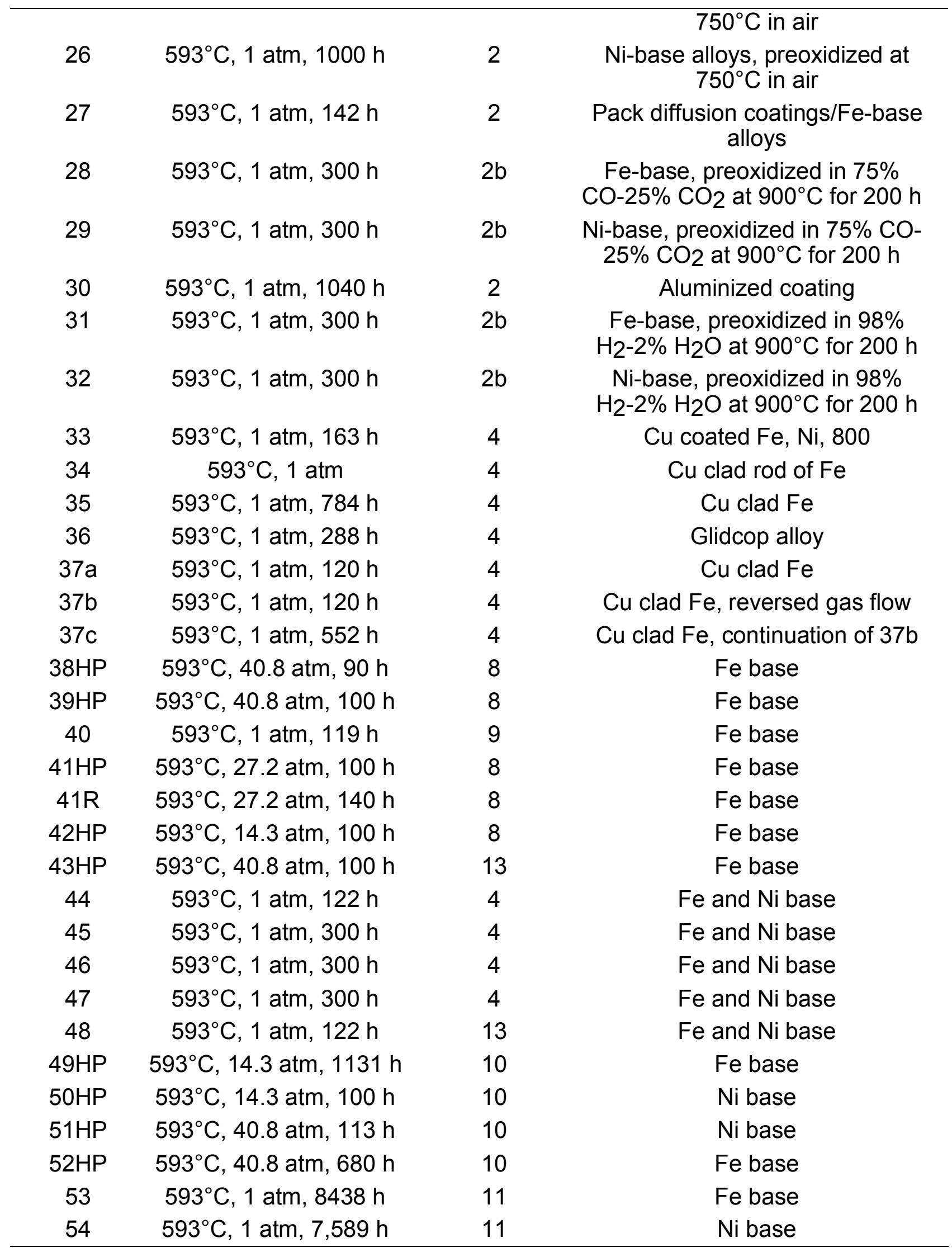




\begin{tabular}{cccl}
\hline 55 & $593^{\circ} \mathrm{C}, 1 \mathrm{~atm}, 6678 \mathrm{~h}$ & 17 & Ni base \\
56 & $593^{\circ} \mathrm{C}, 1 \mathrm{~atm}, 8157 \mathrm{~h}$ & 14 & Ni base \\
57 & $593^{\circ} \mathrm{C}, 1 \mathrm{~atm}, 3447 \mathrm{~h}$ & 15 & Ni base \\
58 & $593^{\circ} \mathrm{C}, 1 \mathrm{~atm}$ & 16 & Ni base \\
$59 \mathrm{HP}$ & $593^{\circ} \mathrm{C}, 14.3 \mathrm{~atm}, 9700 \mathrm{~h}$ & 10 & Ni base \\
60 & $593^{\circ} \mathrm{C}, 1 \mathrm{~atm}, 246 \mathrm{~h}$ & 10 & Ni base \\
$60 \mathrm{HP}$ & $593^{\circ} \mathrm{C}, 30 \mathrm{~atm}, 1800 \mathrm{~h}$ & 18 & Ni base \\
61 & $593^{\circ} \mathrm{C}, 1 \mathrm{~atm}, 5839 \mathrm{~h}$ & 21 & Ni base \\
62 & $593^{\circ} \mathrm{C}, 1 \mathrm{~atm}, 3114 \mathrm{~h}$ & 21 & Ni-base alloy weldments \\
\hline
\end{tabular}




\section{TEST RESULTS AND DISCUSSION}

We reported earlier that Ni-base alloys exhibit better resistance to metal dusting attack than Fe-base alloys, and indicated that differences in the lattice mismatch in catalytic crystallization of carbon may be one reason (Zeng et al. 2001 and Zeng and Natesan 2003). The misfit between the $\mathrm{Ni}$ and graphite lattice $(3.6 \%)$ is much greater than that between $\mathrm{Fe}_{3} \mathrm{C}$ and graphite $(0.28 \%)$. The lattice of $\mathrm{Fe}_{3} \mathrm{C}$ almost perfectly matches the lattice of graphite, indicating that carbon atoms move easier from the former to the latter than that do nickel atoms. Therefore, the energy barrier for the precipitation of carbon on the surface of $\mathrm{Ni}$ is higher than that needed for precipitation on the surface of $\mathrm{Fe}_{3} \mathrm{C}$. This condition leads to a lower carbon precipitation rate, smaller crystallite size, and lower metal dusting rate on the Ni. The observed crystallite size of coke on $\mathrm{Ni}$ was smaller than that on $\mathrm{Fe}$. This difference suggests that $\mathrm{Fe}_{3} \mathrm{C}$ is better than $\mathrm{Ni}$ in serving as a template for the catalytic crystallization of carbon and may explain why the metal dusting rate of $\mathrm{Fe}$ and Fe-base alloys is higher than that of $\mathrm{Ni}$ and Ni-base alloys. The other factor that can affect the metal dusting rate is the chemical and mechanical integrity of the oxide layer that develops on the surface of alloys. In this report, we present results from a study of the effect of alloy chemistry and phase composition of oxides present on the surface of Ni-base alloys on metal dusting rate. We also examined the metal dusting rate of several Ni-base alloys to establish the materials that are most resistant to metal dusting corrosion.

\subsection{Weight Loss Data for Ni-Base Alloys at Carbon Activity of $\mathbf{3 1}$}

Metal dusting attack, as measured by weight loss, was observed on all of the $\mathrm{Ni}$ base alloys when tested for $9700 \mathrm{~h}$ in the same gas environment at $593^{\circ} \mathrm{C}$ and $14.3 \mathrm{~atm}$ (see Fig. 3.1). However, the weight loss rates for Alloys 693 and 602CA were very low. Both alloys contain $\mathrm{Al}$ and have high $\mathrm{Cr}$ and low Fe content. The weight loss rate for Alloy 45TM was the highest among the Ni-base alloys used in the study, although the $\mathrm{Cr}$ content in this alloy is fairly high. The Fe content in Alloy 45TM is also the highest among these alloys. The weight loss rate of Alloy 601 was also high; the Fe content of this alloy is the second highest among these alloys. The results indicate that addition of $\mathrm{Fe}$ to the Ni-base alloys leads to a substantial decrease in incubation time for the onset of metal dusting. When the Fe content in the alloy is $>10 \mathrm{wt} \%$, the alloy is readily attacked, as evidenced by numerous pits on the exposed surfaces of the alloy specimens.

The weight loss rate for the Co-containing Alloy 617 is the second highest among these alloys. Addition of Mo to this alloy did not improve its resistance to metal dusting corrosion. The other Co-containing Alloy, HR160, also exhibited metal dusting degradation, although it contained $28 \% \mathrm{Cr}$. Therefore, addition of Co to alloys is also not beneficial to metal dusting resistance. The $\mathrm{Cr}$ content in Alloy 214 is the lowest among these alloys, and its weight loss rate was also high, although it contained Al. High $\mathrm{Cr}$ content in alloys seems essential but not entirely sufficient for preventing metal dusting corrosion in Ni-base alloys. 


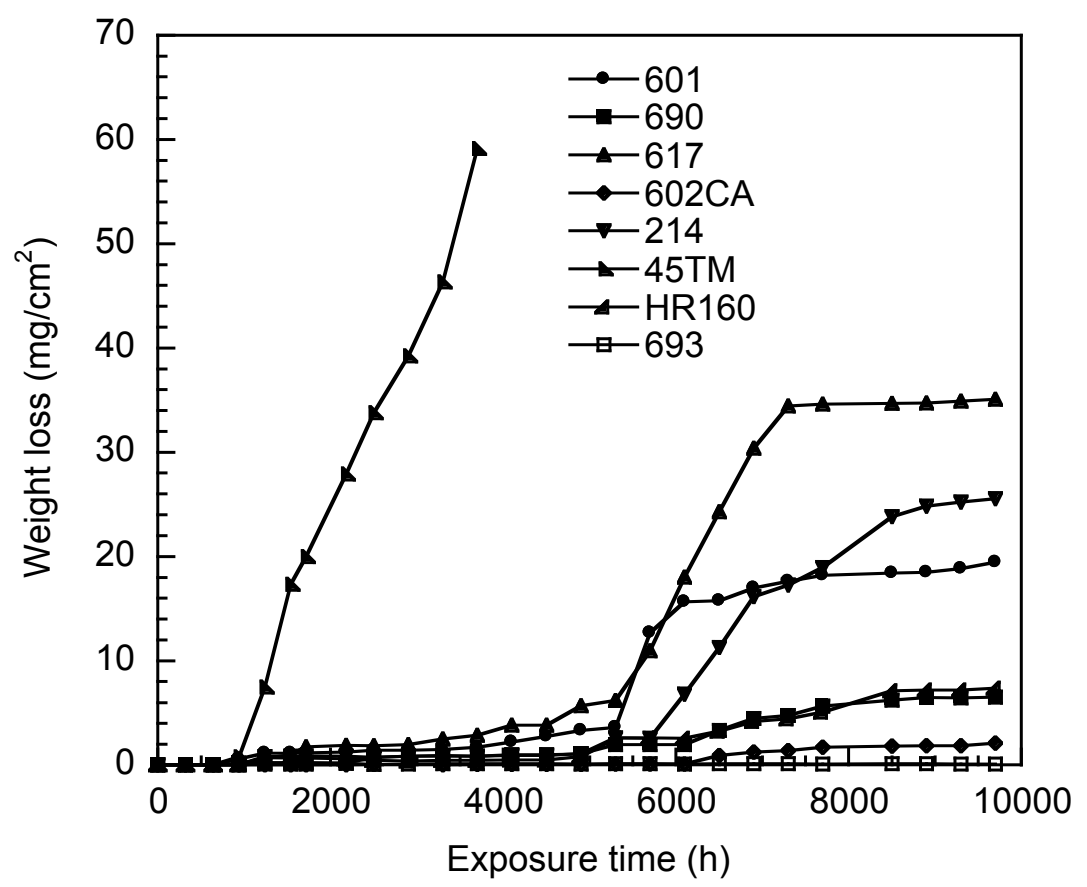

Figure 3.1 Weight loss data for Ni-base alloys that were exposed in Gas 10 at $593^{\circ} \mathrm{C}$ and $14.3 \mathrm{~atm}(210 \mathrm{psi})$.

Even though weight loss data developed for various alloys are useful in the evaluation and ranking of the alloys according to their susceptibility to metal dusting, such data may indicate the protective capacity of the surface oxide scale and, furthermore, may represent only an average behavior for the alloy in a given exposure environment and temperature. Because corrosion damage of the alloy occurs by nucleation of pits on the surface and their growth inward, it is essential that we develop an understanding of the morphology of pits (size, distribution, depth, etc.) on the alloy surface and of the maximum growth rate of the pits to evaluate the ultimate damage of component failure under a given set of exposure (process) conditions.

\subsection{Characterization of Pits on Ni-Base Alloys at Carbon Activity of 31}

In Run 59HP, we exposed several Ni-base alloys to Gas 10 at $593^{\circ} \mathrm{C}$ and 14.3 atm for a total time of $9700 \mathrm{~h}$. During the course of the experiment, we retrieved the specimens periodically and took SEM photomicrographs of various surface regions to characterize and monitor the growth of pits as a function of exposure time. Lacking the capability to measure the pit depth during that period, we concentrated on measuring changes in the diameter of several pits on the surface of each alloy.

No metal dusting attack was observed on Ni-base alloys in the relatively short exposure time of $246 \mathrm{~h}$ at 1 -atm pressure (Table 3.1). However, pits were observed on Alloys $601,690,617$, and 214 when exposed in the same gas at $593^{\circ} \mathrm{C}$ and $14.3 \mathrm{~atm}$. Similar results were obtained when specimens were tested at $40.8 \mathrm{~atm}$. Table 3.2 gives the pit characteristics after $9700 \mathrm{~h}$. The results show that the ratio of pit depth to pit 
diameter for Alloy HR160 is the smallest among the alloys tested. This alloy corroded by forming shallow pits. The ratio of pit depth to pit diameter for Alloy 693 was the largest among these alloys, but the absolute value of pit diameter in this alloy was substantially smaller than that in other alloys.

Table 3.1. Surface Characteristics of alloys after 246-h exposure at 1, 14.3, and 40.8 atm and $593^{\circ} \mathrm{C}$.

\begin{tabular}{lccc}
\hline \multicolumn{1}{c}{ Alloy } & 1 atm & $14.3 \mathrm{~atm}$ & $40.8 \mathrm{~atm}$ \\
\hline 601 & Clean surface & Pits & Pits \\
690 & Clean surface & Pits & Pits \\
617 & Clean surface & Pits & Pits \\
$602 \mathrm{CA}$ & Clean surface & Clean surface & Clean surface \\
214 & Clean surface & Pits & Pits \\
45TM & Clean surface & Clean surface & Clean surface \\
HR160 & Clean surface & Clean surface & Clean surface \\
\hline
\end{tabular}

Table 3.2. Maximum pit size and weight loss for alloys after 9700-h exposure in Run 59HP.

\begin{tabular}{ccccc}
\hline Alloy. & $\begin{array}{c}\text { Weight loss } \\
\left(\mathrm{mg} / \mathrm{cm}^{2}\right)\end{array}$ & $\begin{array}{c}\text { Pit depth } \\
(\mu \mathrm{m})\end{array}$ & $\begin{array}{c}\text { Pit diameter } \\
(\mu \mathrm{m})\end{array}$ & $\begin{array}{c}\text { Ratio of pit depth to } \\
\text { pit diameter }\end{array}$ \\
\hline 601 & 19.5 & 110 & 450 & 0.244 \\
690 & 6.5 & 147 & 440 & 0.334 \\
617 & 35.1 & 201 & 887 & 0.227 \\
$602 \mathrm{CA}$ & 2.1 & 96 & 374 & 0.256 \\
214 & 25.6 & $-^{\mathrm{a}}$ & $-^{\mathrm{a}}$ & $-^{\mathrm{a}}$ \\
$45 \mathrm{TM}^{\mathrm{b}}$ & 59.1 & 141 & 600 & 0.235 \\
HR160 $^{2}$ & 7.3 & 13 & 210 & 0.062 \\
693 & 0.1 & 37 & 99 & 0.374 \\
\hline
\end{tabular}

aSpecimen uniformly corroded.

${ }^{\mathrm{b}}$ Exposed for only 3,300 $\mathrm{h}$.

Figure 3.2 shows a comparison of the surfaces of several alloys after exposure at $593^{\circ} \mathrm{C}$ and 1 and $14.3 \mathrm{~atm}$. The carbon activity in the gas in the latter case is 14 times higher than at $1 \mathrm{~atm}$, which can decrease the incubation time for the initiation of metal dusting pits on the alloy surface.

Figure 3.3 shows SEM photomicrographs of the pit morphology observed on Alloy 601 for exposure times in the range of 6900 and $9300 \mathrm{~h}$. The figures show that numerous pits form in Alloy 601 and undergo significant growth as a function of exposure time. Figure 3.4 shows the SEM photomicrographs of pit morphology for Alloy690 for exposure times in the range of 2900 and $9300 \mathrm{~h}$. The compositional difference between Alloys 601 and 690 is that the latter contains 27.2 wt. $\% \mathrm{Cr}$ versus 21.9 wt. \% in 601 . However, Alloy 601 contains 1.4 wt.\% Al, which is supposed to be beneficial in resisting metal dusting. Nonetheless, the pit density in Alloy 601 was significantly larger than in Alloy 690. Figure 3.5 shows photomicrographs of pit 
morphology in Alloy 617. Figure 3.6 shows photomicrographs of pit development in Alloy $602 \mathrm{CA}$, which contains $\approx 2.7 \mathrm{wt}$. $\%$ Al. The alloy showed very few pits for the same exposure time as Alloys 601, 690, and 617, and the growth rate of the pits was also less than the other three alloys. Figure 3.7 shows the pit morphology in Alloy 45TM. The pit density in this alloy was large, as was the pit growth rate; as a result, the exposure of this alloy was shortened to $3300 \mathrm{~h}$.

Figure 3.8 shows the pit morphology in Alloy HR160. This alloy contained 28 wt. $\% \mathrm{Cr}, 30 \mathrm{wt} . \% \mathrm{Co}$, and $2.8 \mathrm{wt} . \% \mathrm{Si}$, but the pit density seemed large under exposure conditions of Run 59HP. Figure 3.9 shows the pit morphology in Alloy 214, which contained only $15.9 \mathrm{wt} . \% \mathrm{Cr}$ but had $3.7 \mathrm{wt} . \%$ Al. The alloy had numerous pits on the surface, and the pits seemed to coalesce, with the result that the attack was more uniform than occurs with local pit formation. Alloy 693 was most resistant to metal dusting among the alloys tested, and no pits of significant size were detected over $\approx 8000 \mathrm{~h}$. After 9300 -h exposure, the alloy exhibited a number of small pits as shown in Fig. 3.10. The pit diameter ranged between 100 and $150 \mu \mathrm{m}$ after $9300 \mathrm{~h}$ exposure.
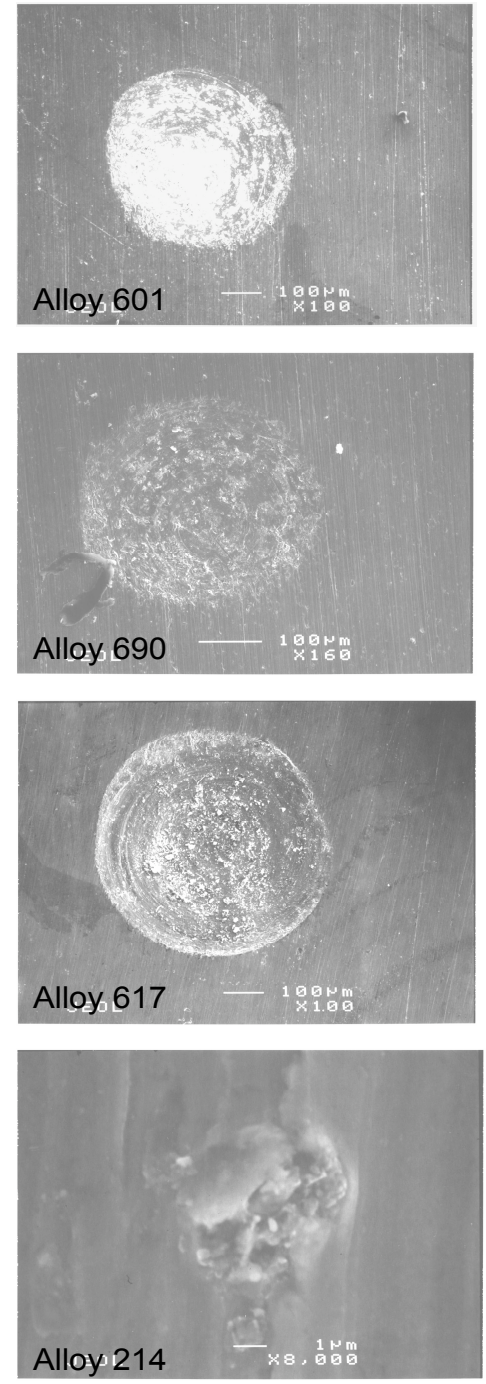
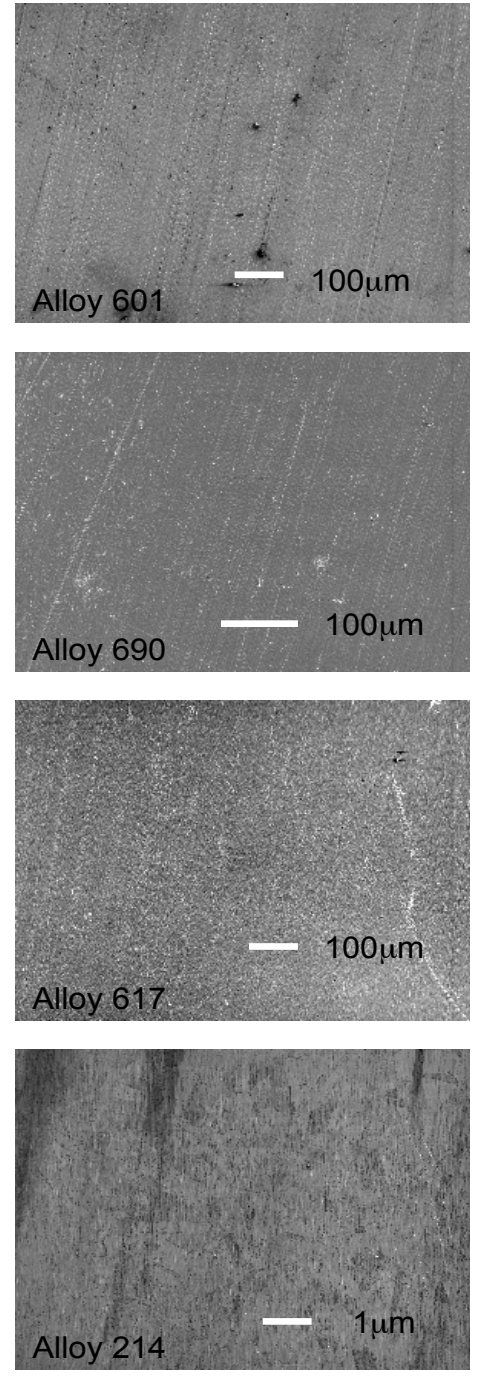

Figure 3.2. SEM photomicrographs of surfaces of several Ni-base alloys after exposure to metal dusting environment. Left: exposed at $14.3 \mathrm{~atm}$ and $593^{\circ} \mathrm{C}$ for $160 \mathrm{~h}$; metal dusting pits were observed. Right: exposed at $1 \mathrm{~atm}$ and $593^{\circ} \mathrm{C}$ for $240 \mathrm{~h}$; surfaces of alloys are smooth and no metal dusting pits appear. 


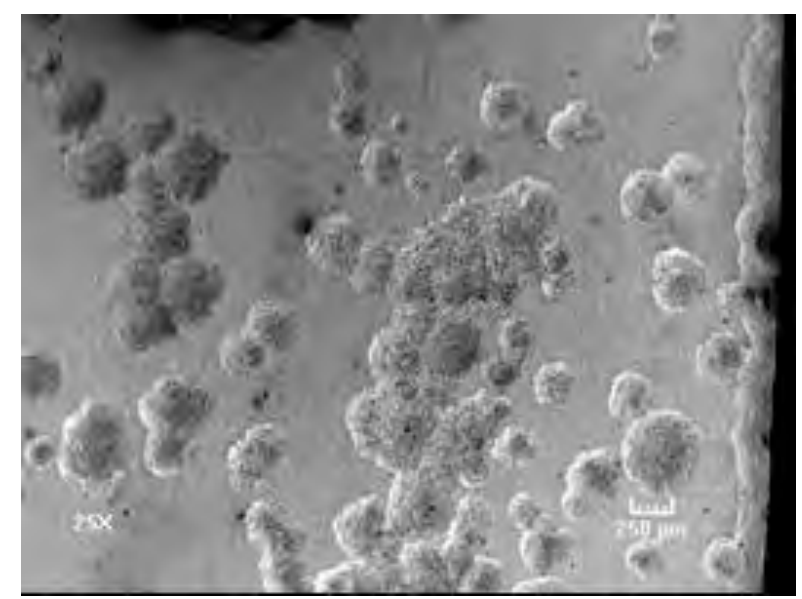

$6900 \mathrm{~h}$

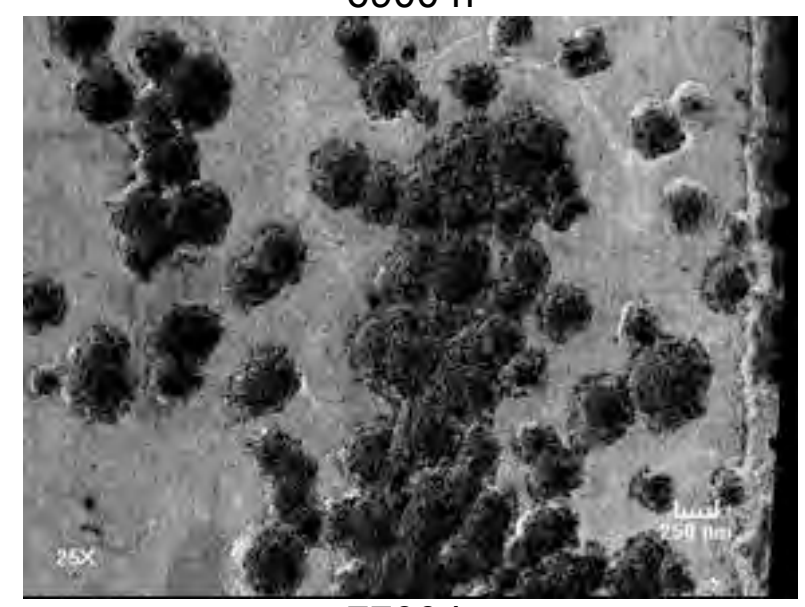

$7700 \mathrm{~h}$

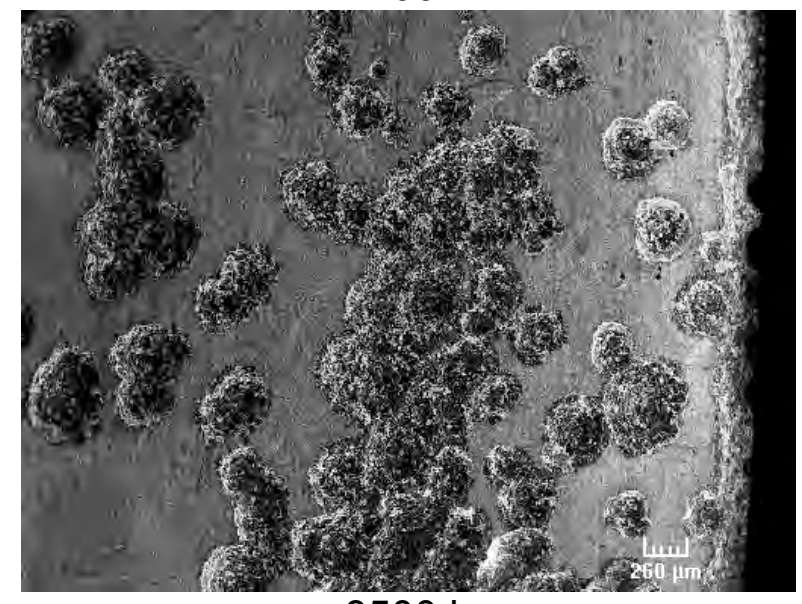

$8500 \mathrm{~h}$

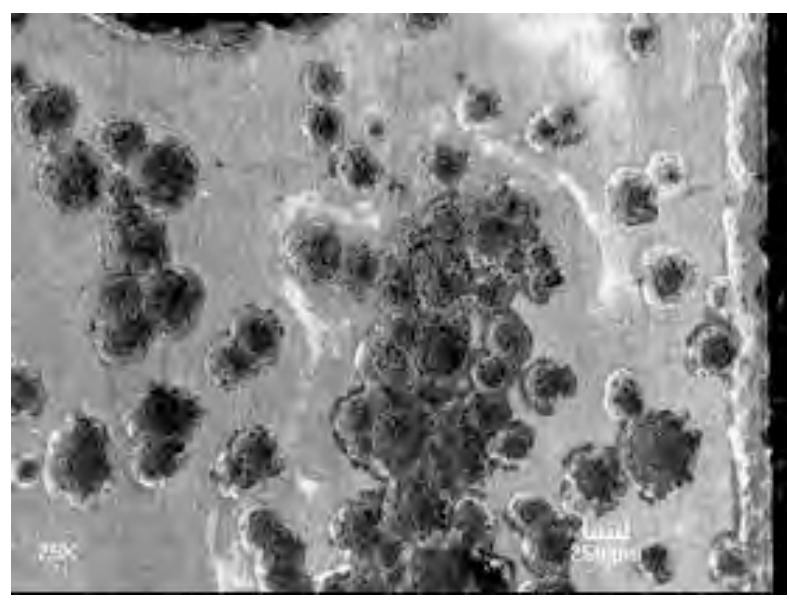

$7300 \mathrm{~h}$

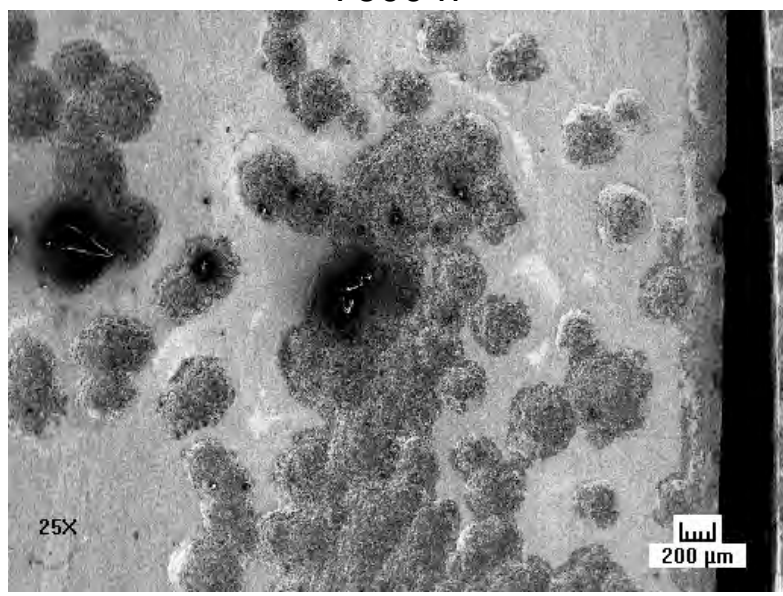

$8100 \mathrm{~h}$

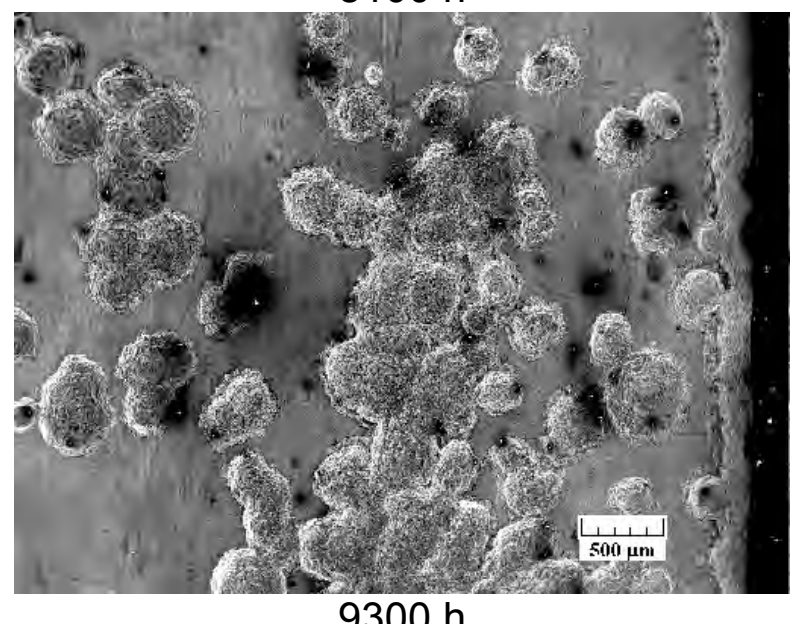

$9300 \mathrm{~h}$

Figure 3.3. Pit morphology as a function of time for Alloy 601 exposed to Gas 10 at $593^{\circ} \mathrm{C}$ and $14.3 \mathrm{~atm}(210 \mathrm{psi})$. 


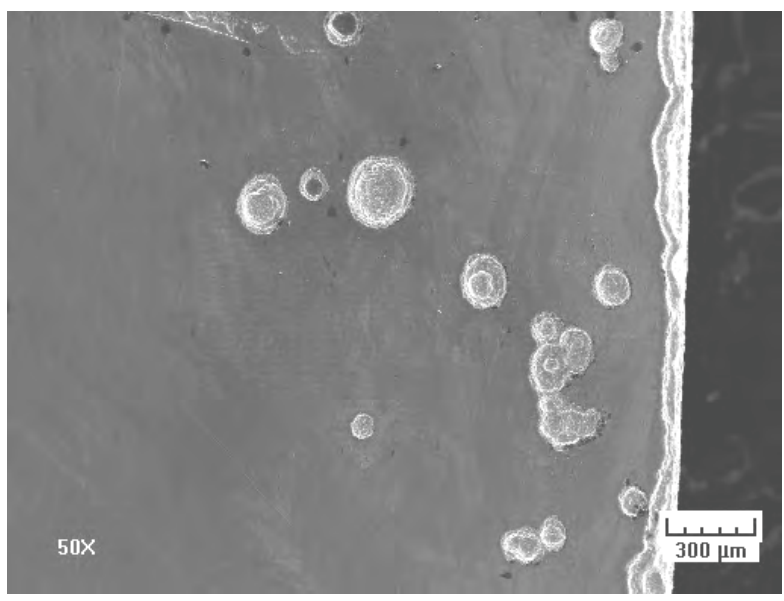

$2900 \mathrm{~h}$

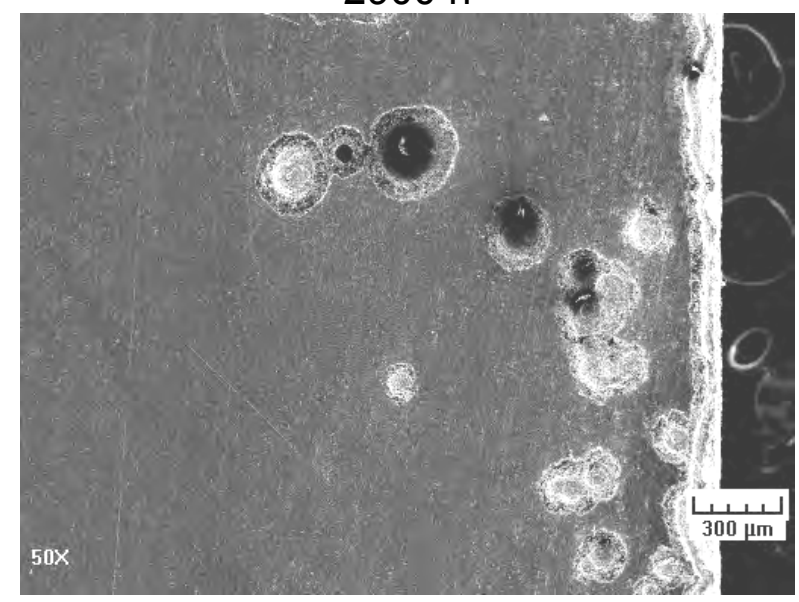

$4500 \mathrm{~h}$

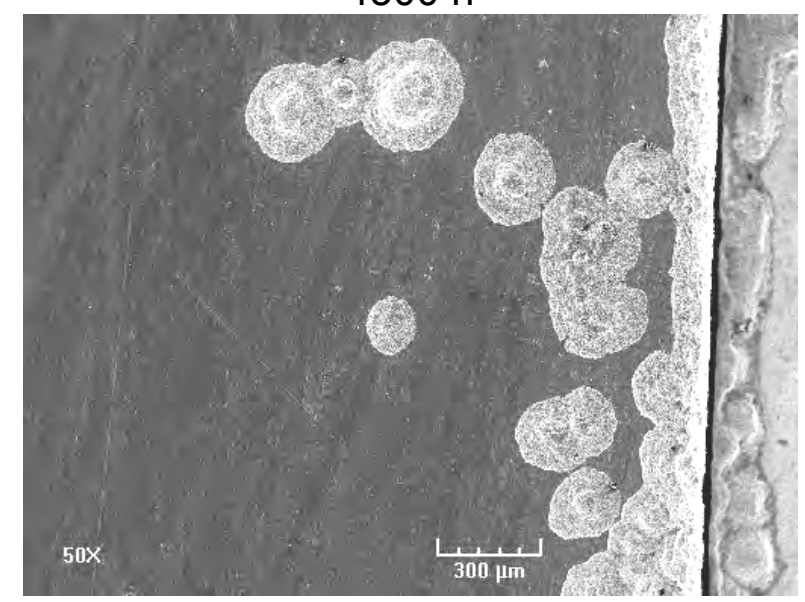

$5300 \mathrm{~h}$

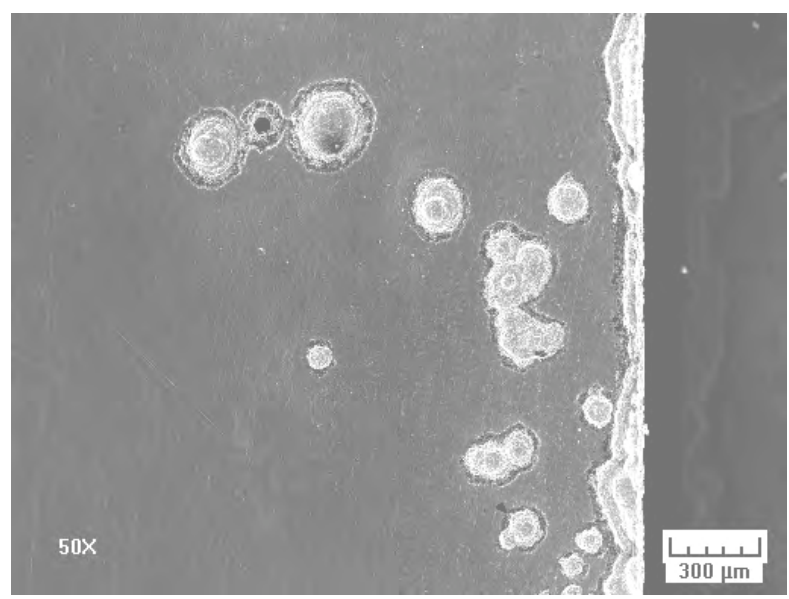

$4100 \mathrm{~h}$

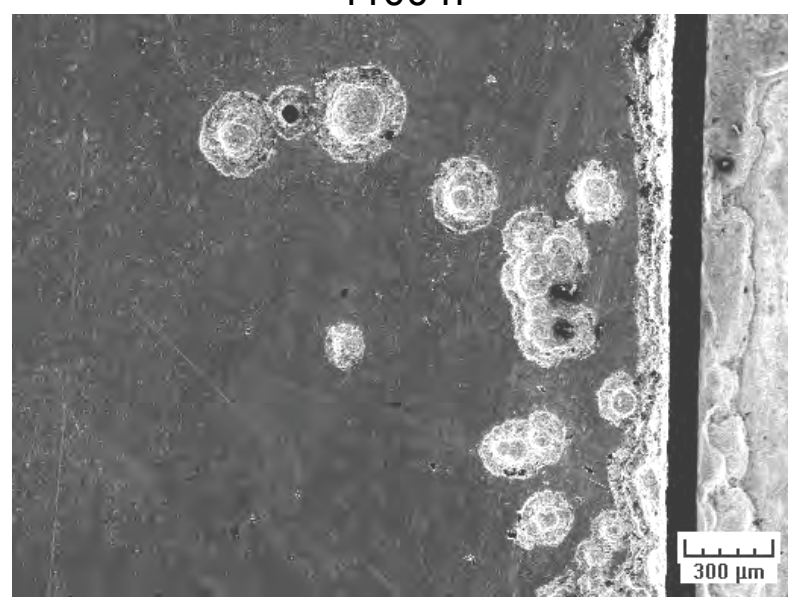

$4900 \mathrm{~h}$

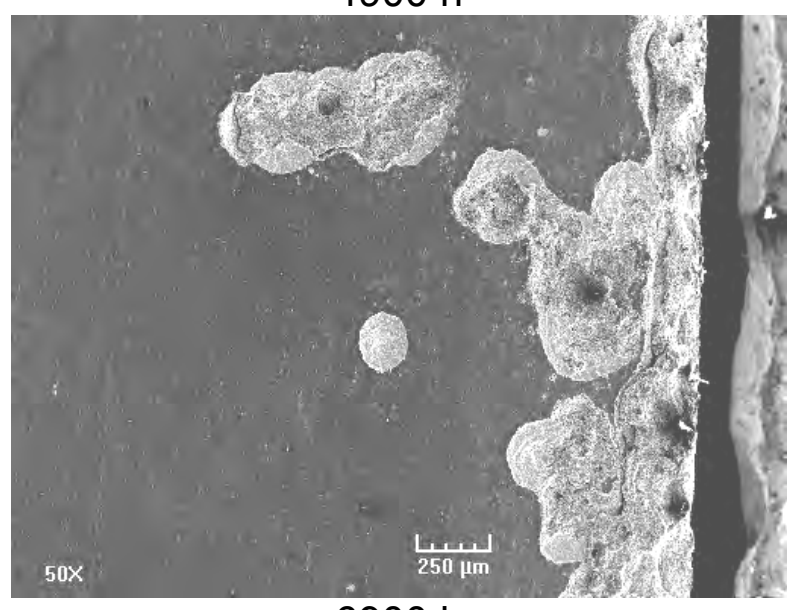

$6900 \mathrm{~h}$

Figure 3.4. Pit morphology as a function of time for Alloy 690 exposed to Gas 10 at $593^{\circ} \mathrm{C}$ and $14.3 \mathrm{~atm}(210 \mathrm{psi})$. 

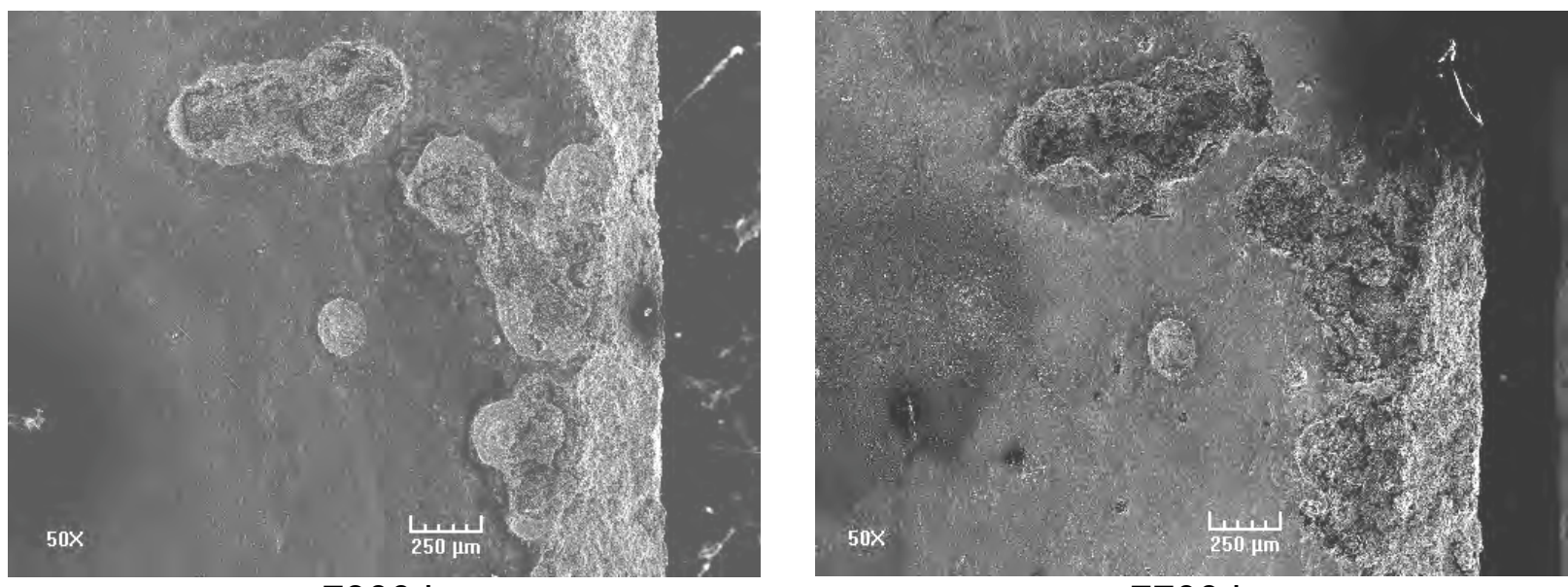

$7300 \mathrm{~h}$

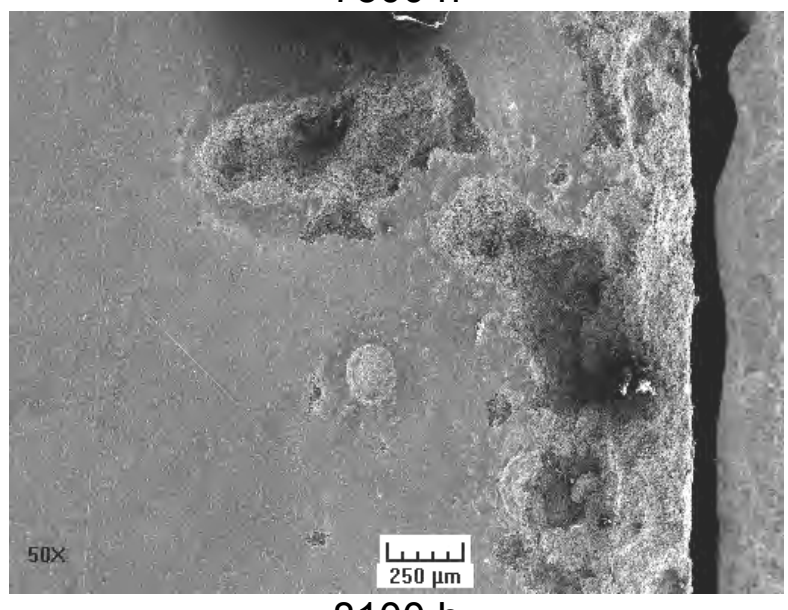

$8100 \mathrm{~h}$
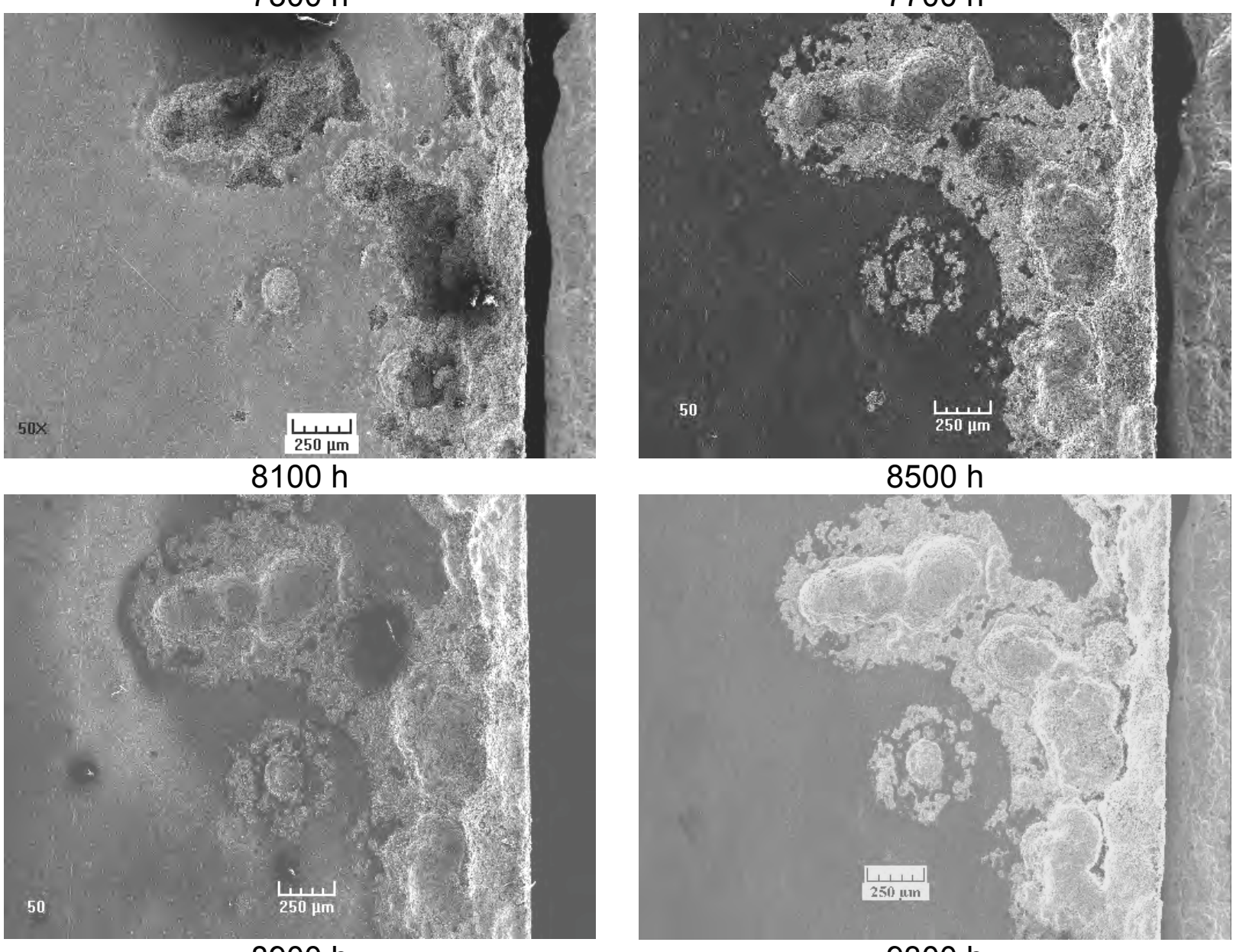

$8900 \mathrm{~h}$

$9300 \mathrm{~h}$

(Figure 3.4 continued.) Pit morphology as a function of time for Alloy 690 exposed to Gas 10 at $593^{\circ} \mathrm{C}$ and $14.3 \mathrm{~atm}(210 \mathrm{psi})$. 

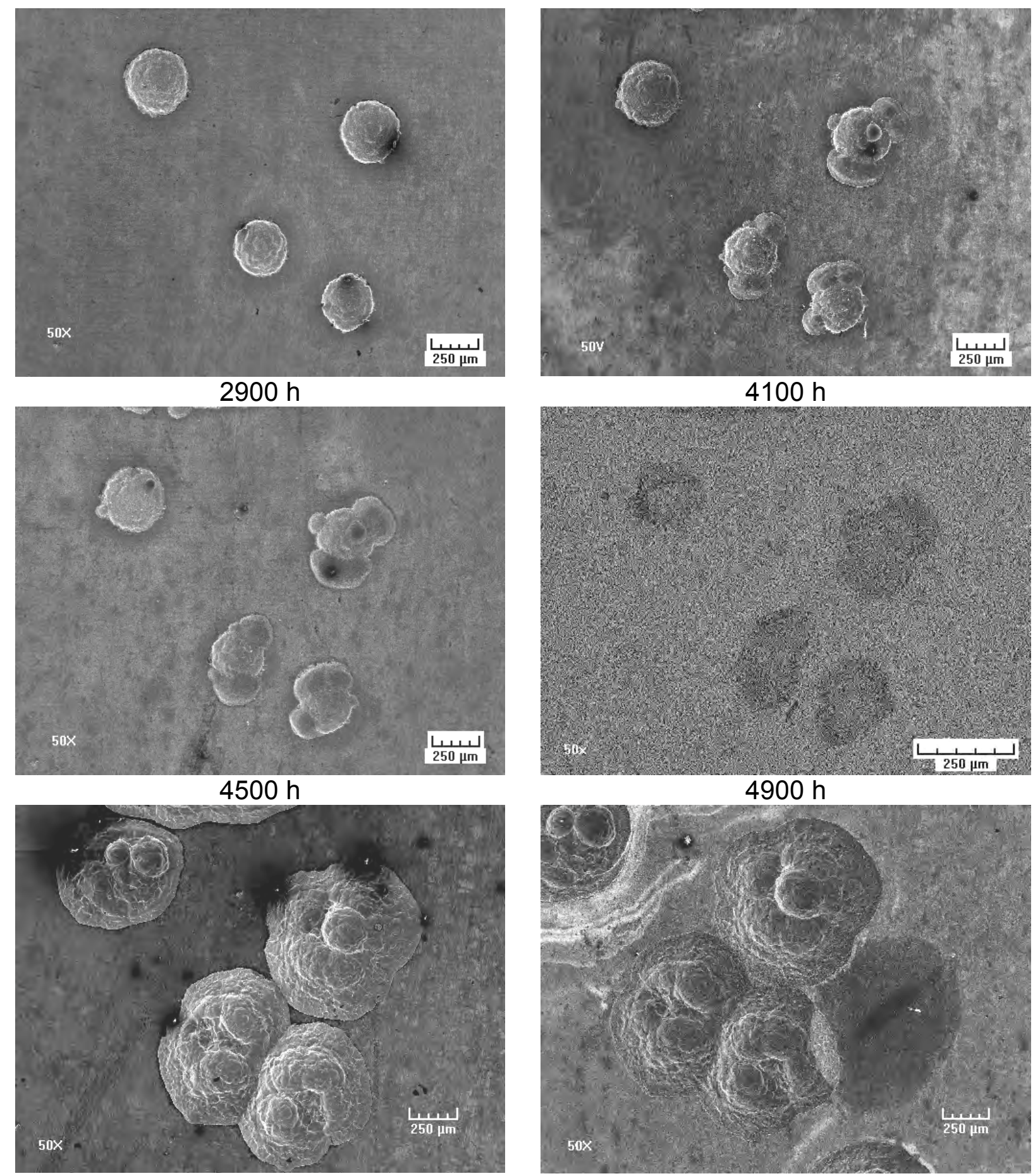

$5300 \mathrm{~h}$

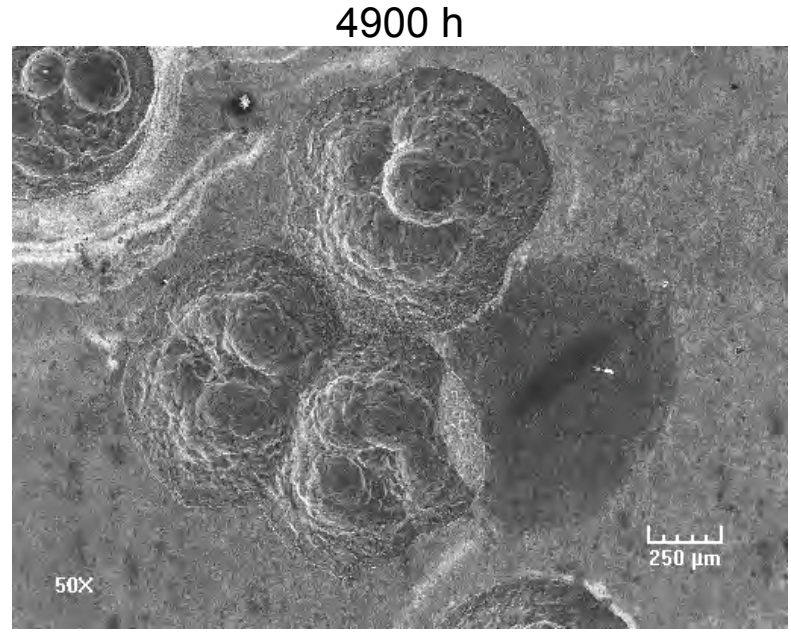

$6900 \mathrm{~h}$

Figure 3.5. Pit morphology as a function of time for Alloy 617 exposed to Gas 10 at $593^{\circ} \mathrm{C}$ and $14.3 \mathrm{~atm}(210 \mathrm{psi})$. 


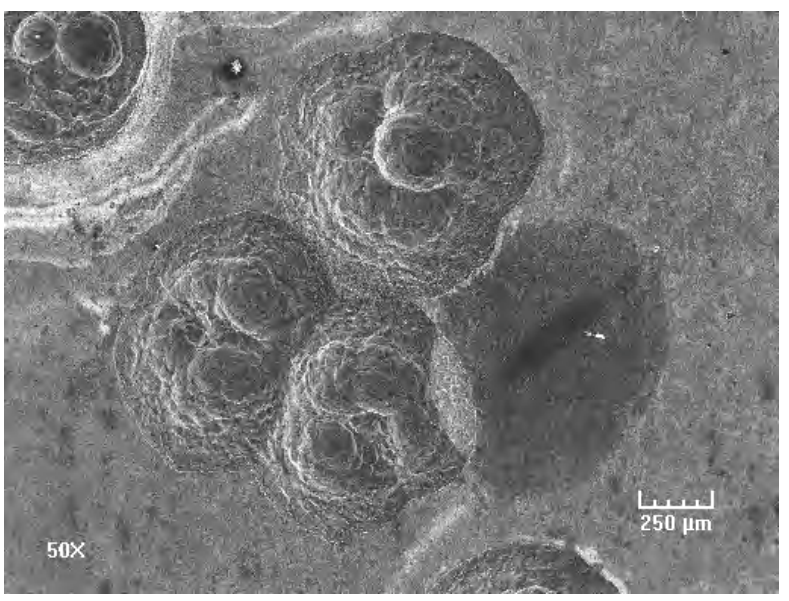

$7300 \mathrm{~h}$

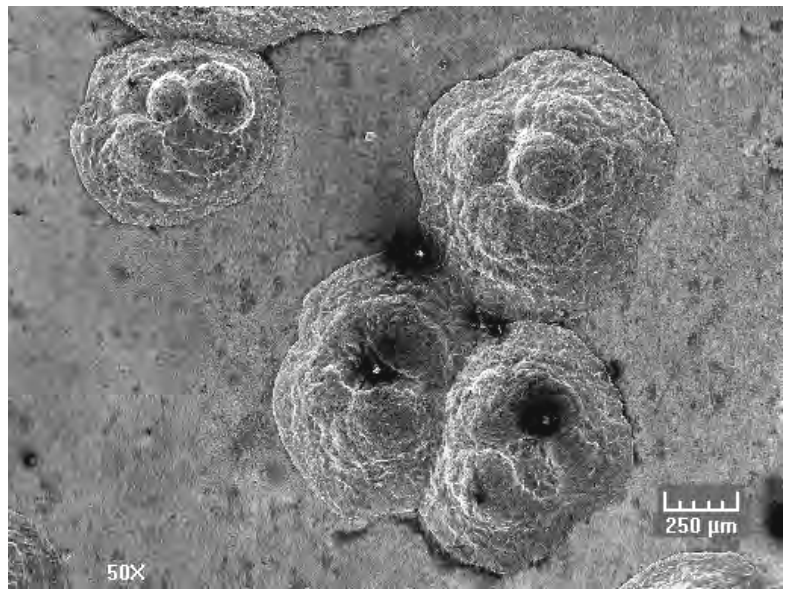

$8100 \mathrm{~h}$

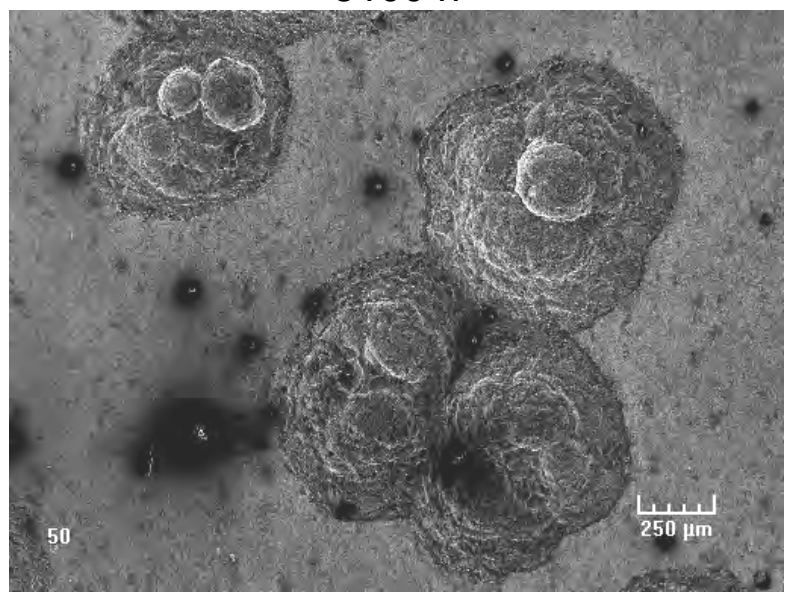

$8900 \mathrm{~h}$

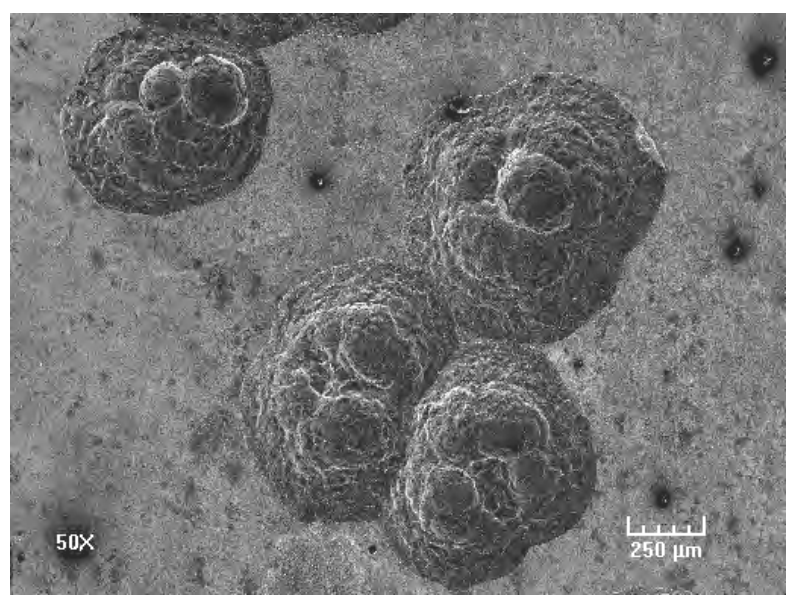

$7700 \mathrm{~h}$

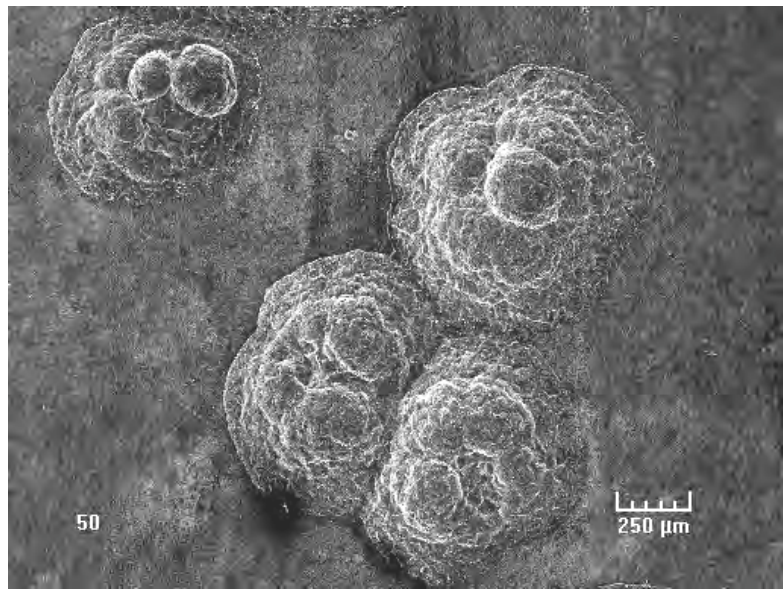

$8500 \mathrm{~h}$

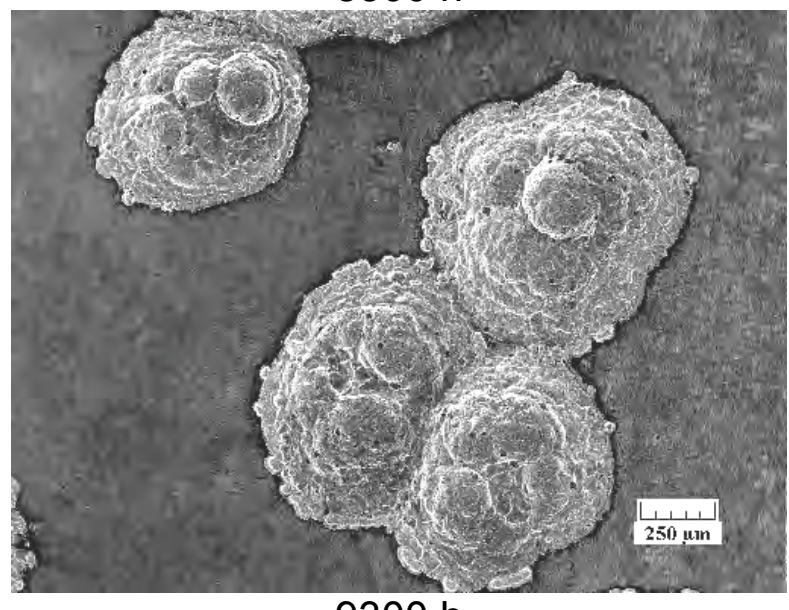

$9300 \mathrm{~h}$

(Figure 3.5 continued.) Pit morphology as a function of time for Alloy 617 exposed to Gas 10 at $593^{\circ} \mathrm{C}$ and 210 psi. 


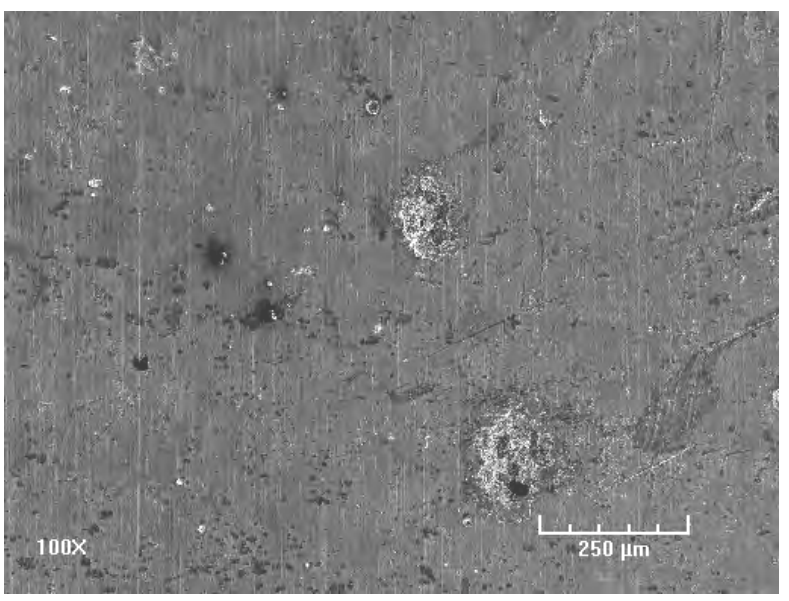

$6900 \mathrm{~h}$

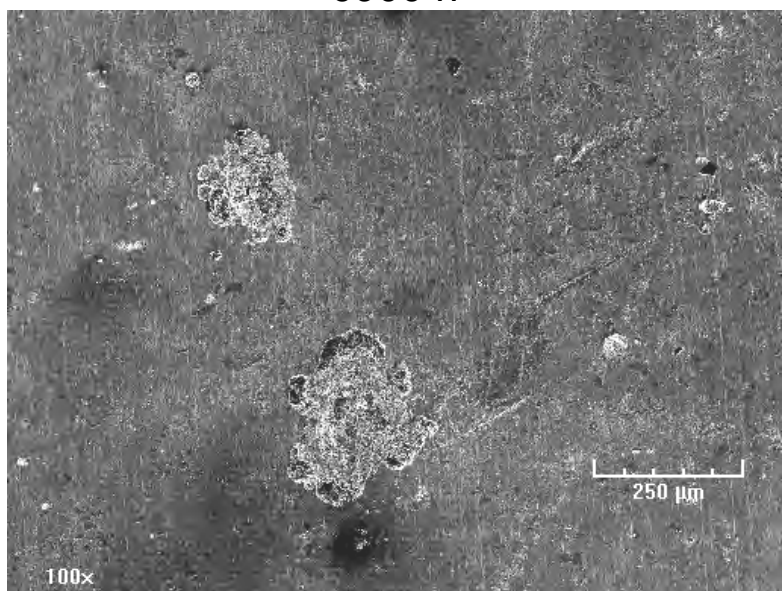

$7700 \mathrm{~h}$

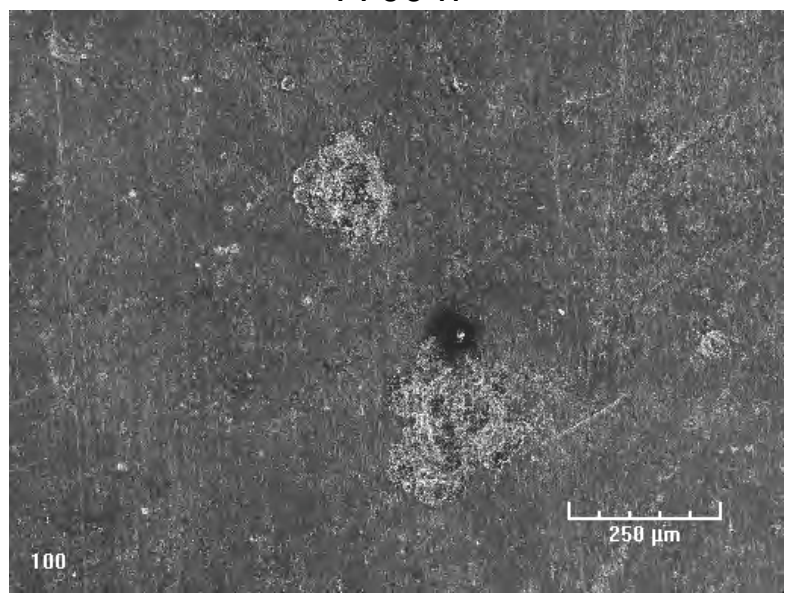

$8900 \mathrm{~h}$

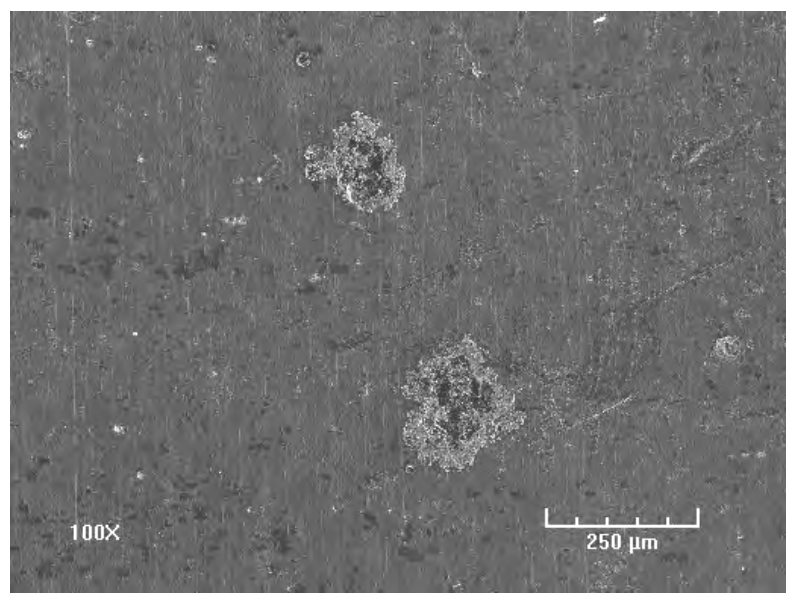

$7300 \mathrm{~h}$

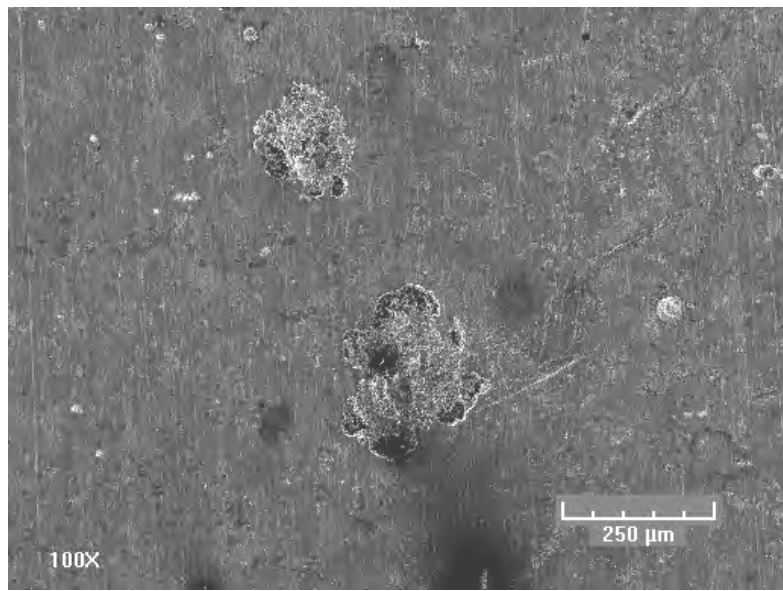

$8100 \mathrm{~h}$

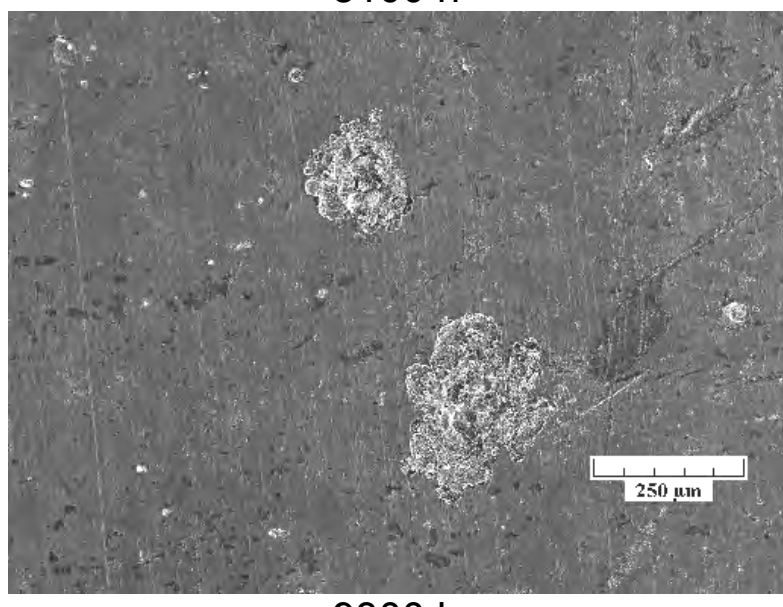

$9300 \mathrm{~h}$

Figure 3.6. Pit morphology as a function of time for Alloy 602CA exposed to Gas 10 at $593^{\circ} \mathrm{C}$ and $14.3 \mathrm{~atm}(210 \mathrm{psi})$. 

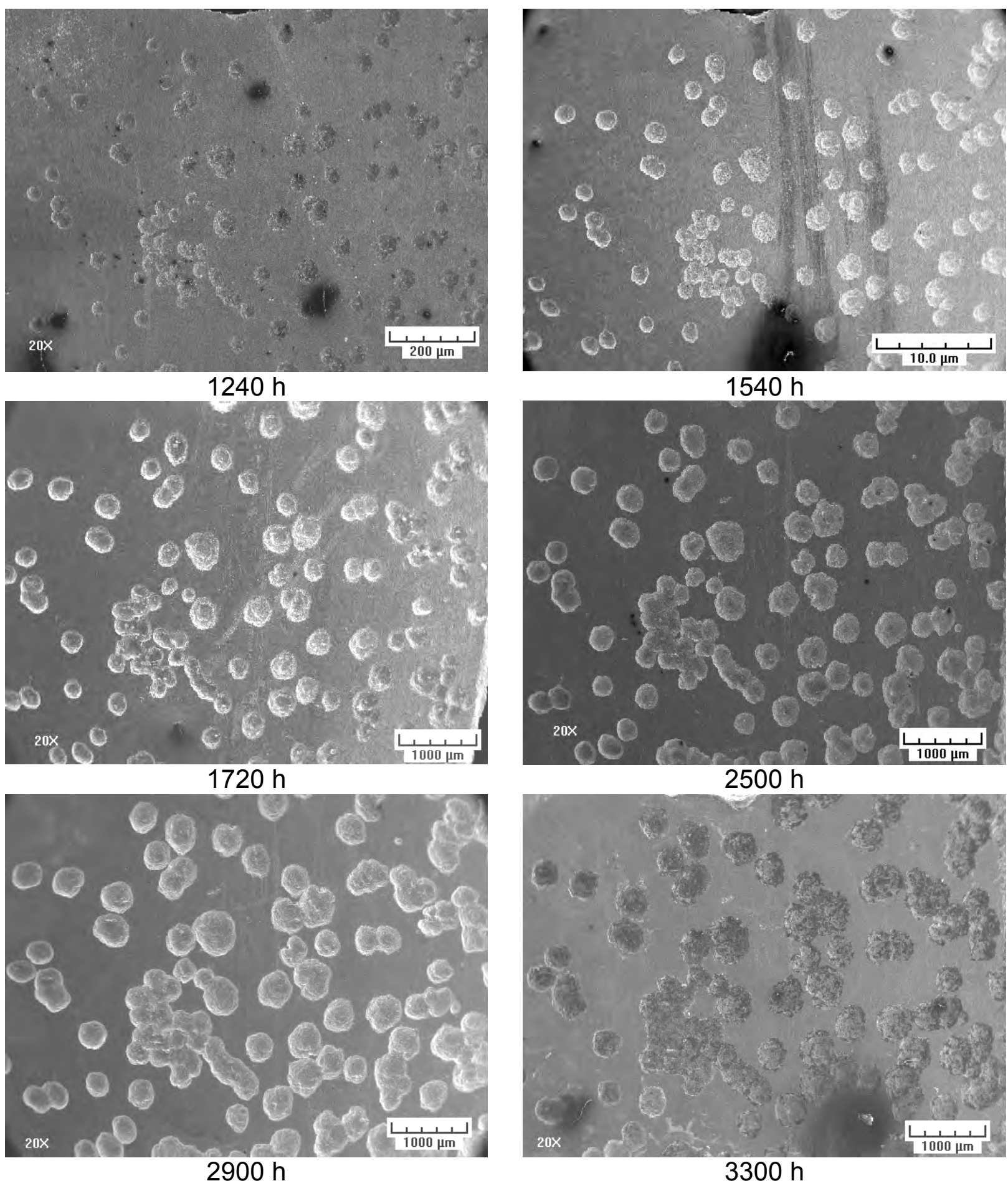

Figure 3.7. Pit morphology as a function of time for Alloy 45TM exposed to Gas 10 at $593^{\circ} \mathrm{C}$ and $14.3 \mathrm{~atm}(210 \mathrm{psi})$. 


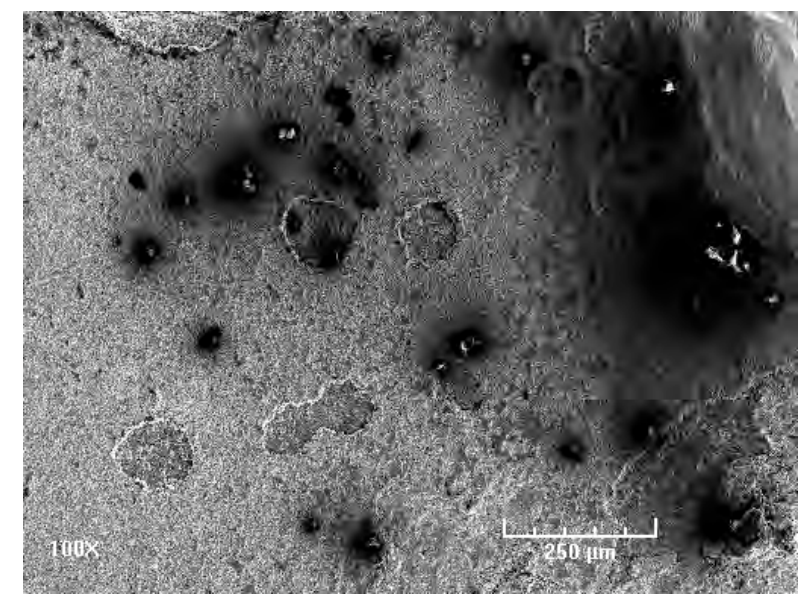

$6900 \mathrm{~h}$

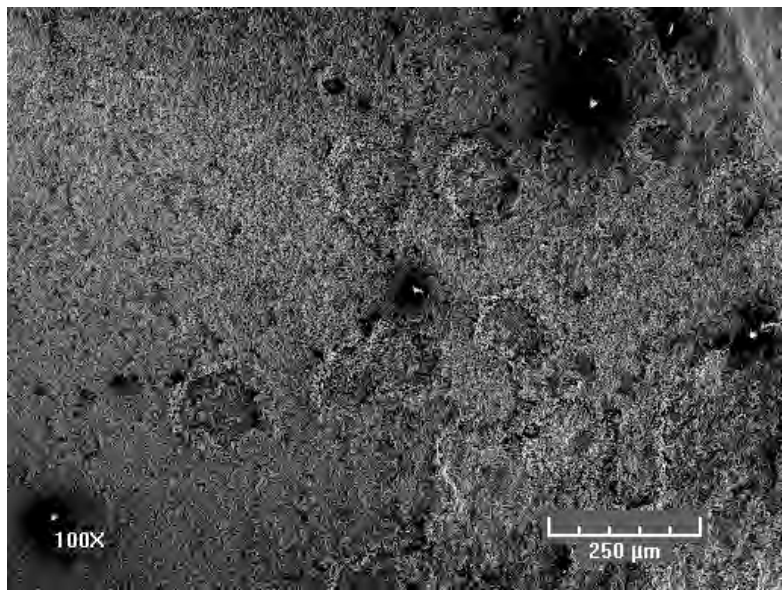

$8100 \mathrm{~h}$

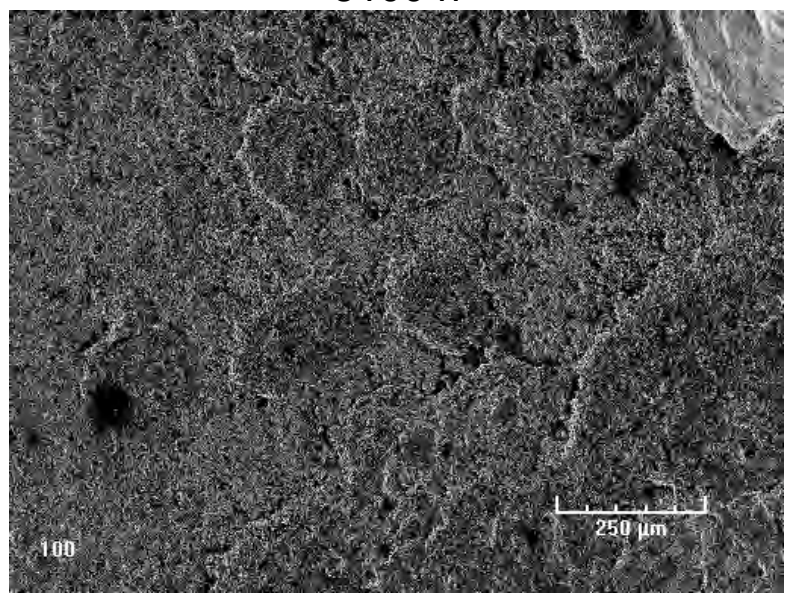

$8900 \mathrm{~h}$

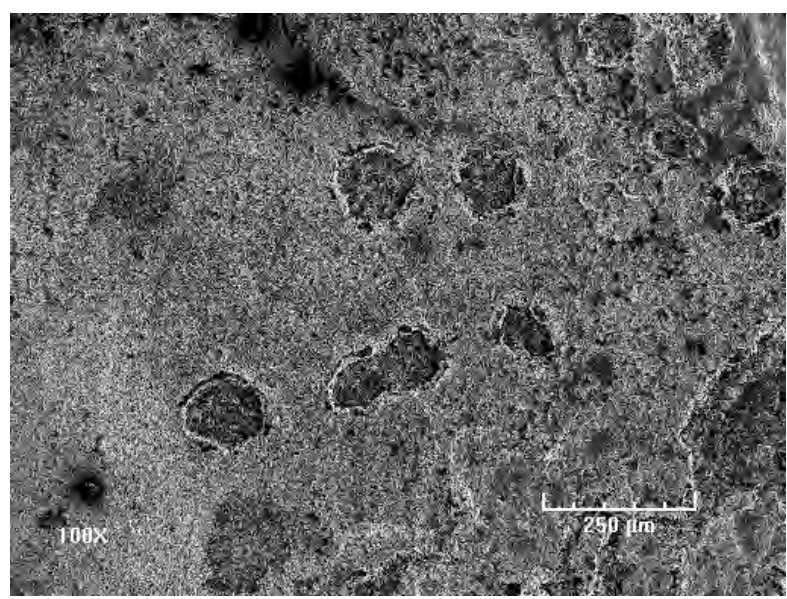

$7300 \mathrm{~h}$

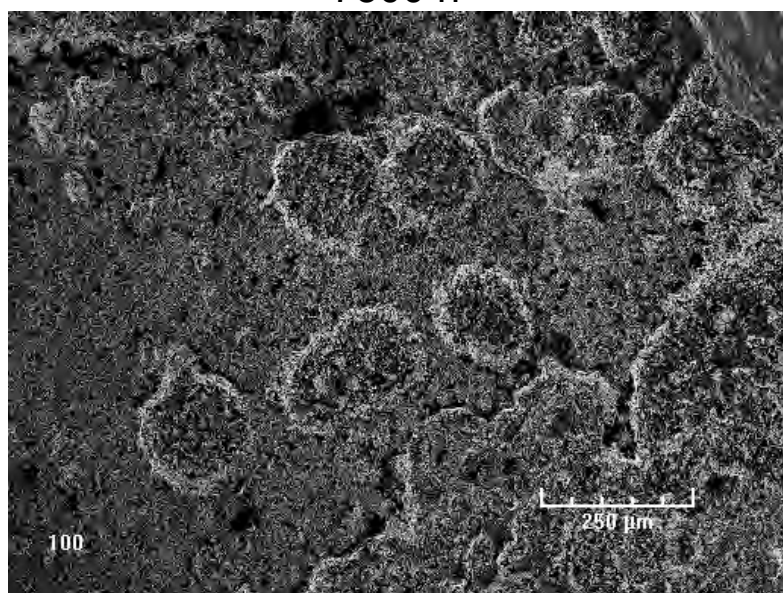

$8500 \mathrm{~h}$

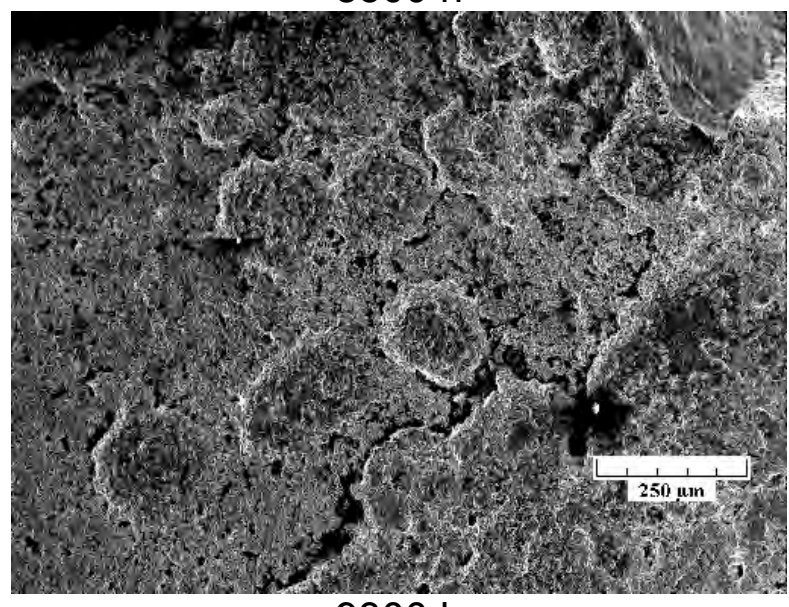

$9300 \mathrm{~h}$

Figure 3.8. Pit morphology as a function of time for Alloy HR160 exposed to Gas 10 at $593^{\circ} \mathrm{C}$ and $14.3 \mathrm{~atm}(210 \mathrm{psi})$. 


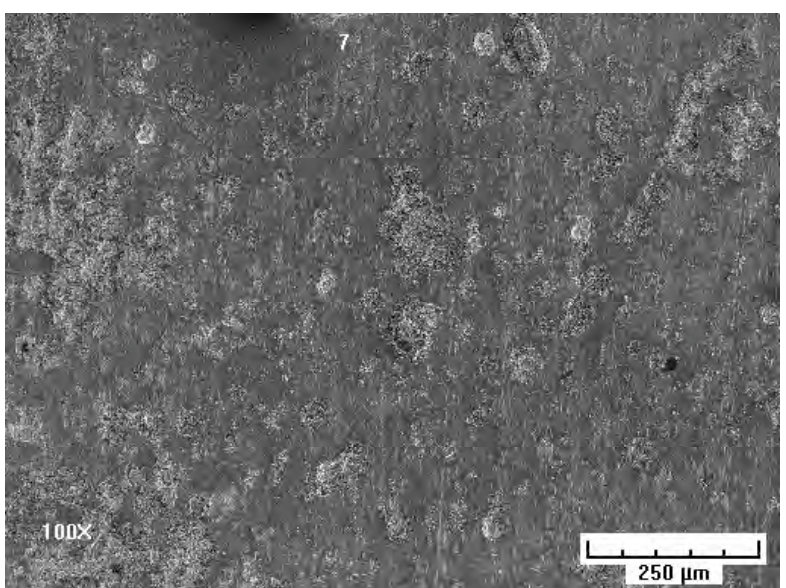

$1240 \mathrm{~h}$

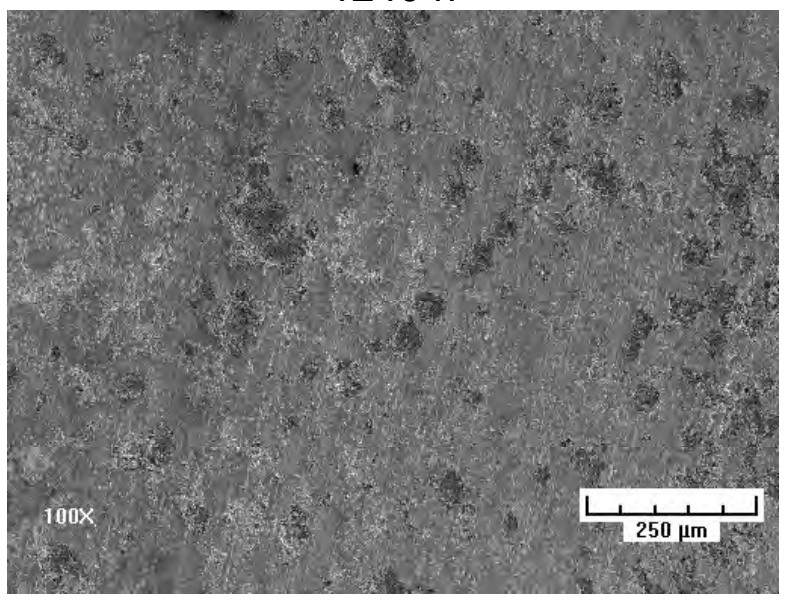

$2500 \mathrm{~h}$

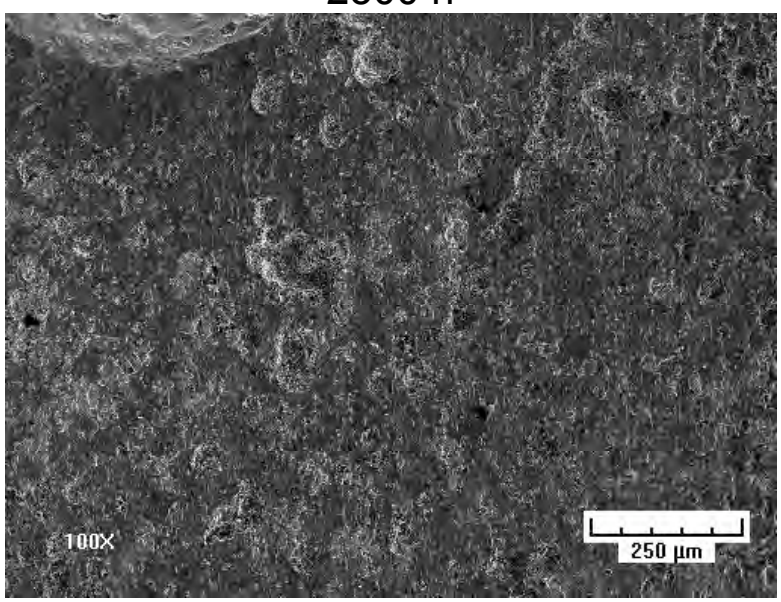

$4100 \mathrm{~h}$

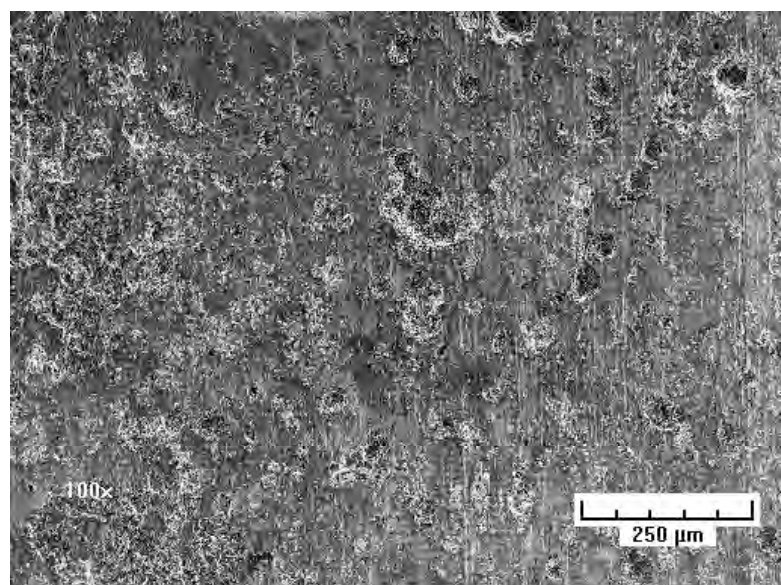

$1720 \mathrm{~h}$

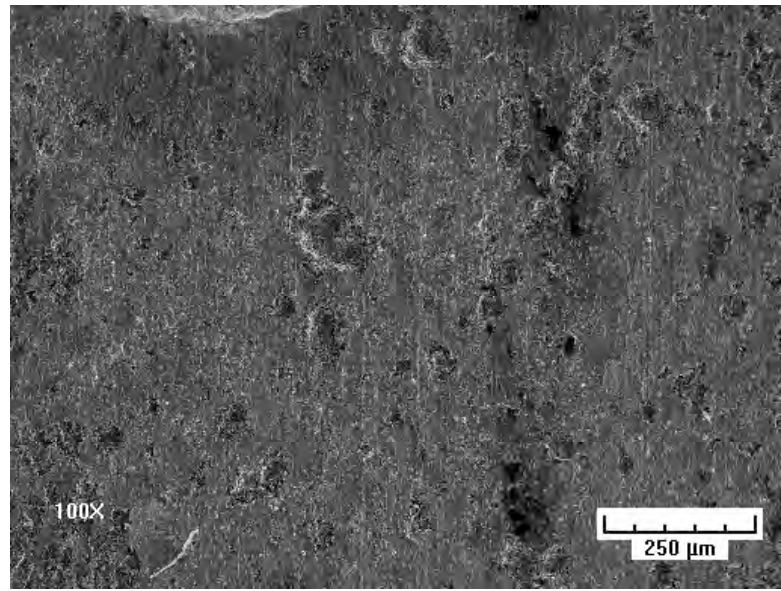

$3300 \mathrm{~h}$

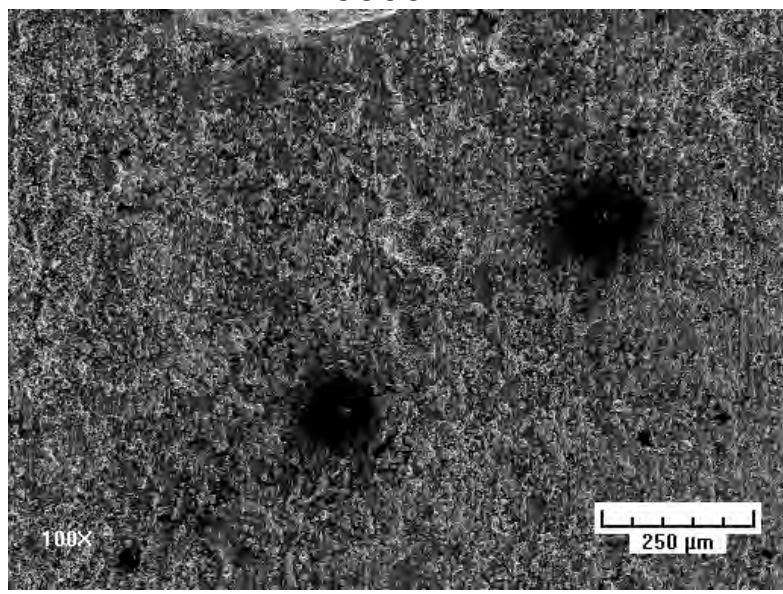

$4900 \mathrm{~h}$

Figure 3.9. Pit morphology as a function of time for Alloy 214 exposed to Gas 10 at $593^{\circ} \mathrm{C}$ and $14.3 \mathrm{~atm}(210 \mathrm{psi})$. 


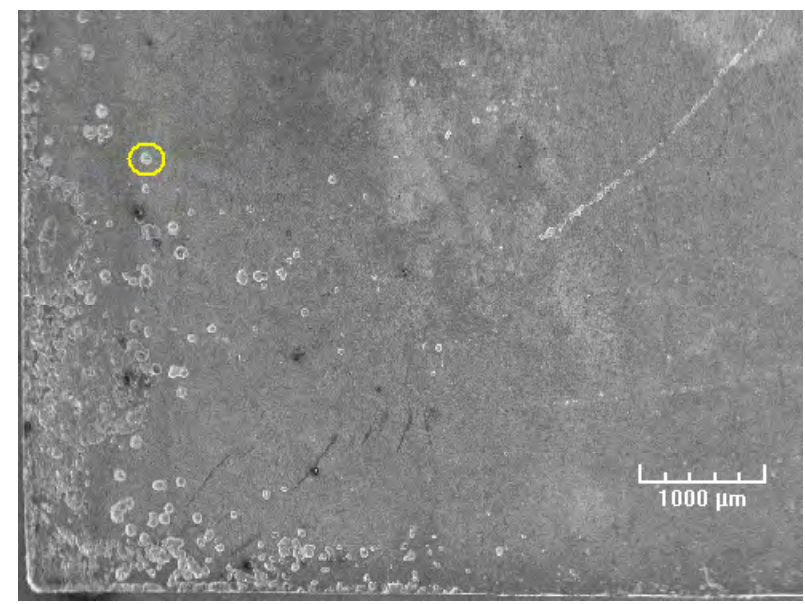

(a)

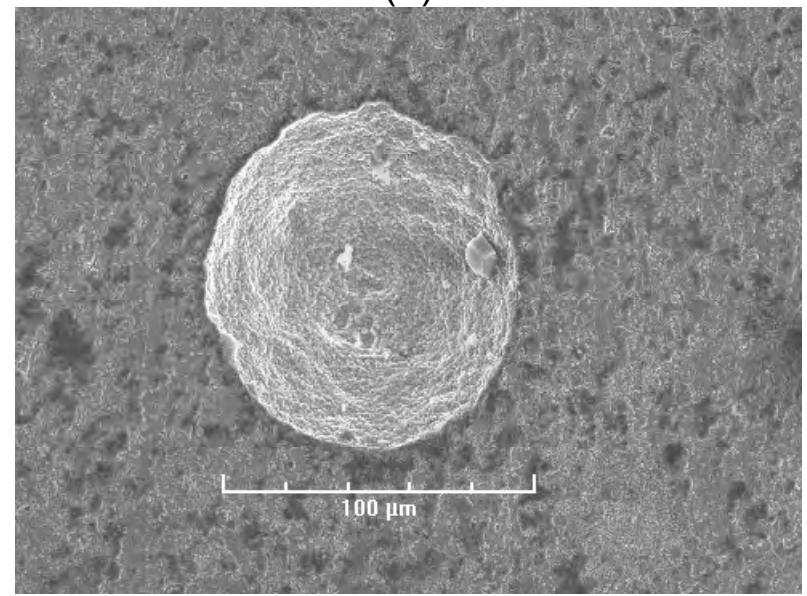

(c)

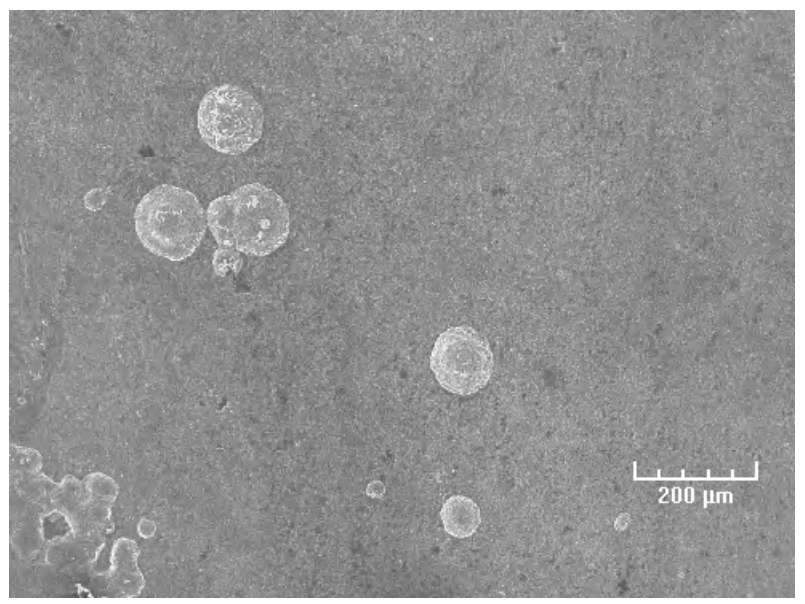

(b)

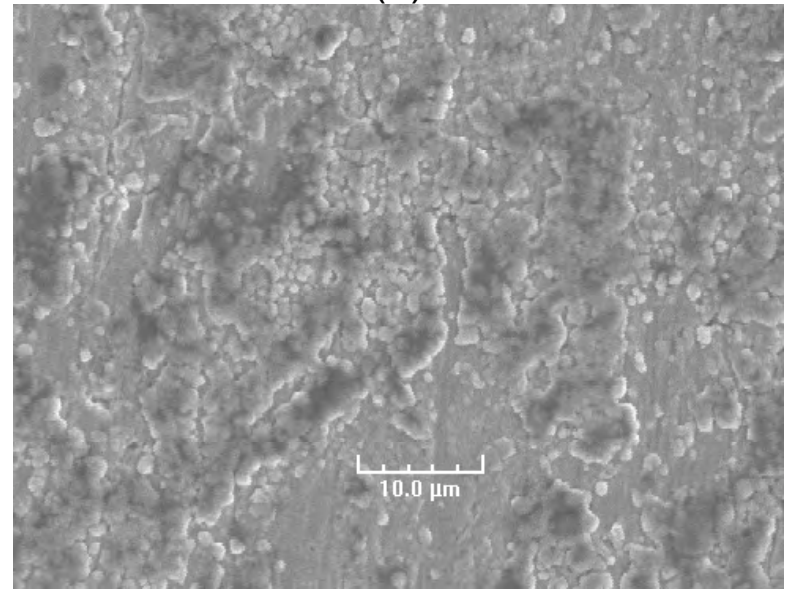

(d)

Figure 3.10. Pit morphology for Alloy 693 after 9300-h exposure to Gas 10 at $593^{\circ} \mathrm{C}$ and $14.3 \mathrm{~atm}(210 \mathrm{psi})$.

\subsection{Pit Diameter and Density in Ni-Base Alloys}

To determine the growth rate for the pits and the pit density (as a function of pit size), a fixed area of surface of each specimen was examined as a function of exposure time. All the specimens were exposed to Gas 10 at $593^{\circ} \mathrm{C}$ and $14.3 \mathrm{~atm}(210 \mathrm{psi})$. The pit diameter and number of pits of different diameter ranges were measured by optical and scanning electron microscopy. Figures 3.11 to 3.17 show the distribution of different size pits for seven alloys. It is evident that the medium-size pits (over the exposure time of $9700 \mathrm{~h}$ in the present test) are most common. Furthermore, the larger pits increase in numbers with exposure time, but the smaller pits decrease. This decrease indicates that the nucleation of new pits is not prevalent under the test conditions used. Also, the increased oxide thickness (with exposure time) seems beneficial in preventing/minimizing carbon transport inwards and Fe transport outwards, thereby reducing the formation of Fe-containing spinel phase. 


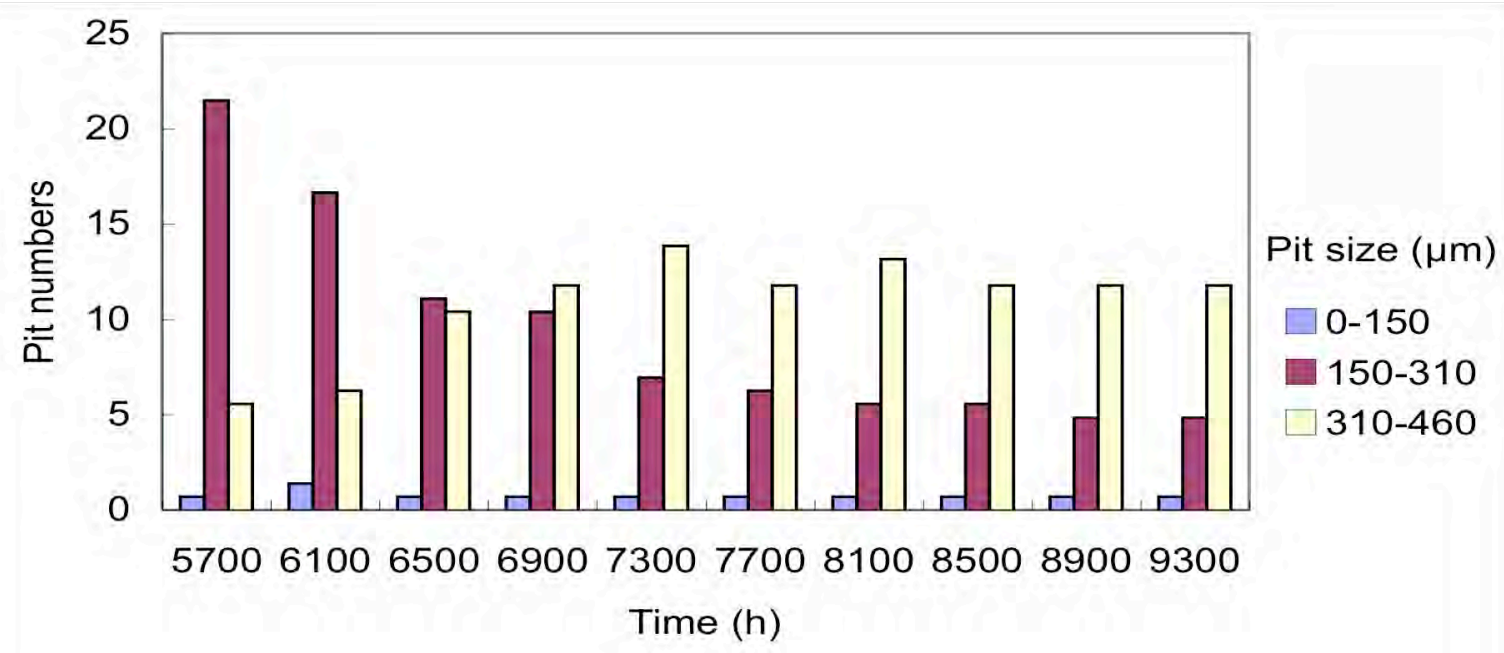

Figure 3.11. Pit diameter and density for Alloy 601 as a function of exposure time in Gas 10 at $593^{\circ} \mathrm{C}$ and $14.3 \mathrm{~atm}(210 \mathrm{psi})$.

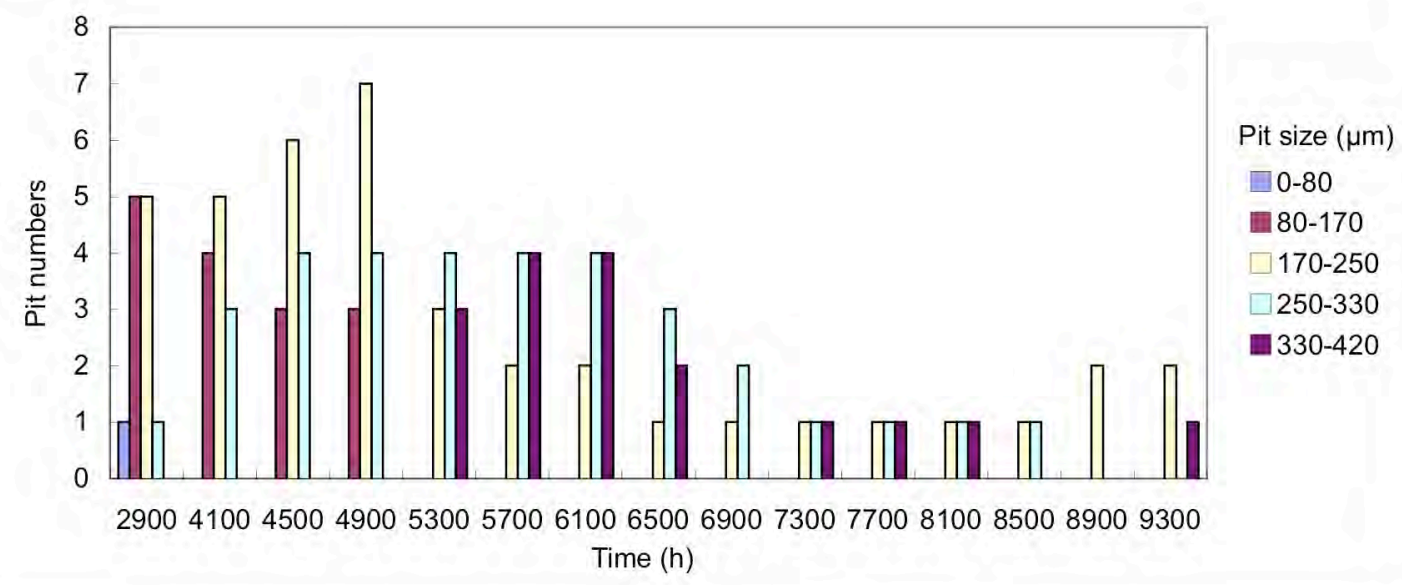

Figure 3.12. Pit diameter and density for Alloy 690 as a function of exposure time in Gas 10 at $593^{\circ} \mathrm{C}$ and $14.3 \mathrm{~atm}(210 \mathrm{psi})$.

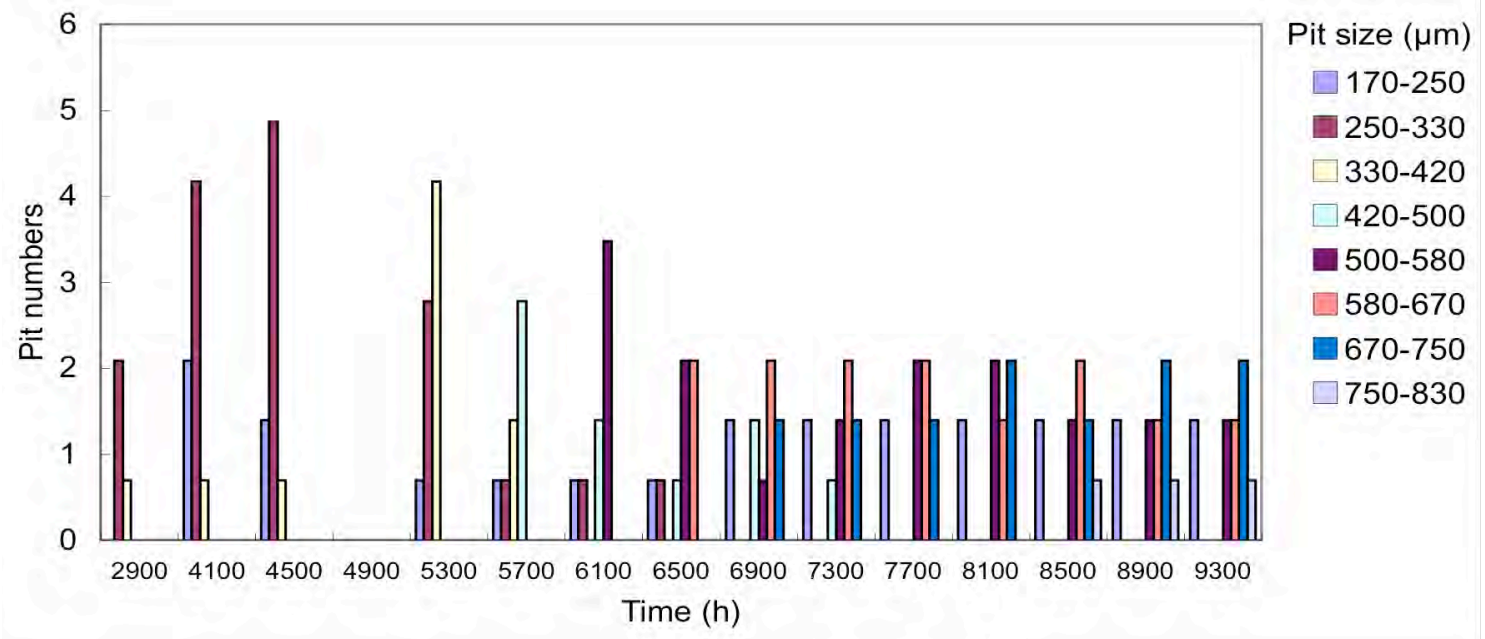

Figure 3.13. Pit diameter and density for Alloy 617 as a function of exposure time in Gas 10 at $593^{\circ} \mathrm{C}$ and $14.3 \mathrm{~atm}(210 \mathrm{psi})$. 


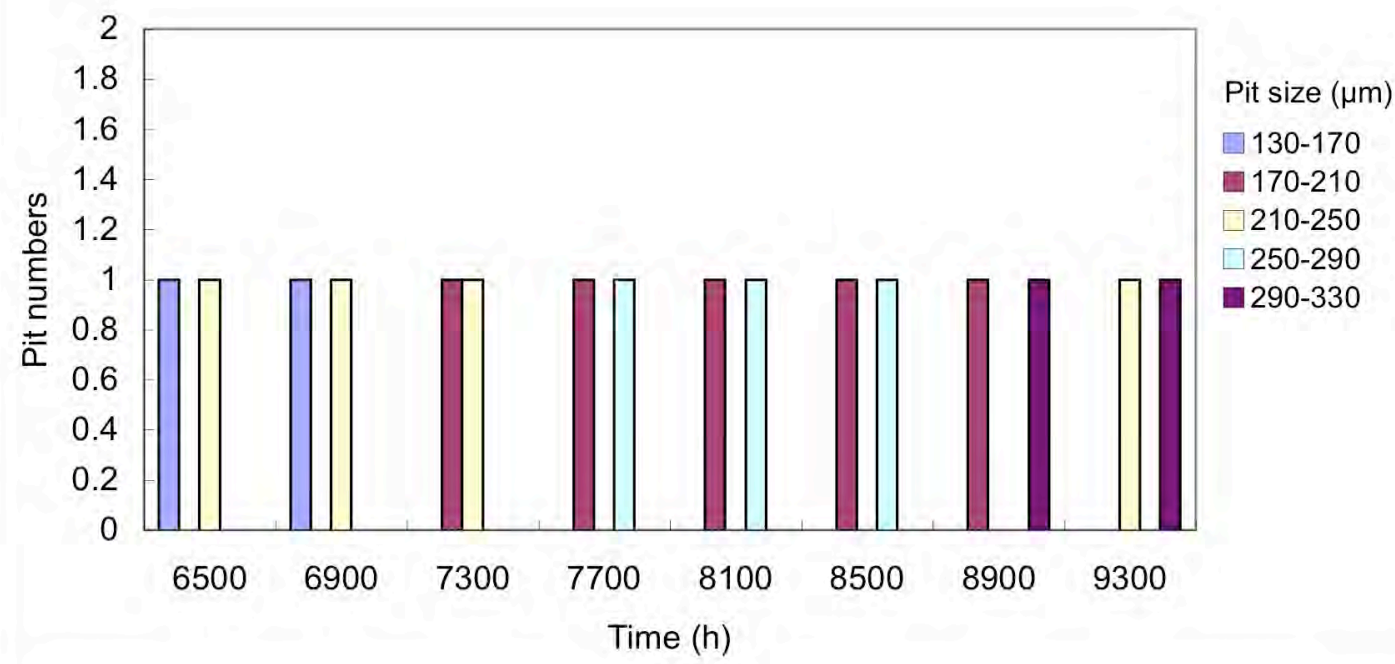

Figure 3.14. Pit diameter and density for Alloy $602 \mathrm{CA}$ as a function of exposure time in Gas 10 at $593^{\circ} \mathrm{C}$ and $14.3 \mathrm{~atm}(210 \mathrm{psi})$.

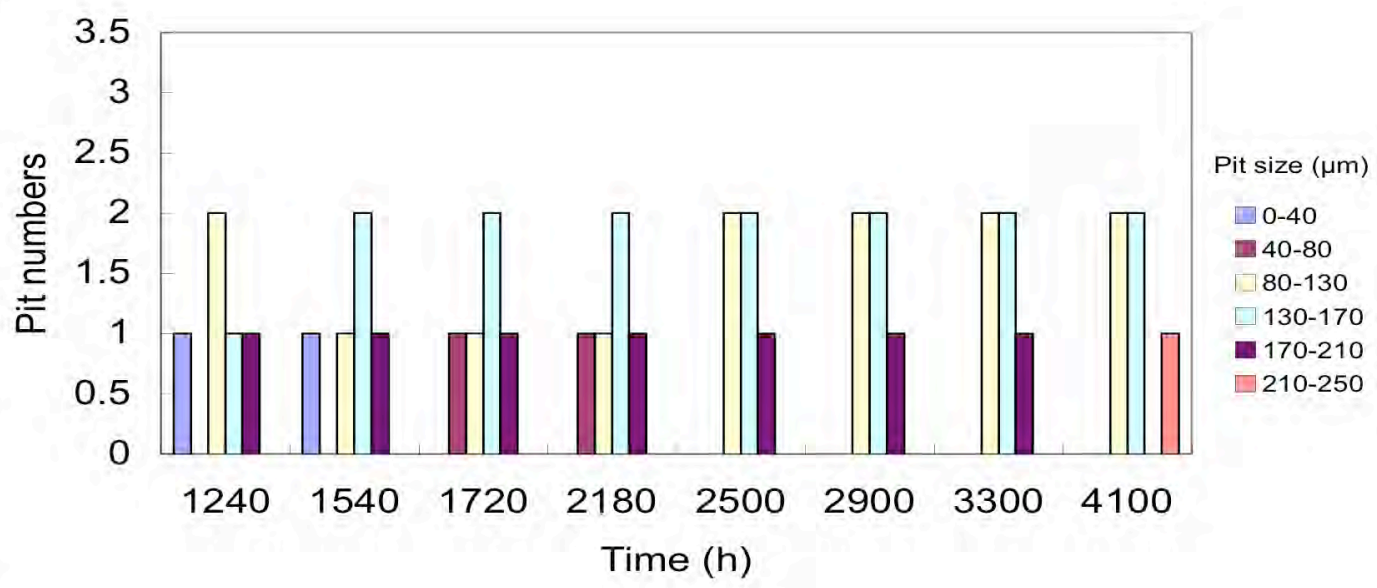

Figure 3.15. Pit diameter and density for Alloy 214 as a function of exposure time in Gas 10 at $593^{\circ} \mathrm{C}$ and $14.3 \mathrm{~atm}(210 \mathrm{psi})$.

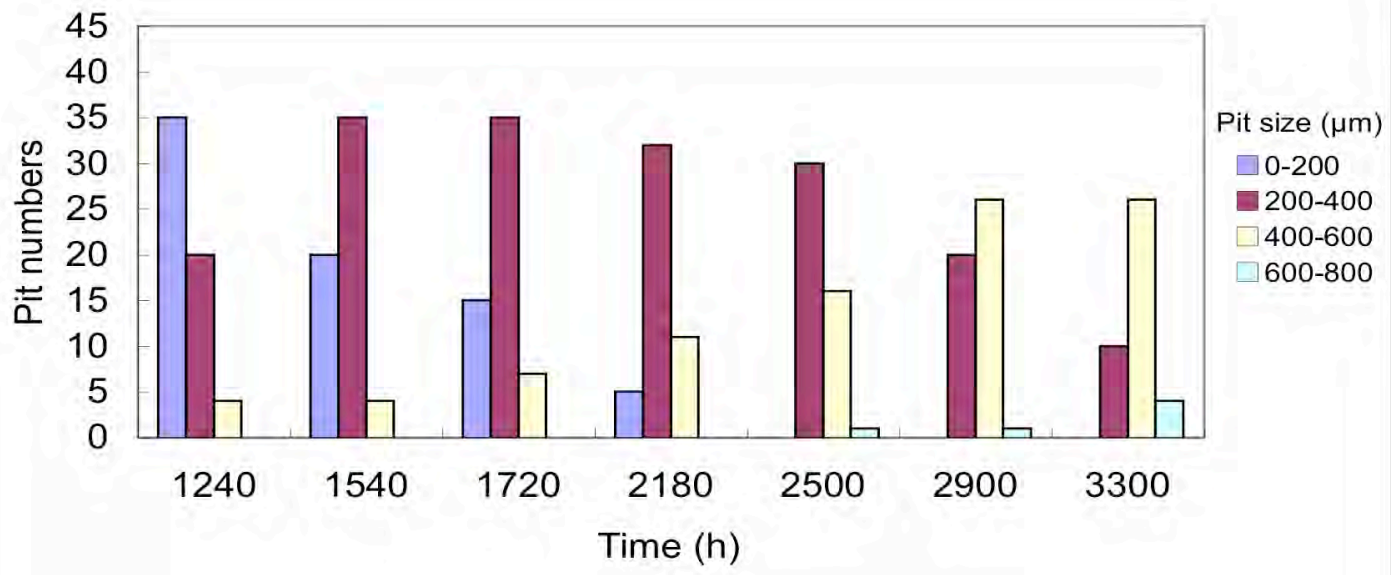

Figure 3.16. Pit diameter and density for Alloy 45TM as a function of exposure time in Gas 10 at $593^{\circ} \mathrm{C}$ and $14.3 \mathrm{~atm}(210 \mathrm{psi})$. 


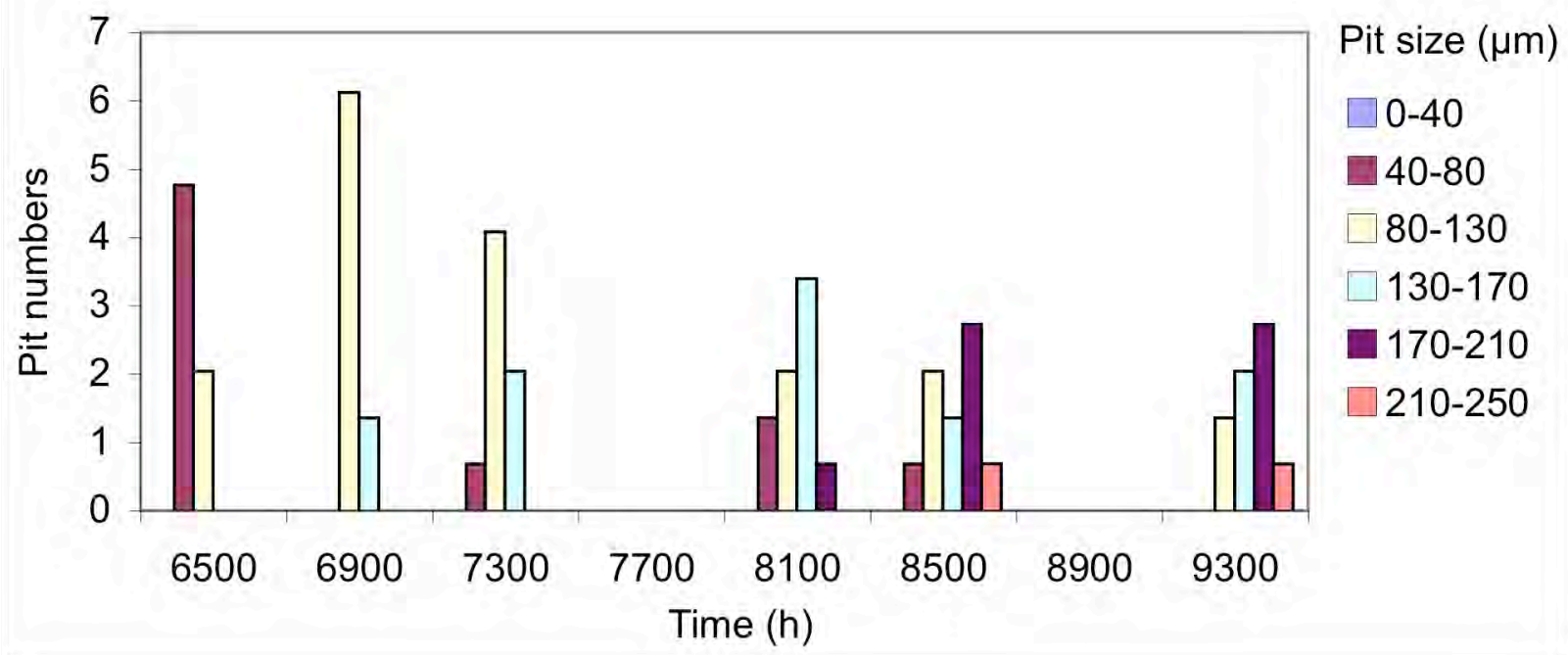

Figure 3.17. Pit diameter and density for Alloy HR160 as a function of exposure time in Gas 10 at $593^{\circ} \mathrm{C}$ and $14.3 \mathrm{~atm}(210 \mathrm{psi})$.

At the end of the $9700 \mathrm{~h}$ exposure, we procured and installed a surface profilometer that could provide a 3-dimensional view of the pits in various specimens and measure the depth of pits at various locations on the specimens. Most of the alloys from Run 59HP exhibited discrete pitting except Alloy 214, which showed numerous pits approaching uniform corrosion (indicated by a rough surface). Both pitting and uniform corrosion were observed on Alloy HR160. Figure 3.18 shows a 3-D map of various specimens after 9700-h exposure (in Gas 10) in Run 59HP.

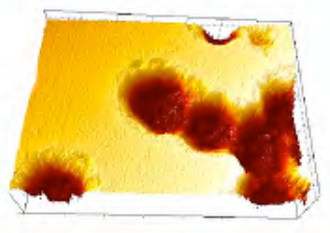

601

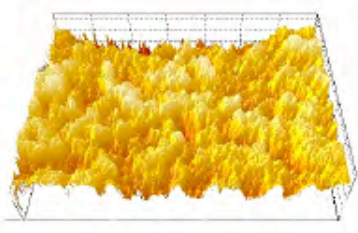

214

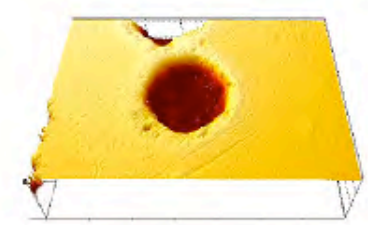

690

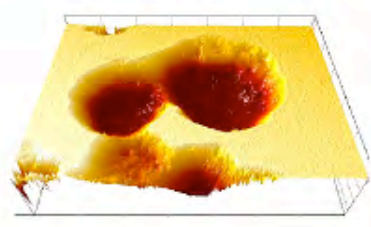

45TM

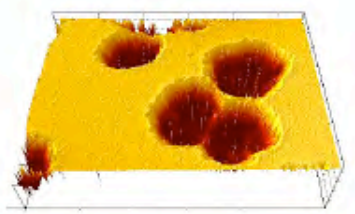

617

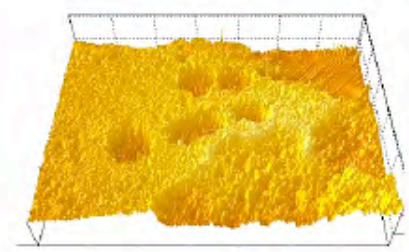

HR160

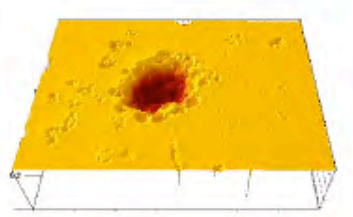

602CA

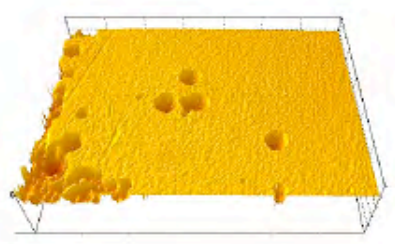

693

Figure 3.18. 3-D profile map of Ni-base alloys after 9700-h exposure in Gas 10 at $593^{\circ} \mathrm{C}$ and $14.3 \mathrm{~atm}(210 \mathrm{psi})$. 


\subsection{Correlation between Pit Growth Rate and Weight Loss}

We have measured the dimension of a single pit (for each alloy) as a function of exposure time and correlated the pit size data with measured weight change for the corresponding alloys. Table 3.2 lists the maximum pit size and weight loss for various alloys that were exposed in Run 59HP. Figure 3.19 shows the measured pit size and weight change for all the alloys used in the present study. The plots, for most of the alloys, indicate a good correlation between the growth in size of an arbitrarily selected pit on the surface of the alloy with the measured weight change. The data also show an "S" shaped behavior for both the pit growth and weight change, indicating an incubation time for the pit to develop and grow. Furthermore, the absolute increase in pit size as a function of exposure time is different for different alloys. For example, the pit size increases from 200 to $450 \mu \mathrm{m}$ as the exposure time increases from 4,000 to $9,300 \mathrm{~h}$ for Alloy 601. The corresponding increases for Alloy 690 are 70 to $200 \mu \mathrm{m}$ for a time increase from 2900 to $9300 \mathrm{~h}$. Similar information for other alloys can be obtained from the curves shown in Fig. 3.19.

The behavior of Alloy 214 is somewhat different from that of others, because it shows a poor correlation between the size increase of a single pit with its weight change. The reason for this poor correlation is that this alloy contains a low (15.9 wt.\%) concentration of $\mathrm{Cr}$ and a high (3.7 wt.\%) concentration of $\mathrm{Al}$ and develops a large number of small pits. The nucleation and growth of a large number of small pits with low growth rates are reflected in the weight loss but not in the growth rate of an individual pit. The alloy exhibited uniform coverage after $\approx 3000 \mathrm{~h}$ of exposure, and we could not measure the size of an individual pit. Alloy 45TM exhibited an extremely rapid growth rate for the pit ( 380 to $600 \mu \mathrm{m}$ during 1400 to $3400 \mathrm{~h}$ ), and its exposure was terminated after $3800 \mathrm{~h}$. The cause for this rapid increase in pit growth can be attributed to the higher (26.7 wt.\%) Fe content of the alloy. 

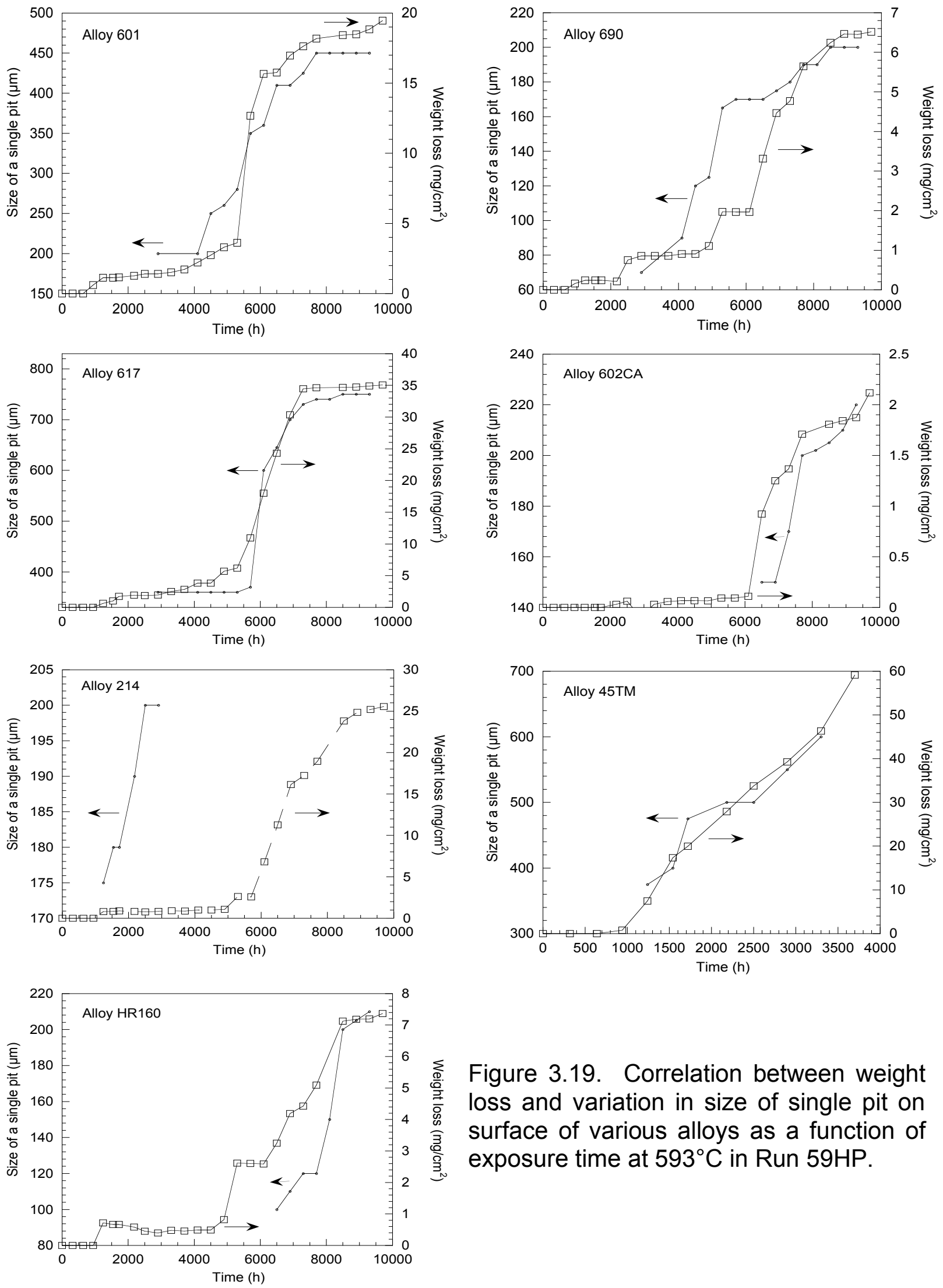

Figure 3.19. Correlation between weight loss and variation in size of single pit on surface of various alloys as a function of exposure time at $593^{\circ} \mathrm{C}$ in Run $59 \mathrm{HP}$. 


\subsection{Effect of System Pressure on Metal Dusting Corrosion of Ni-base Alloys}

To evaluate the role of system pressure in the initiation and propagation of metal dusting pits on various Ni-base alloys, we conducted experiments at atmospheric pressure with a gas composition adjusted to yield the same carbon activity of 31 as the high-pressure Run 59HP [14.3 atm (210 psi)]. Specimens of various alloys were exposed to Gas $11\left(79.5 \% \mathrm{H}_{2}, 18.2 \% \mathrm{CO}\right.$, and $\left.2.3 \% \mathrm{H}_{2} \mathrm{O}\right)$ at $1 \mathrm{~atm}$ for $7589 \mathrm{~h}$. The specimens from the run at atmospheric pressure were also retrieved periodically, cleaned, and weighed to determine the weight loss as a function of exposure time.

Figure 3.20 shows weight loss data obtained for various alloys exposed at system pressures of 1 and $14.3 \mathrm{~atm}$, but at the same carbon activity of $\approx 31$ and the same temperature of $593^{\circ} \mathrm{C}$. The results indicate that all the tested alloys showed a sharp decrease in initiation time for metal dusting degradation at higher system pressure. Only Alloy 601 showed initiation of attack at both system pressures. All the other alloys exhibited attack at high pressure, but not at $1 \mathrm{~atm}$, even after $7589 \mathrm{~h}$. The data for Alloy 601 also indicate that once the attack began, the weight loss rate (slope of the weight loss versus time) is almost similar for the two pressures. Even though substantiated only by Alloy 601, the data clearly indicate that the increase in system pressure decreases the metal dusting initiation and may not alter the weight loss or pit propagation rate. The weight loss rate for Alloy 693 was negligibly small, even at high system pressure, but this alloy showed pitting after $9700 \mathrm{~h}$ as was discussed earlier (see Fig. 3.10).

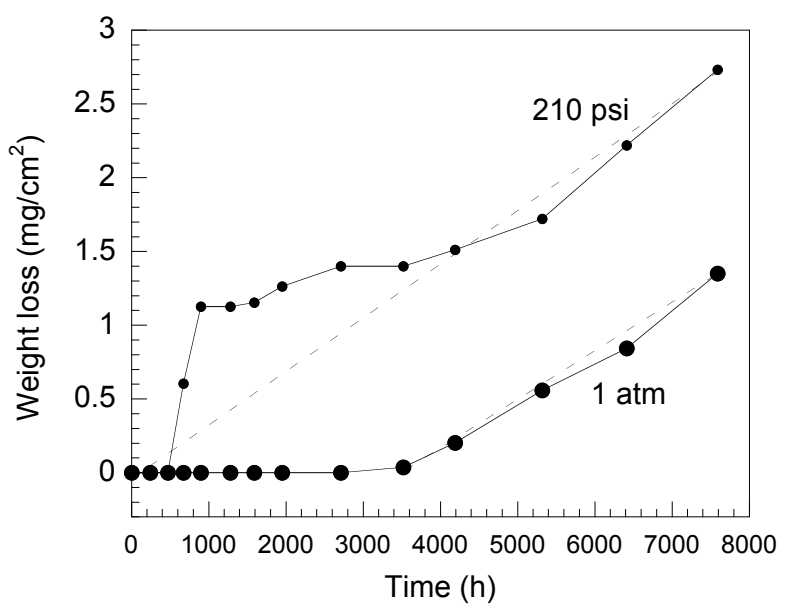

Alloy 601

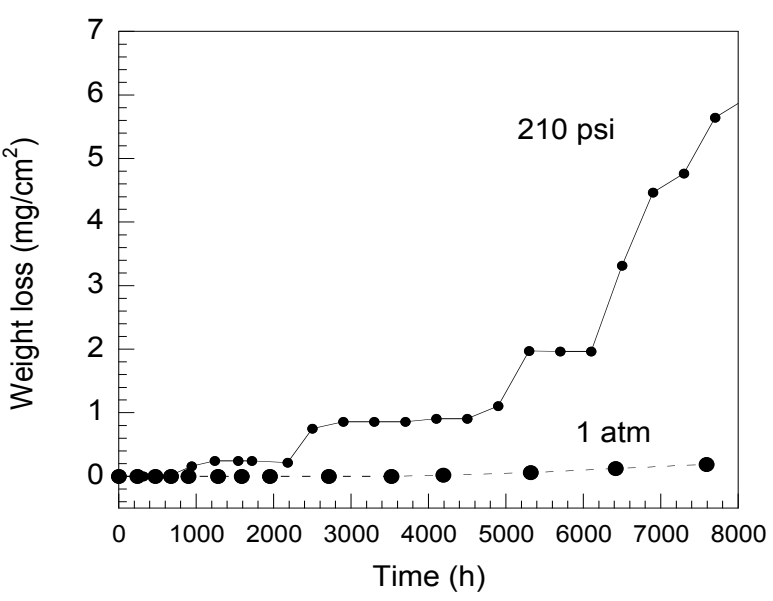

Alloy 690 

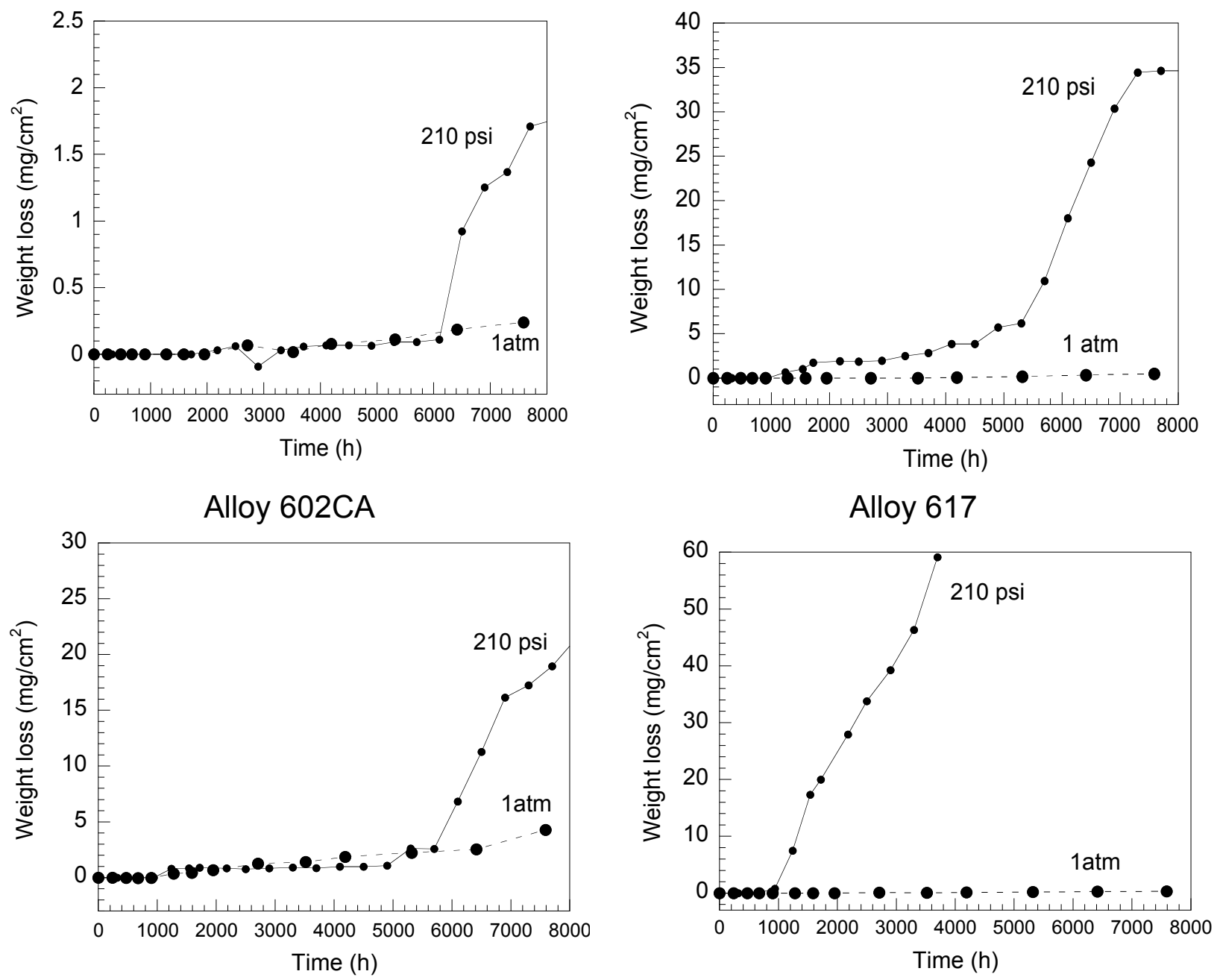

Alloy 214

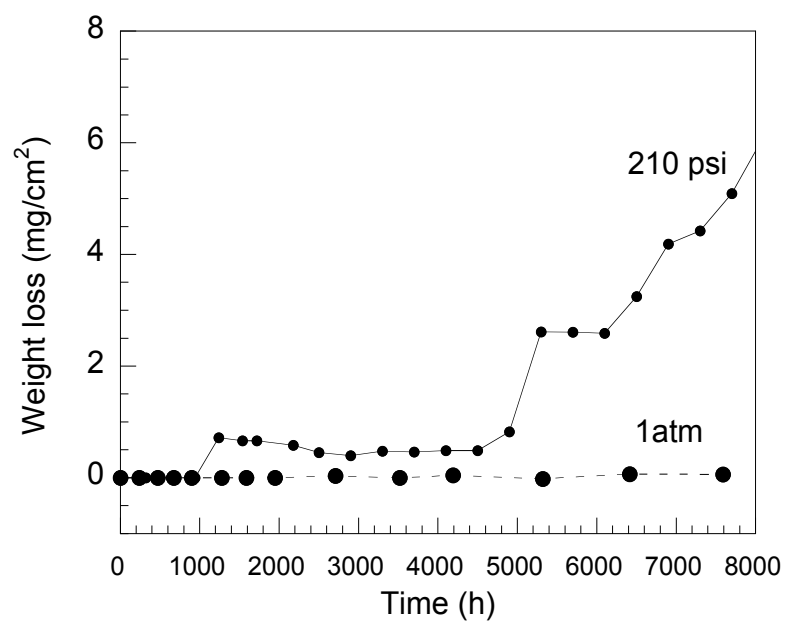

Alloy HR160

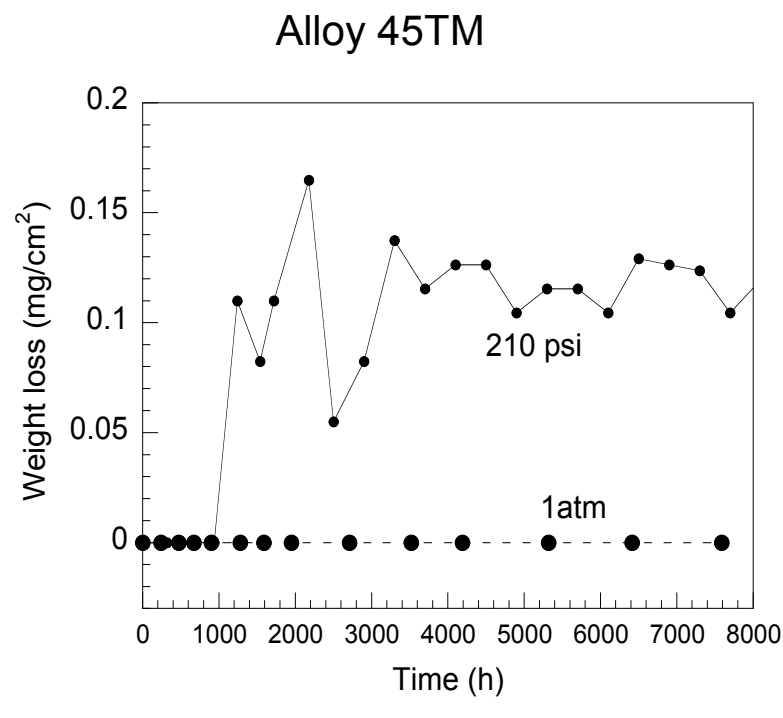

Alloy 693

Figure 3.20. Weight loss for Ni-base alloys at system pressures of 1 and $14.3 \mathrm{~atm}$, a carbon activity of $\approx 31$, and temperature of $593^{\circ} \mathrm{C}$. 


\subsection{Pre-pitting Experiment}

Alloys are generally protected by thin oxide scales, which form when the alloys are exposed to metal dusting environments. As defects develop in the oxide scale, locally, pits start to form due to carbon ingress, and the pits continue to grow at several isolated locations on the oxide surface. The metal dusting process involves two steps: onset of initiation and propagation, the latter being more important since the metallic components in service are expected to last years and the rate of attack plays a large role in establishing the component service life. However, even the not-so-resistant $\mathrm{Ni}$ base alloy can have an incubation time of the order of a few thousand hours; therefore, it is desirable to expedite the initiation step for the Ni-base alloys and to conduct propagation tests in the laboratory over long time periods in environments that simulate process conditions.

For this reason, we initiated a program to develop pre-pitting approaches. In several instances, the pits seem to develop along the edges of specimens and eventually grow over the surface. Figure 3.21 shows pits that developed in Alloy 800 and Type 321 stainless steel upon exposure to the metal dusting environment. Most pits appeared at the edge of Alloy 321, and the pits of Alloy 800 coalesced to larger areas at the edge. While carbon diffusion is retarded by the oxide scale on the flat surface, more defects are expected at the sharp edge, as shown in Fig. 3.22.

Since the Fe-base alloys, generally, exhibit shorter initiation time than the $\mathrm{Ni}$ base alloys, we used Alloy 800 and Fe-9Cr-1Mo steel as surrogates to evaluate our experimental approach for pre-pitting. At least two methods are able to break the oxide scale without a long incubation time and to initiate pitting. First is a mechanical, and the second is chemical. We focus on the mechanical method in this report. If this method is successful, we can apply it to Ni-base alloys that have a long incubation time.

Surfaces of Alloy 800 and $9 \mathrm{Cr}-1 \mathrm{Mo}$ steel were scratched by an engraver with a carbide-tipped point. Figure 3.23 shows the sample before exposure in a metal dusting experiment. Both alloys were exposed to a flowing carburizing atmosphere consisting of $72.2 \% \mathrm{H}_{2}-8.3 \% \mathrm{CO}_{2}-17.6 \% \mathrm{CO}-1.96 \% \mathrm{H}_{2} \mathrm{O}$ at $593^{\circ} \mathrm{C}$. After each exposure period, the specimens were examined with a scanning electron microscope. Any adhering coke was removed with an ultrasonic bath and acetone

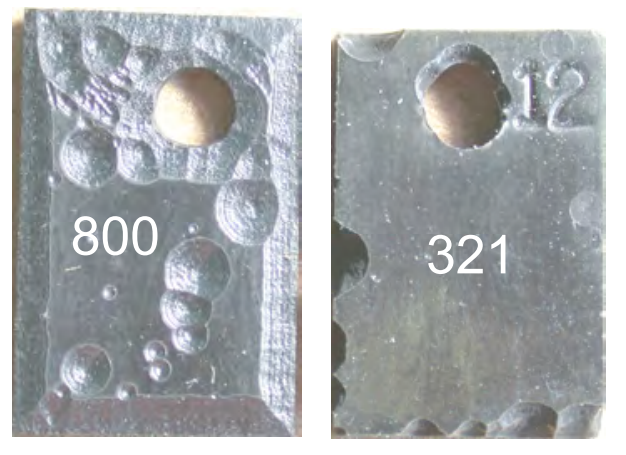

Figure 3.21. Metal dusting pits on the edges of Alloy 800 and Type 321 stainless steel. 


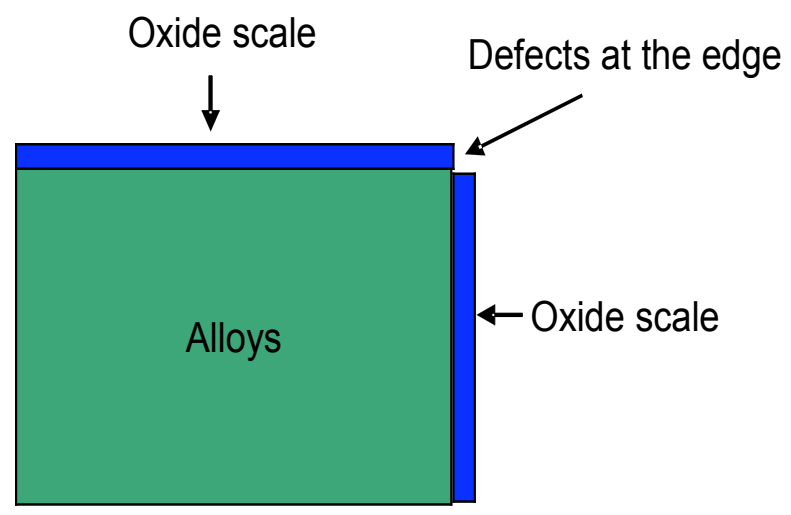

Figure 3.22. Schematic of scale cracking at the corner of the alloy.

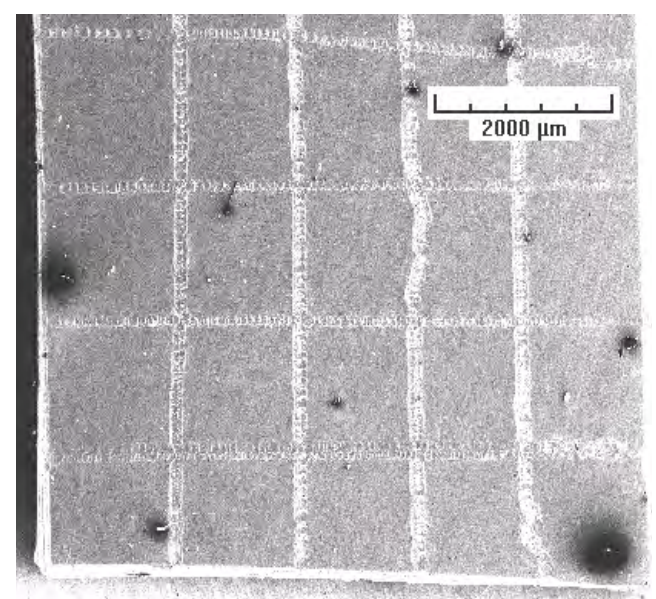

Figure 3.23. Alloy 800 scratched by an engraver with carbide-tipped point.
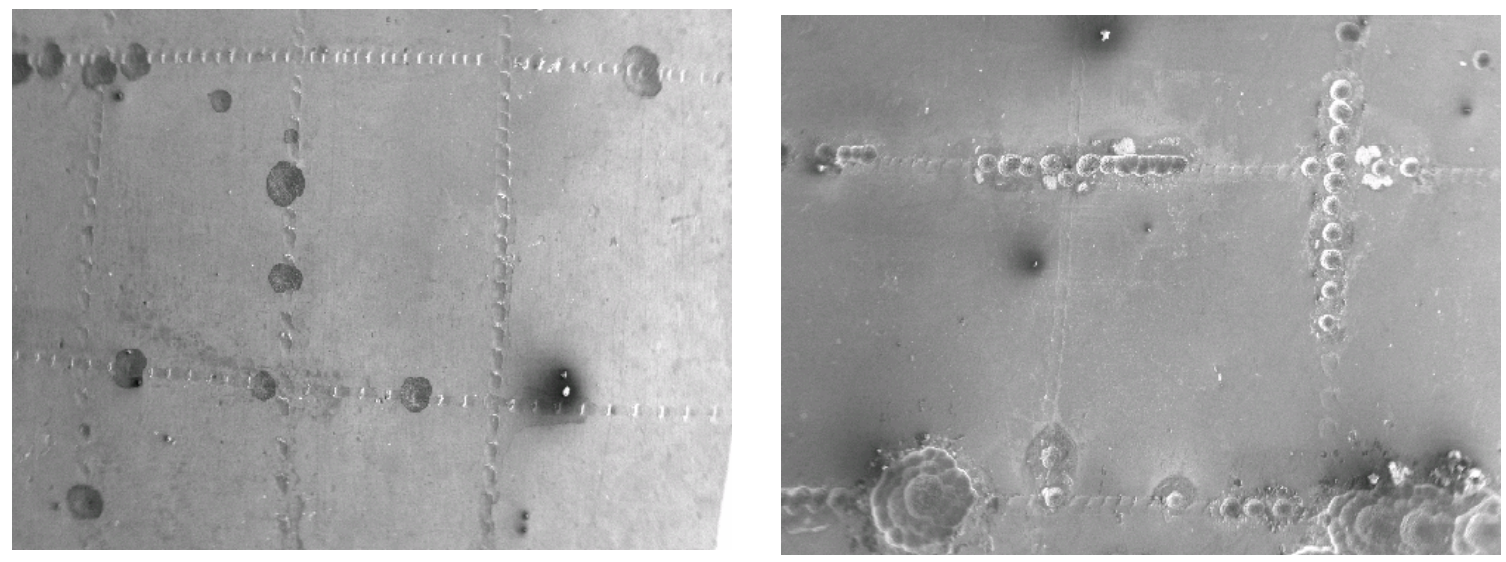

Area 1

Area 2

Figure 3.24. Metal dusting pits on Alloy 800 after 6-day exposure to a flowing carburizing atmosphere consisting of $72.2 \% \mathrm{H}_{2}-8.3 \% \mathrm{CO}_{2}-17.6 \% \mathrm{CO}-1.96 \% \mathrm{H}_{2} \mathrm{O}$ at $593^{\circ} \mathrm{C}$.

Metal dusting pits appeared along the scratched area on the surface of Alloy 800 . At area 1 in Fig. 3.24, only one pit appeared at the non-scratched area. The other 12 pits appeared along the scratched lines. In area 2 in Fig. 3.24, 38 pits appeared along 
the scratched lines, and only one pit appeared at the non-scratched area. With $9 \mathrm{Cr}$ 1 Mo steel, metal dusting pits also appeared at the scratched areas. Small pits (Fig. 3.25) grew to large pits (Fig. 3.26) and finally coalesced to area wide degradation (Fig. 3.27). These results indicate that pitting can be initiated by a mechanical scratching approach. They also suggest that the alloy surface should not have scratch-like defects, since those regions can act as pit-initiation sites when exposed in the metal dusting environment.

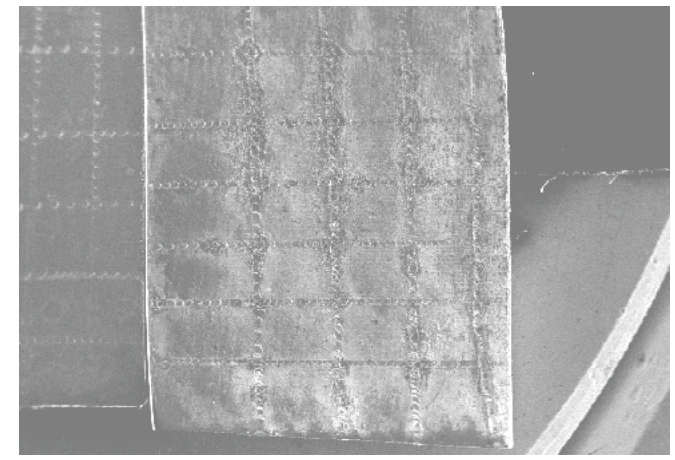

$10 \times$

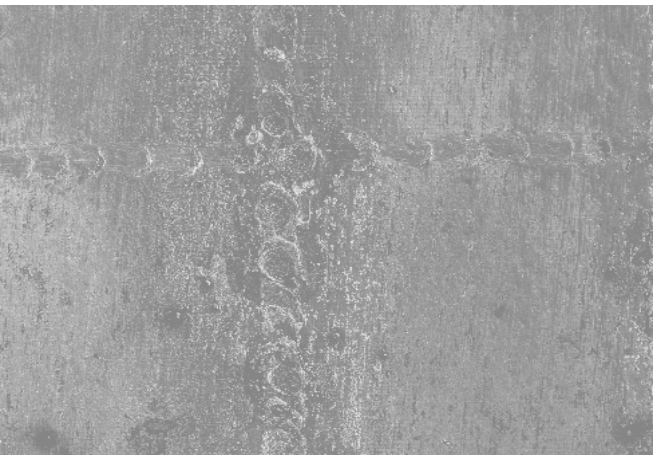

$50 X$

Figure 3.25. Metal dusting pits on Alloy $9 \mathrm{Cr}-1 \mathrm{Mo}$ after 2-day exposure to a flowing carburizing atmosphere consisting of $72.2 \% \mathrm{H}_{2}-8.3 \% \mathrm{CO}_{2}-17.6 \% \mathrm{CO}-1.96 \% \mathrm{H}_{2} \mathrm{O}$ at $593^{\circ} \mathrm{C}$.
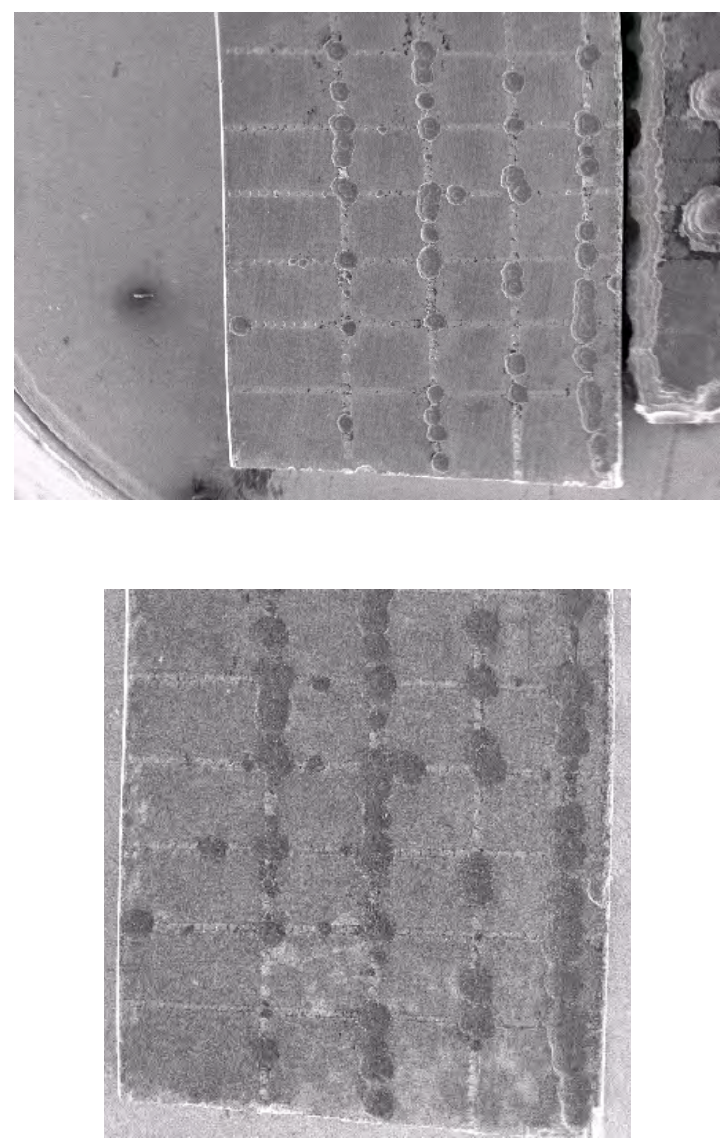

Figure 3.26. Metal dusting pits on Alloy $9 \mathrm{Cr}$-1Mo after 4-day exposure to a flowing carburizing atmosphere consisting of $72.2 \% \quad \mathrm{H}_{2}-8.3 \% \quad \mathrm{CO}_{2}-$ $17.6 \% \mathrm{CO}-1.96 \% \mathrm{H}_{2} \mathrm{O}$ at $593^{\circ} \mathrm{C}$.

Figure 3.27. Metal dusting pits on Alloy $9 \mathrm{Cr}$-1Mo after 6-day exposure to a flowing carburizing atmosphere consisting of $72.2 \% \quad \mathrm{H}_{2}-8.3 \% \mathrm{CO}_{2}-$ $17.6 \% \mathrm{CO}-1.96 \% \mathrm{H}_{2} \mathrm{O}$ at $593^{\circ} \mathrm{C}$. 
To understand the effect of scratches on the metal dusting corrosion, we scanned the scratched area with energy-dispersive X-ray (EDX) analysis. However, EDX could not locate small channels (Fig. 3.28) for carbon transfer. One possible reason is that the channel is not a straight line perpendicular to the alloy surface. Electrons go straight down to the oxide scale in the EDX experiment. The composition difference between the channels of carbon transfer and the oxide scale could not be distinguished by EDX because the signals from the channels were masked by signals from the oxide scale. One possible method to locate these channels of carbon transfer is to measure the electrical resistance on the surface. Oxides such as chromium oxide and spinel are insulators at room temperature, but $\mathrm{Ni}$ and $\mathrm{Fe}_{3} \mathrm{C}$ are good conductors. If there is a channel consisting of $\mathrm{Ni}$ metal or $\mathrm{Fe}_{3} \mathrm{C}$, its electrical resistance will be much smaller than that of oxide scale. Therefore, we developed a technique to detect the possible carbon transfer channel.

The procedure for detecting the low-resistance area on the surface of alloys is to deposit metal (such as copper) particles by an electrochemical method. Figure 3.29 shows a device in which copper is deposited on the alloys by immersing them in the $\mathrm{CuSO}_{4}$ solution and applying a voltage across the electrodes. The areas with low resistance will have deposits of copper particles because current can pass through them. Deposited copper particles thus act as an indicator to locate the carbon transfer channels. Such areas can be identified under a microscope and probably indicate regions of active degradation via metal dusting.

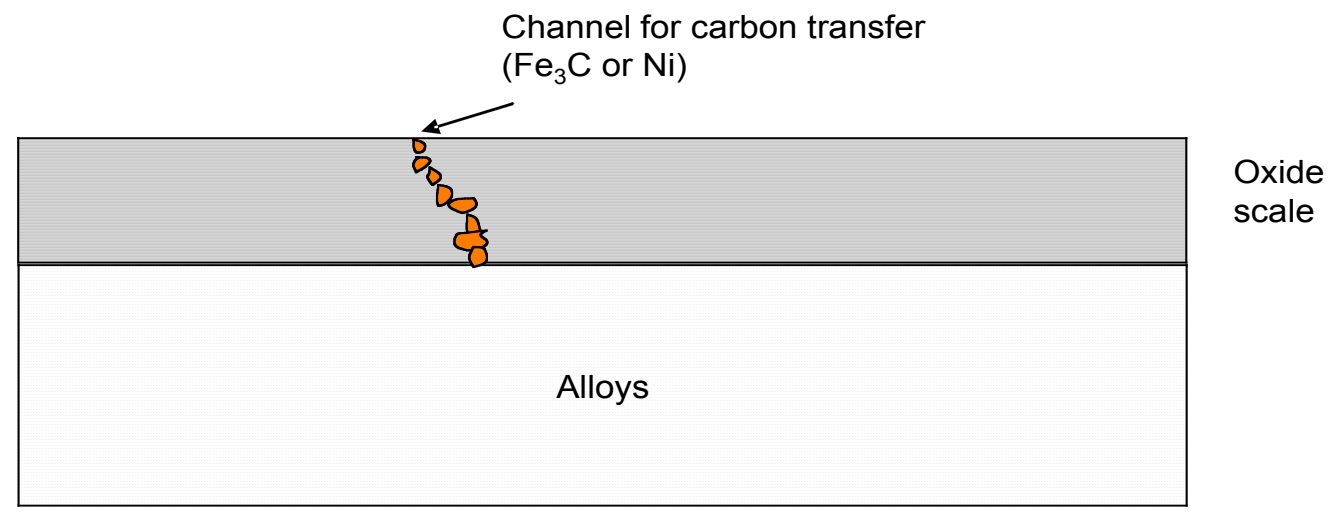

Figure 3.28. Model of possible carbon transferring channel.

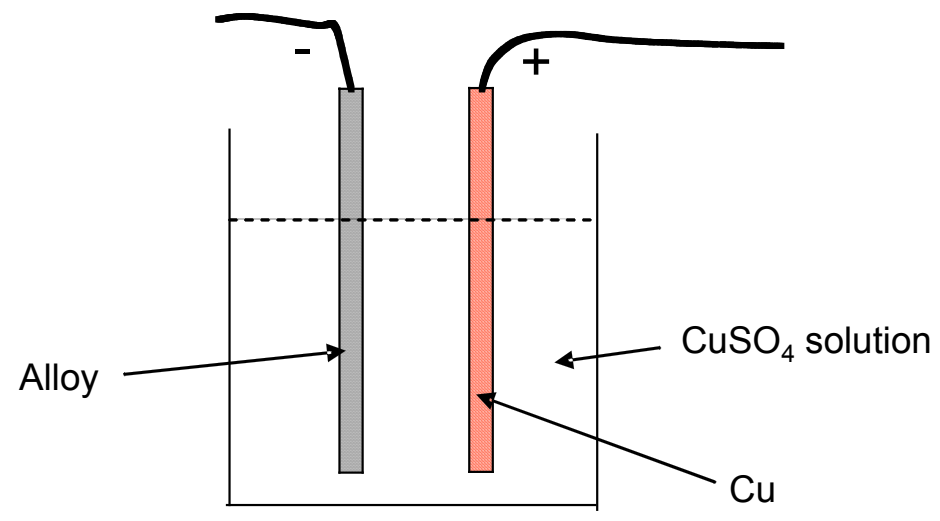

Figure 3.29. Device for electrochemical deposition of copper. 
Figures 3.30 and 3.31 show alloy surfaces from copper indicator experiment. Copper accumulated at the scratched regions in both Alloy 800 and $9 \mathrm{Cr}-1 \mathrm{Mo}$, indicating the susceptibility of these locations to metal dusting. If there is a metal dusting pit, most of the copper accumulates at the pit (Fig. 3.32).
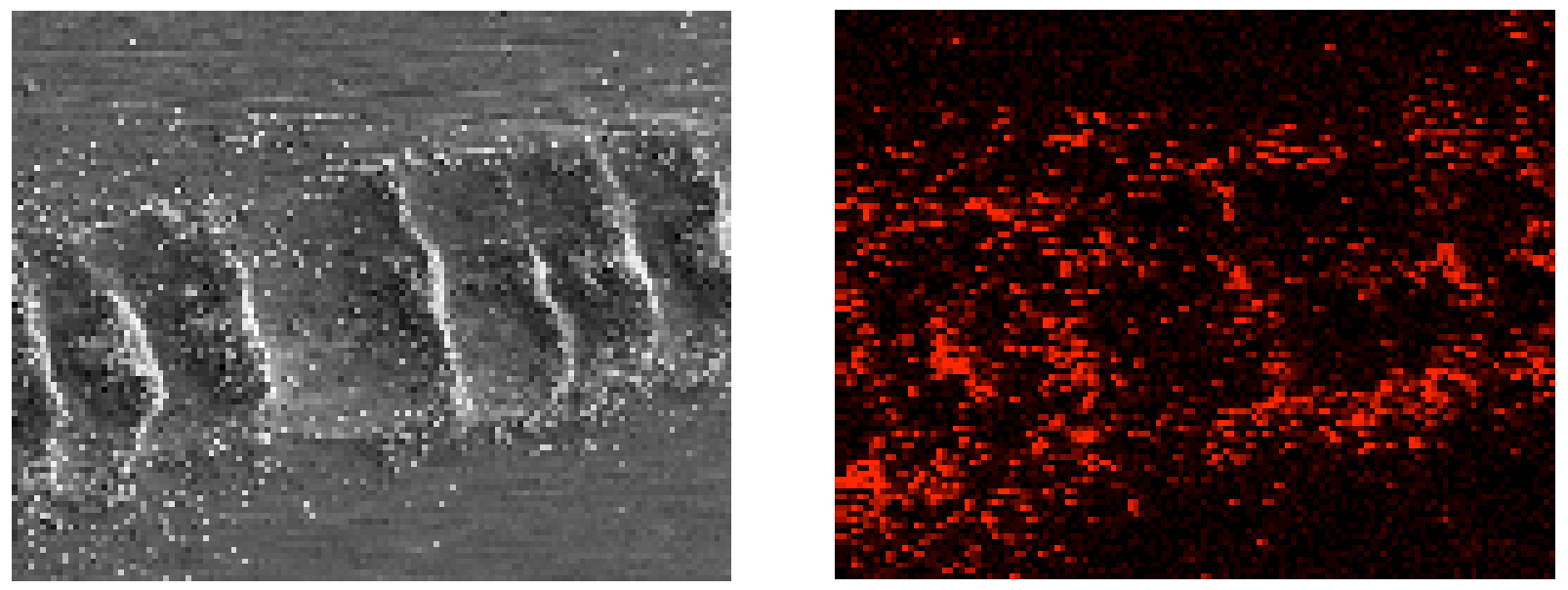

Figure 3.30. Left: SEM micrograph of Alloy 800 after exposure to a carburizing atmosphere. The surface was scratched by an engraver prior to exposure. Right: Copper electrochemically deposited on the Alloy 800 surface. The copper enhancement (in scratched areas) indicates regions susceptible to metal dusting.
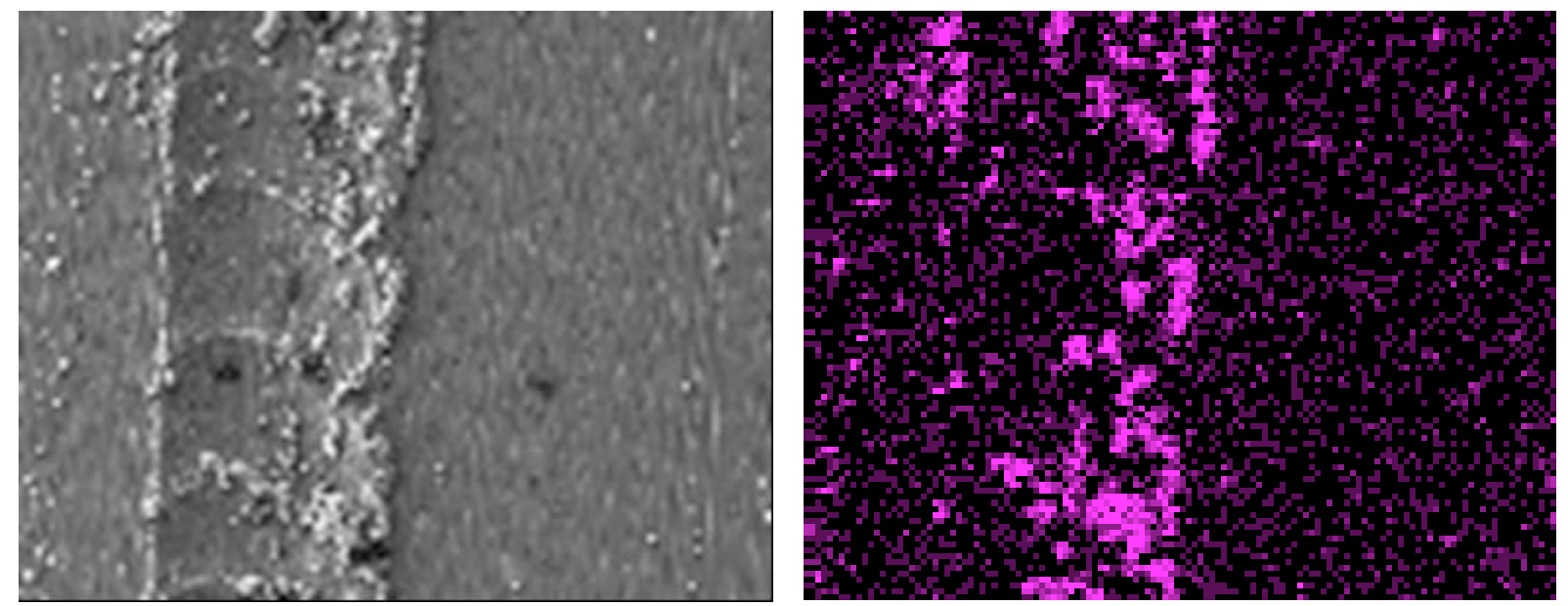

Figure 3.31. Left: SEM micrograph of Alloy $9 \mathrm{Cr}$-1Mo after exposure to a carburizing atmosphere. The surface was scratched by an engraver prior to exposure. Right: Copper was electrochemically deposited on the Alloy $9 \mathrm{Cr}-1$ Mo surface. The copper enhancement (in scratched areas) indicates regions susceptible to metal dusting. 

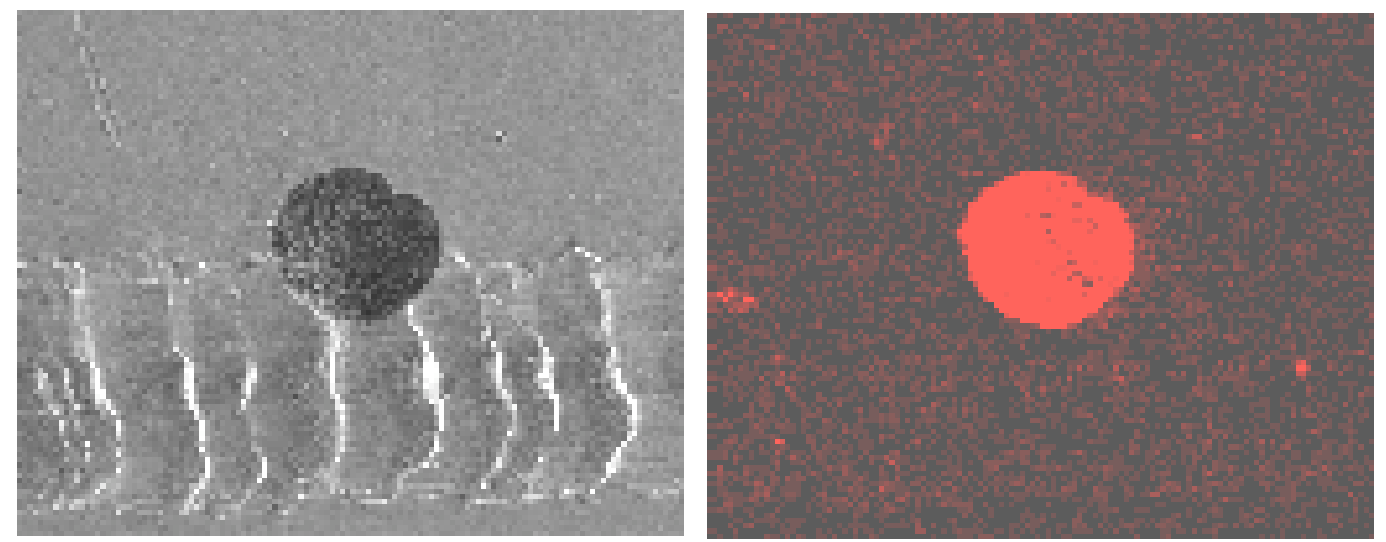

Figure 3.32. Left: SEM micrograph of Alloy 800 after exposure to a carburizing atmosphere. The surface was scratched by an engraver prior to exposure. A single pit was observed along the scratch line. Right: Copper electrochemically deposited on the surface of Alloy 800 .

Similar pre-pitting experiments were initiated with Ni-base alloys that were scratched with a diamond tip. The effect of temperature on the pit growth of Ni-based alloys was studied. We found that the temperature effect differed with alloy composition. The behavior of Alloy 601 was similar at 593 and $704^{\circ} \mathrm{C}$. SEM photomicrographs show that the pit diameter in Alloy 601 after exposure to a carburizing gas mixture at $593^{\circ} \mathrm{C}$ for $500 \mathrm{~h}$ is close to that exposed at $704^{\circ} \mathrm{C}$ (Fig. 3.33). However, the pit depths were different. Figure 3.34 shows the pit depths, measured by the surface profiler, in Alloy 601 exposed at the two temperatures. The pit depths were 27.2 and $61.8 \mu \mathrm{m}$ at 593 and $704^{\circ} \mathrm{C}$, respectively, after 500-h exposure to a carburizing gas consisting of $50 \% \mathrm{H}_{2}$ and $50 \% \mathrm{CO}$.

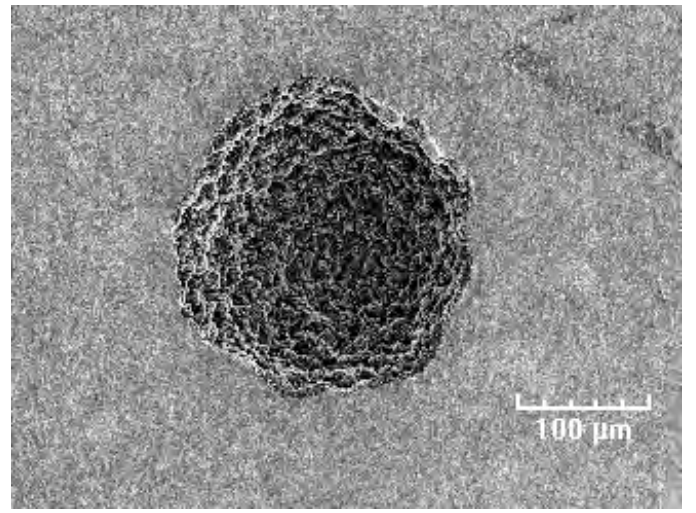

Alloy 601 tested at $704^{\circ} \mathrm{C}$

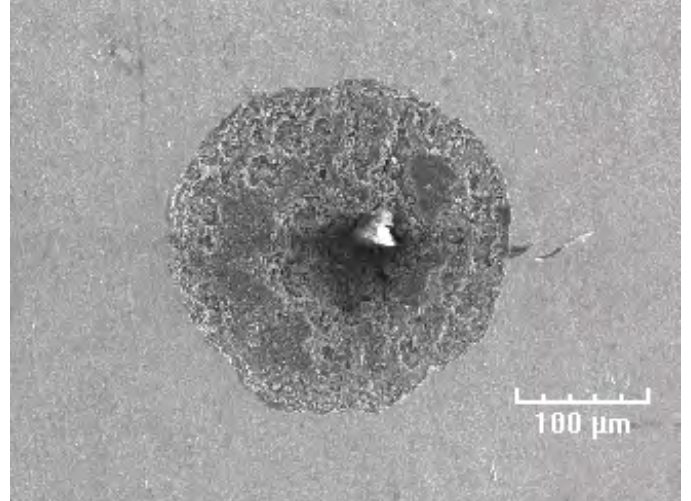

Alloy 601 tested at $593^{\circ} \mathrm{C}$

Figure 3.33. SEM micrographs of Alloy 601 after 500-h exposure to a carburizing gas consisting of $50 \% \mathrm{H}_{2}$ and $50 \% \mathrm{CO}$ at 593 and $704^{\circ} \mathrm{C}$. 


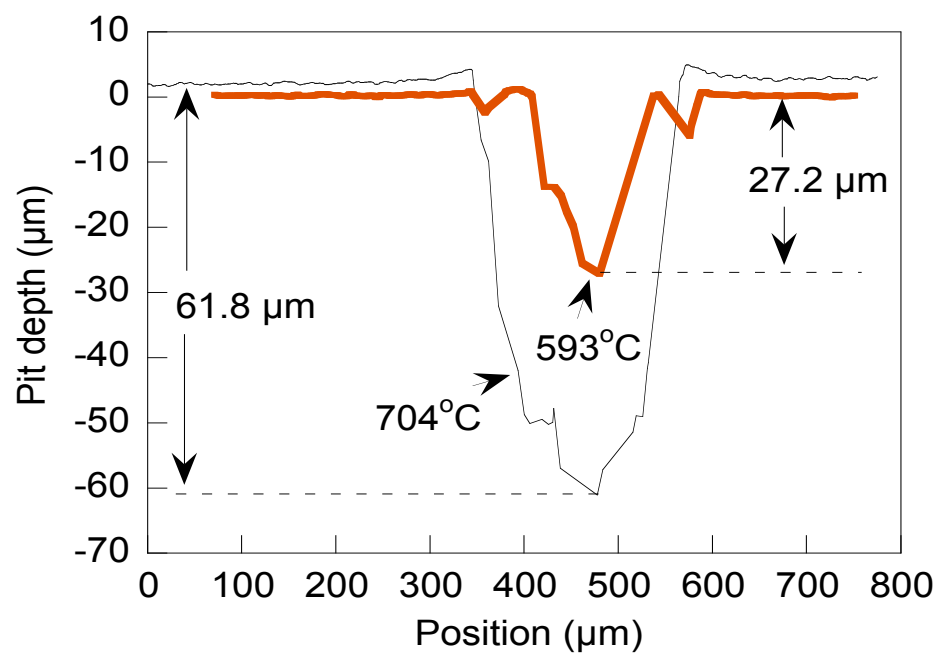

Figure 3.34. Surface profile of Alloy 601 after 500-h exposure to a carburizing gas consisting of $50 \% \mathrm{H}_{2}$ and $50 \% \mathrm{CO}$ at 593 and $704^{\circ} \mathrm{C}$.

Pits developed faster on Alloy 617 at $593^{\circ} \mathrm{C}$ than at $704^{\circ} \mathrm{C}$. Figure 3.35 shows that only two small pits appeared on Alloy 617 when the sample was exposed to a carburizing gas at $704^{\circ} \mathrm{C}$. However, pit density on Alloy 617 exposed to the same gas at $593^{\circ} \mathrm{C}$ was as high as 2500 pits $/ \mathrm{cm}^{2}$. Alloy 617 developed shallow pits at both $593^{\circ} \mathrm{C}$ and $704^{\circ} \mathrm{C}$. These pits developed faster at $704^{\circ} \mathrm{C}$ than $593^{\circ} \mathrm{C}$.

The behavior of Alloy 602CA was different from that of Alloy 617. Figure 3.36 shows deep pit $(\approx 73 \mu \mathrm{m})$ that formed in Alloy 602CA after 500-h exposure to a carburizing gas at $704^{\circ} \mathrm{C}$. However, when this alloy was tested at $593^{\circ} \mathrm{C}$, no real pit was observed, but some material grew out of the surface of Alloy 602CA (Fig. 3.37), which may be the early stage of a pit growth. Alloy 214 developed big and deep pits at $704^{\circ} \mathrm{C}$ (Fig. 3.38), but the pit density was much higher at $593^{\circ} \mathrm{C}$ than $704^{\circ} \mathrm{C}$.

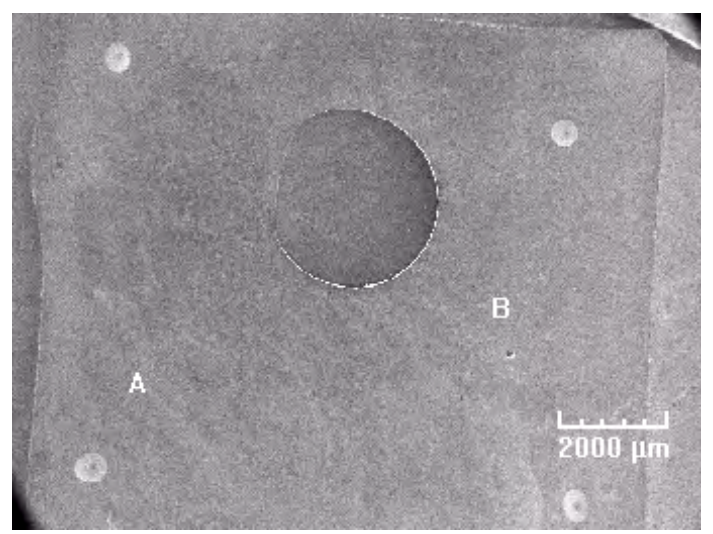

Alloy 617 tested at $704^{\circ} \mathrm{C}$

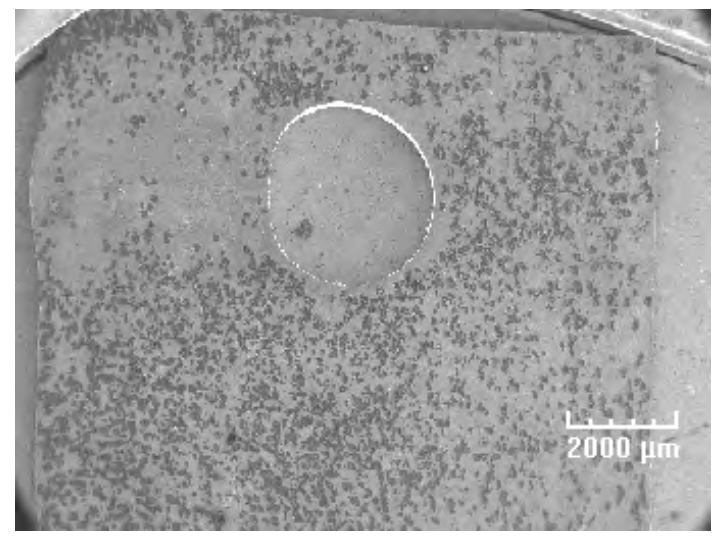

Alloy 617 tested at $593^{\circ} \mathrm{C}$

Figure 3.35. SEM photomicrographs of Alloy 617 after 500-h exposure to a carburizing gas consisting of $50 \% \mathrm{H}_{2}$ and $50 \% \mathrm{CO}$ at 593 and $704^{\circ} \mathrm{C}$. 


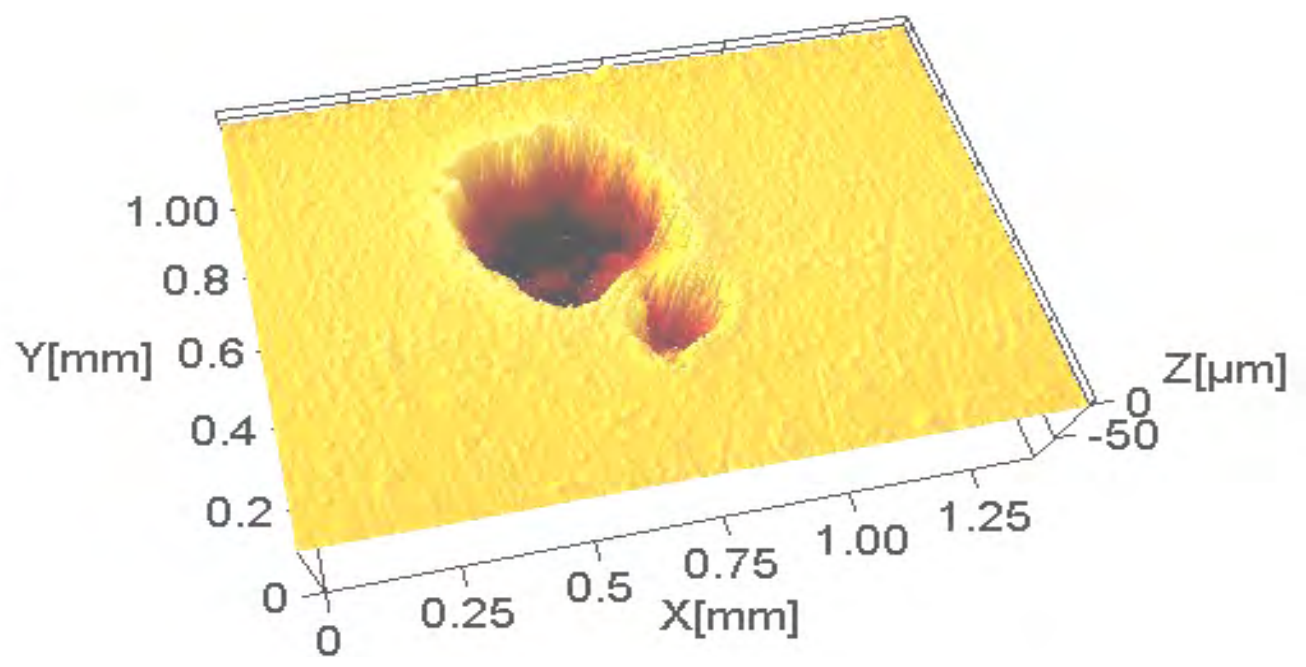

Figure 3.36. Profile map of Alloy 602CA exposed to a carburizing gas consisting of $50 \% \mathrm{H}_{2}-50 \% \mathrm{CO}$ at $704^{\circ} \mathrm{C}$ for $500 \mathrm{~h}$.

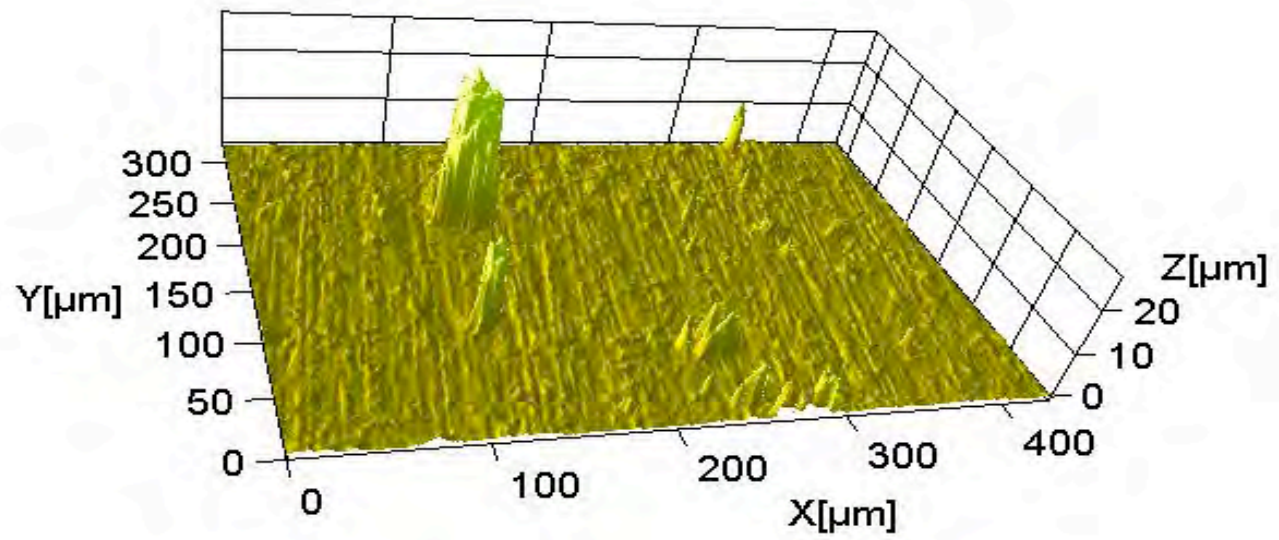

Figure 3.37. Profile map of Alloy 602CA exposed to a carburizing gas consisting of $50 \% \mathrm{H}_{2}-50 \% \mathrm{CO}$ at $593^{\circ} \mathrm{C}$ for $500 \mathrm{~h}$.

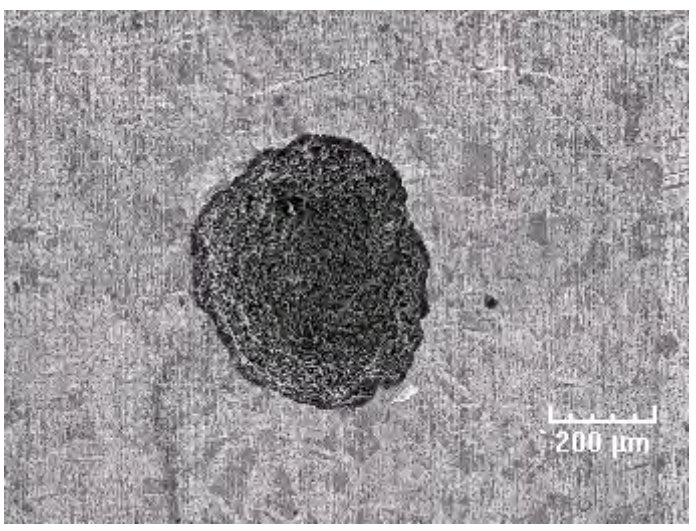

Alloy 214 tested at $704^{\circ} \mathrm{C}$

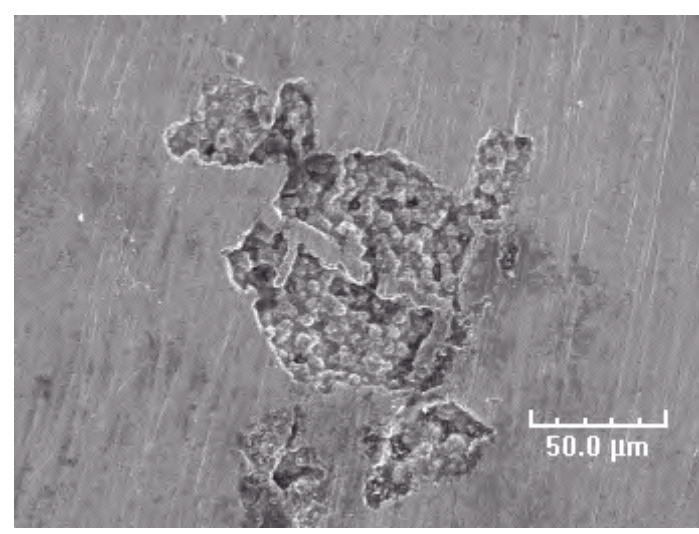

Alloy 214 tested at $593^{\circ} \mathrm{C}$

Figure 3.38. SEM photomicrographs of Alloy 214 exposed to a carburizing gas consisting of $50 \% \mathrm{H}_{2}-50 \% \mathrm{CO}$ at 593 and $704^{\circ} \mathrm{C}$ for $500 \mathrm{~h}$. 


\subsection{Approach to Mitigate Metal Dusting Corrosion}

In recent years, we studied the mechanism for metal dusting degradation in simulated hydrogen reformer environments and established the causes for the initiation of pits in both Fe- and Ni-base alloys (Zeng and Natesan 2003, Zeng et al. 2004). The information that we developed on the performance of various alloys led us to model the process for the formation of a metal dusting pit. Two major factors can affect the formation of metal dusting pits. First is the rate of carbon diffusion into alloys. If alloys do not develop a protective oxide layer to resist carbon diffusion, the carbon that has diffused into and accumulated in alloys will lead to metal dusting corrosion. Second is the rate of the formation of oxide scale. If alloys can form a continuous oxide scale on their surface, carbon diffusion through the oxide scale is slowed, and carbon accumulation in the alloy diminishes. In general, metal dusting environments contain both oxygen and carbon, and the process that dominates is dictated by several factors, such as temperature, pressure, alloy composition, and gas chemistry.

Generally, the hydrogen reformer environment contains sufficient steam to establish oxygen partial pressures that are conducive to the formation of chromia and/or spinel phases in the oxide scale that develops on Fe- and Ni-base alloys. Therefore, most areas of an alloy surface are protected from metal dusting corrosion. The process can continue only at those areas with carbon transfer channels, as was shown in Fig. 3.28. Figure 3.39 shows an enlarged channel for transferring carbon. The channel consists of $\mathrm{Fe}_{3} \mathrm{C}$ or Ni particles.

At low oxygen partial pressure $\left(\mathrm{pO}_{2}\right)$, oxygen cannot oxidize $\mathrm{Fe}_{3} \mathrm{C}$ and $\mathrm{Ni}$. Carbon diffuses through the channels into the alloys at a relatively high rate. If oxygen can also diffuse through these channels, an oxide scale may form underneath the channel because $\mathrm{Cr}$ can form $\mathrm{Cr}_{2} \mathrm{O}_{3}$ at a much lower $\mathrm{pO}_{2}$ than the oxides of $\mathrm{Fe}$ and $\mathrm{Ni}$. The oxide scale underneath the channel will eventually stop or minimize the diffusion of carbon into the alloys, and metal dusting will cease. However, because the oxygen atom is much larger than the carbon atom, and the diffusion rate of oxygen is not high enough to form a continuous chromium oxide scale, carbon will continue to diffuse into the alloys and lead to metal dusting corrosion. These $\mathrm{Fe}_{3} \mathrm{C}$ and $\mathrm{Ni}$ particles act as filters to allow carbon diffusion but prevent oxygen diffusion. A self-healing mechanism may not work in this situation, and a metal dusting pit will finally form. Although $\mathrm{Cr}$ can still react with oxygen at the pit area, a continuous oxide scale may not form. Many carbon transfer channels form deep roots into alloys (Fig. 3.40), and the process of metal dusting does not stop after the pits develop. However, if we temporarily remove $\mathrm{CO}$ and $\mathrm{CO}_{2}$ from the exposure atmosphere, the diffusion of carbon will cease, whereas diffusion of oxygen will continue. Therefore, a continuous oxide scale could develop underneath the carbon transfer channel without interference from carbon, thereby blocking the channel for further transport of carbon. Results from the following experiments show that this approach retards the growth of metal dusting pits. 


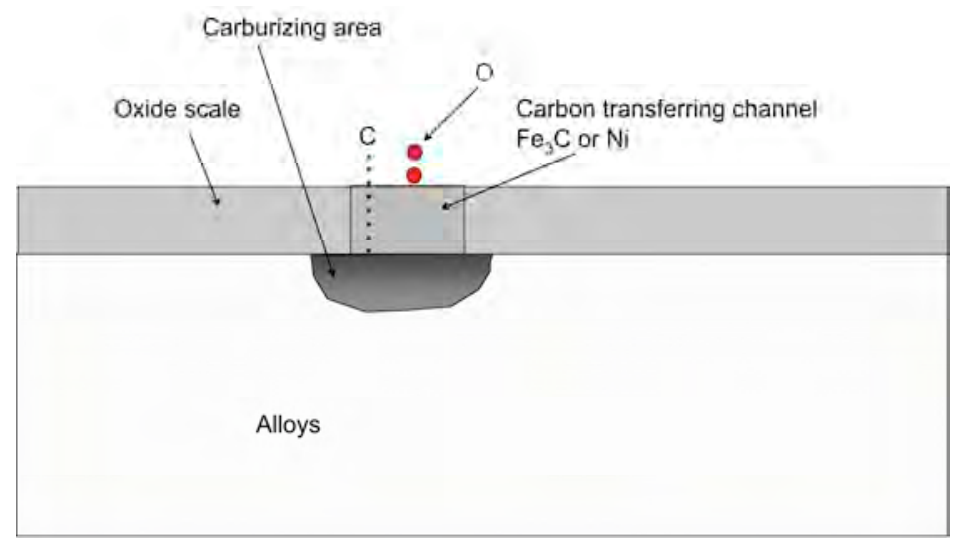

Figure 3.39. Schematic of a model for initiation of a metal dusting pit.

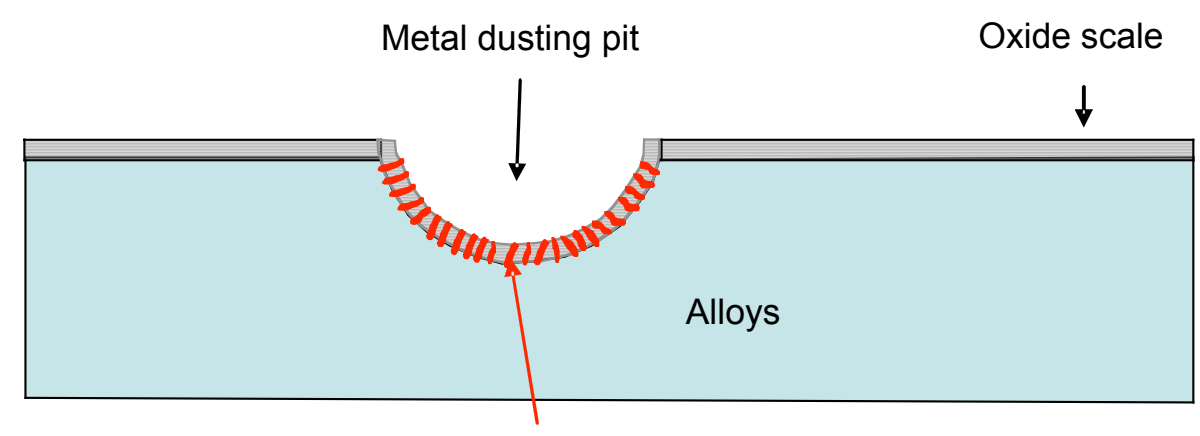

Channels for carbon transfer $\left(\mathrm{Fe}_{3} \mathrm{C}\right.$ or $\left.\mathrm{Ni}\right)$

Figure 3.40. Schematic of carbon transfer channels in a pit.

To examine this intermediate oxidation (in the absence of carbonaceous gases) approach to mitigate metal dusting attack, specimens of Alloy 800 were selected for detailed study. These specimens were exposed for 5 days to a gas mixture consisting of $72.2 \% \mathrm{H}_{2}-8.3 \% \mathrm{CO}_{2}-17.6 \% \mathrm{CO}-1.96 \% \mathrm{H}_{2} \mathrm{O}$ (Gas 5) at $593^{\circ} \mathrm{C}$. Metal dusting pits of 100-200 $\mu \mathrm{m}$ in diameter were observed (Fig. 3.41). The pit surface was rough because of the deposited carbon particles in the pit. Subsequently, the specimen was exposed at $593^{\circ} \mathrm{C}$ for 2 days to a gas consisting of $\mathrm{H}_{2}-2 \% \mathrm{H}_{2} \mathrm{O}$, which has similar water content to Gas 5 but no carbon containing species.
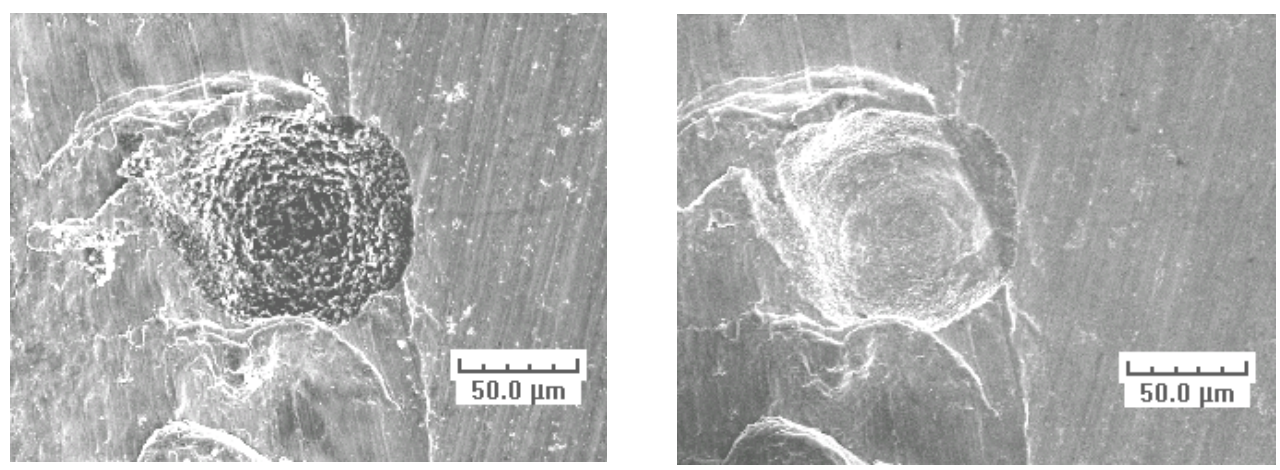

Figure 3.41. Left: Metal dusting pit on Alloy 800 after 5-day exposure to a carburizing gas consisting of $72.2 \% \mathrm{H}_{2}-8.3 \% \mathrm{CO}_{2}-17.6 \% \mathrm{CO}-1.96 \% \mathrm{H}_{2} \mathrm{O}$ at $593^{\circ} \mathrm{C}$. Right: The specimen after further exposure in $\mathrm{H}_{2}-2 \% \mathrm{H}_{2} \mathrm{O}$ gas mixture at $593^{\circ} \mathrm{C}$ for 2 days. 
The pit surface became smooth after exposure to the $\mathrm{H}_{2}-2 \% \mathrm{H}_{2} \mathrm{O}$ environment, because carbon particles in and around the pit were removed by oxidation. The pit area was slightly oxidized by the gas with oxygen partial pressure similar to that of Gas 5 . The sample was again exposed for 4 days to Gas 5 at $593^{\circ} \mathrm{C}$. The pit size remained the same as before exposure (Fig. 3.42, left). No further metal dusting attack occurred at this pit, even when this specimen was exposed to Gas 5 for 6 days (Fig. 3.42, right) after intermediate oxidation by the $\mathrm{H}_{2}-2 \% \mathrm{H}_{2} \mathrm{O}$ gas. Similar observations on the effects of intermediate oxidation were made on other pits on the Alloy 800 surface.
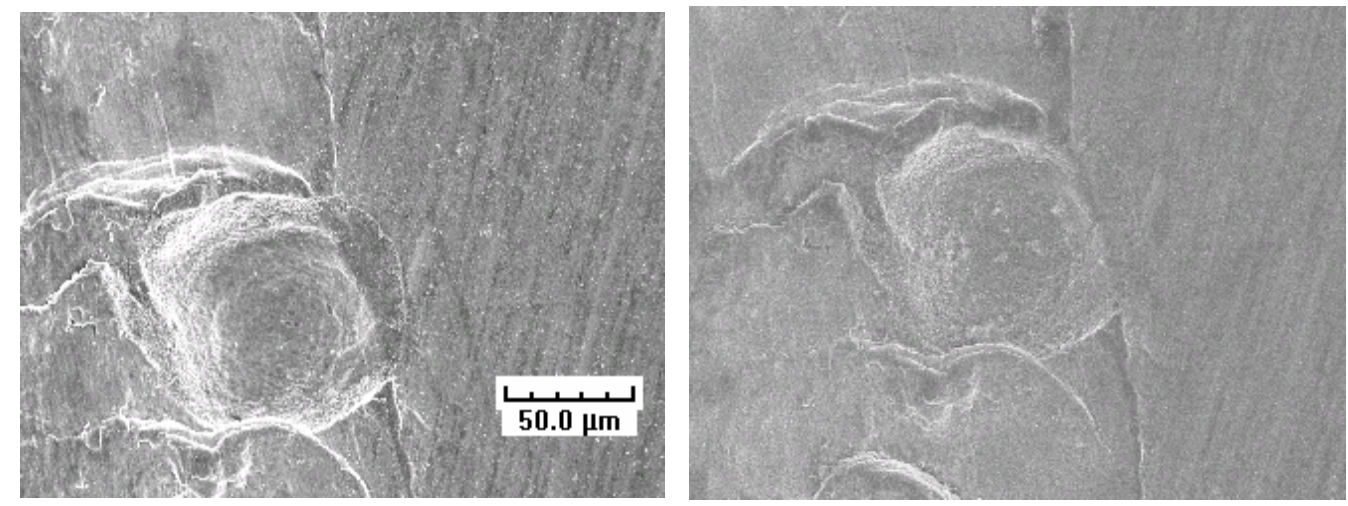

Figure 3.42. The specimen shown in Fig. 3.41 after exposure to $72.2 \% \mathrm{H}_{2}-8.3 \%$ $\mathrm{CO}_{2}-17.6 \% \mathrm{CO}-1.96 \% \mathrm{H}_{2} \mathrm{O}$ at $593^{\circ} \mathrm{C}$ for (left) 4 days and (right) 6 days.

Figures 3.43 and 3.44 show a second metal dusting pit on Alloy 800 that exhibited similar behavior to that of the pit in Fig. 3.41. Figure 3.45 shows the behavior of a third pit on the surface of the same specimen of Alloy 800. In the case of the third pit, the oxide was not protective enough to resist metal dusting, and a small pit could be observed after 4 days exposure of the oxidized specimen [Fig. 3.45(c)]. These observations can be explained by the model shown in Fig. 3.46.

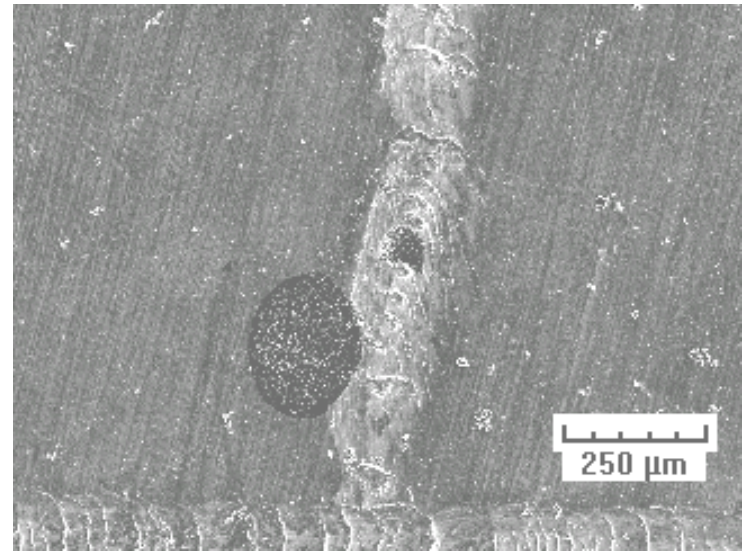

(a)

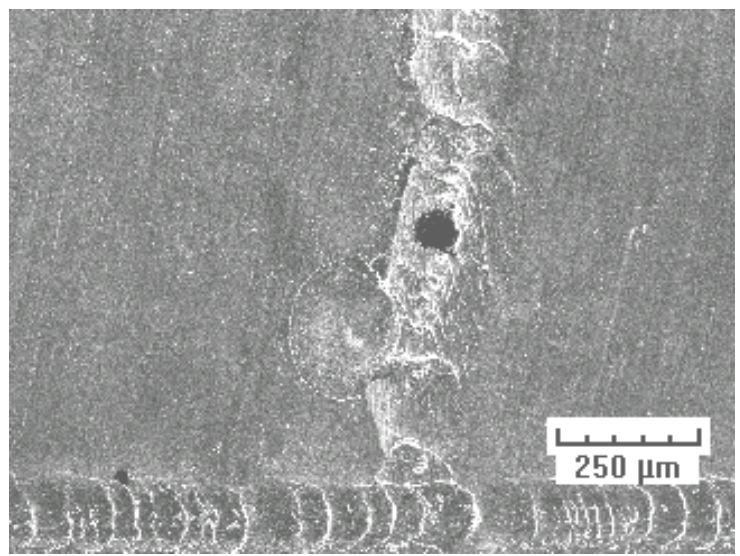

(b)

Figure 3.43. (a) Another metal dusting pit on Alloy 800 after exposure to carburizing atmosphere consisting of $72.2 \% \mathrm{H}_{2}-8.3 \% \mathrm{CO}_{2}-17.6 \% \mathrm{CO}-1.96 \% \mathrm{H}_{2} \mathrm{O}$ at $593^{\circ} \mathrm{C}$ for 5 days. (b) The specimen after further treatment by exposure to a gas consisting of $\mathrm{H}_{2}$ $2 \% \mathrm{H}_{2} \mathrm{O}$ at $593^{\circ} \mathrm{C}$ for 2 days. 


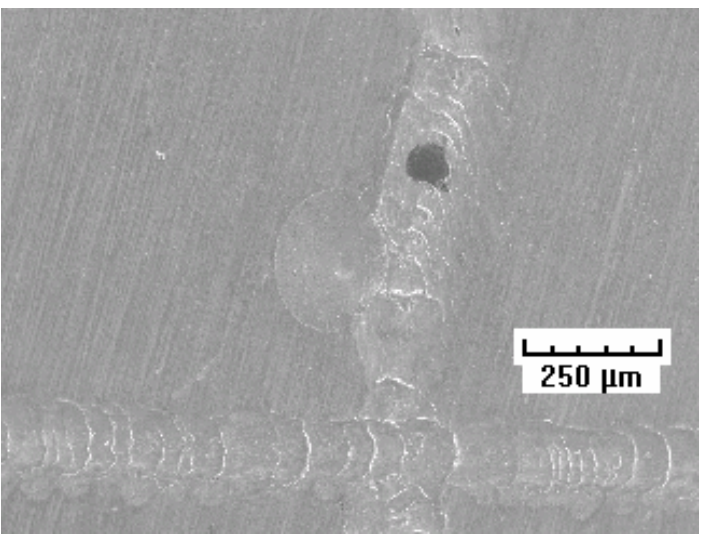

(a)

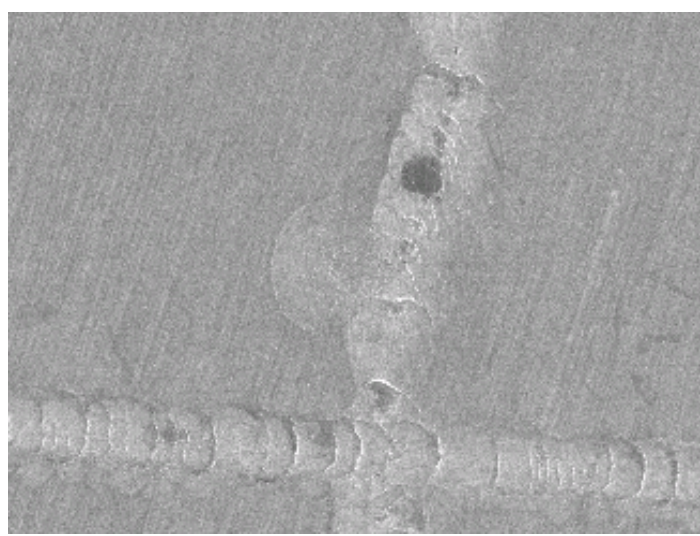

(b)

Figure 3.44. Specimen shown in Fig. 3.43 after further exposure to the carburizing atmosphere for (a) 4 days and (b) 6 days.

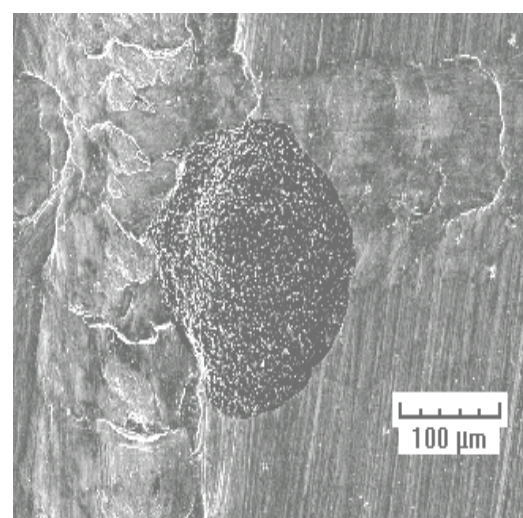

(a)

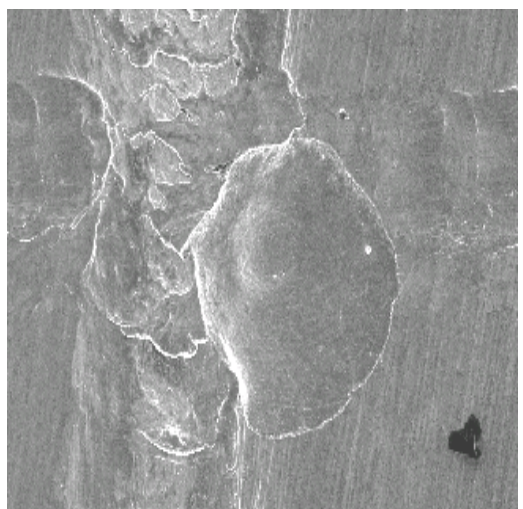

(b)

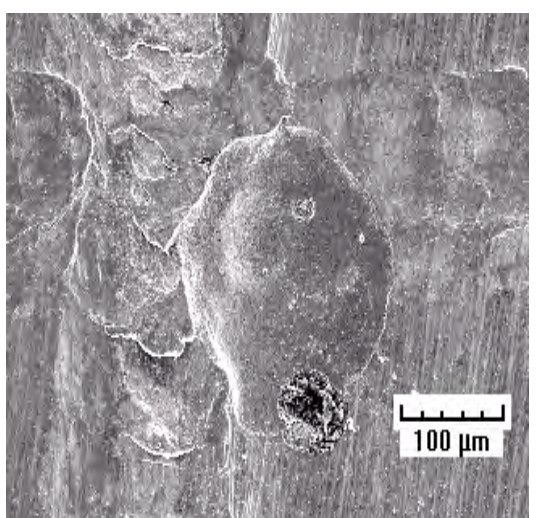

(c)

Figure 3.45. (a) Third pit on Alloy 800 after exposure to carburizing atmosphere consisting of $72.2 \% \mathrm{H}_{2}-8.3 \% \mathrm{CO}_{2}-17.6 \% \mathrm{CO}-1.96 \% \mathrm{H}_{2} \mathrm{O}$ at $593^{\circ} \mathrm{C}$ for 5 days. After the alloy sample was oxidized at $593^{\circ} \mathrm{C}$ for 2 days, the sample was re-exposed to the carburizing atmosphere for (b) 2 days and (c) 4 days.

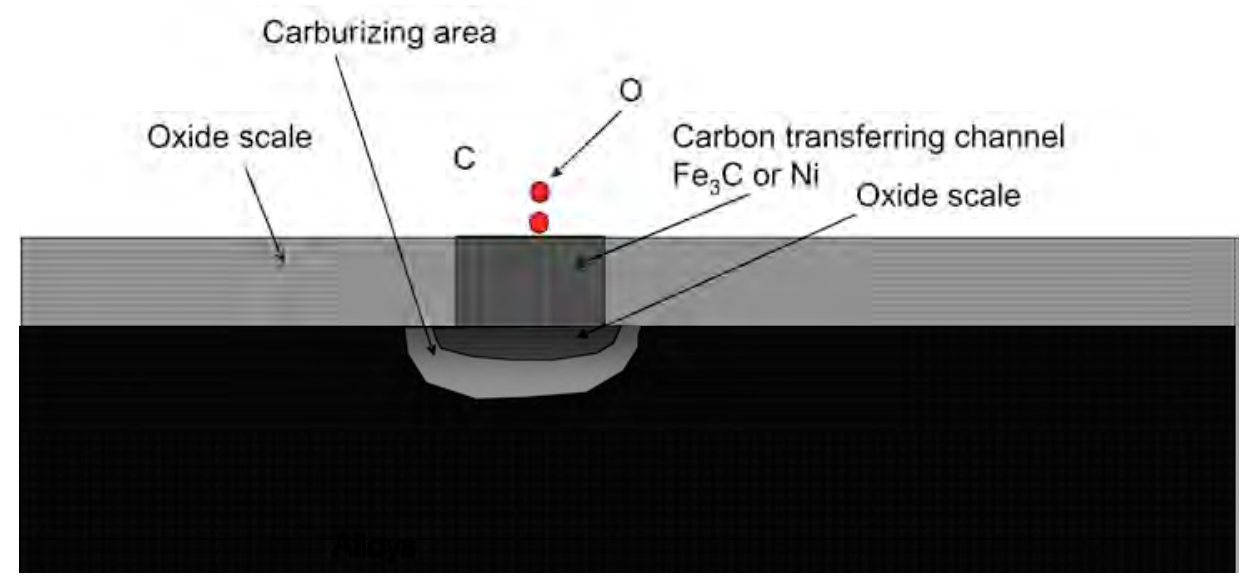

Figure 3.46. Schematic of a model for the blocking action of oxide layer after intermediate oxidation of metal dusted alloy. 
The beneficial effect of intermediate oxidation is depends on the integrity of the oxide that develops in the pit region and the protective capacity (from the standpoint of stability, phases present, etc.) of the oxide against metal dusting initiation when subsequently exposed to the process atmosphere. A continuous protective oxide scale, to stop the continued growth of the pit, could not form since carbon could transfer faster than oxygen through the channels in the oxide scale.

When the carbonaceous gases $\mathrm{CO}$ and $\mathrm{CO}_{2}$ are removed in the intermediate oxidation treatment, a continuous oxide scale could form underneath the channels without the interference of carbon. The newly formed oxide acts as a barrier to further transport of carbon when the specimen is exposed to the metal dusting environment. The incubation time for Alloy 800 is $\approx 100 \mathrm{~h}$ in the gas chemistry and temperature used in our study. Therefore, after the 4 day exposure to a carburizing atmosphere, carbon broke through the new oxide scale and a pit grew, as shown in Fig. 3.45(c).

These results indicate the potential for intermediate oxidation treatment to delay the onset of metal dusting and continued wastage. This approach may not be useful for Alloy 800 because the incubation time of Alloy 800 is short. However, if we apply this method to some of the Fe- and Ni-base alloys with long incubation time, we may be able to greatly extend the life of these alloys and process components in a metal dusting environment.

\section{8 Effect of Carbon Activity on Metal Dusting Corrosion}

We are continuing exposures of $\mathrm{Ni}$-base alloys in several gas mixtures with different carbon activities. Earlier, we reported data for several Ni-base alloys (Run $59 \mathrm{HP}$ with a carbon activity of 31) after $9700-\mathrm{h}$ exposure at $593^{\circ} \mathrm{C}$ and $14.3 \mathrm{~atm}(210$ psi). Subsequent to that run, we initiated exposures of several Ni-base alloys in Gas 18 at $593^{\circ} \mathrm{C}$ and $30 \mathrm{~atm}(440 \mathrm{psi})$. The carbon activity in this run (designated as 60HP) was 100. We also initiated another companion test (Run 61) in Gas $21\left(65.1 \% \mathrm{H}_{2}\right.$, $30 \% \mathrm{CO}, 0.94 \% \mathrm{H}_{2} \mathrm{O}, 4 \% \mathrm{CO}_{2}$ )at $593^{\circ} \mathrm{C}$ and 1 atm. The carbon activity in this experiment was 104.

Figure 3.47 shows the weight loss of Ni-based alloys in Run 61. The weight loss rate of Alloy 214, 600, and 45TM is high in this gas environment. Alloy 602CA, 601, 617, and 690 also began to lose weight. However, Alloy 625, 230, HR160, and 693 were not attacked by metal dusting after 5800 -h exposure to the carburizing gas. The chromium content of both Alloy 214 and 45TM is low. Although Alloy 214 has $3.7 \% \mathrm{Al}$, it was readily attacked by metal dusting. Therefore, the chromium content in the $\mathrm{Ni}$ base alloys has to be over $20 \mathrm{wt} . \%$ to resist metal dusting corrosion. The iron content in 45TM is the highest in these alloys. It also corroded at a higher rate. 

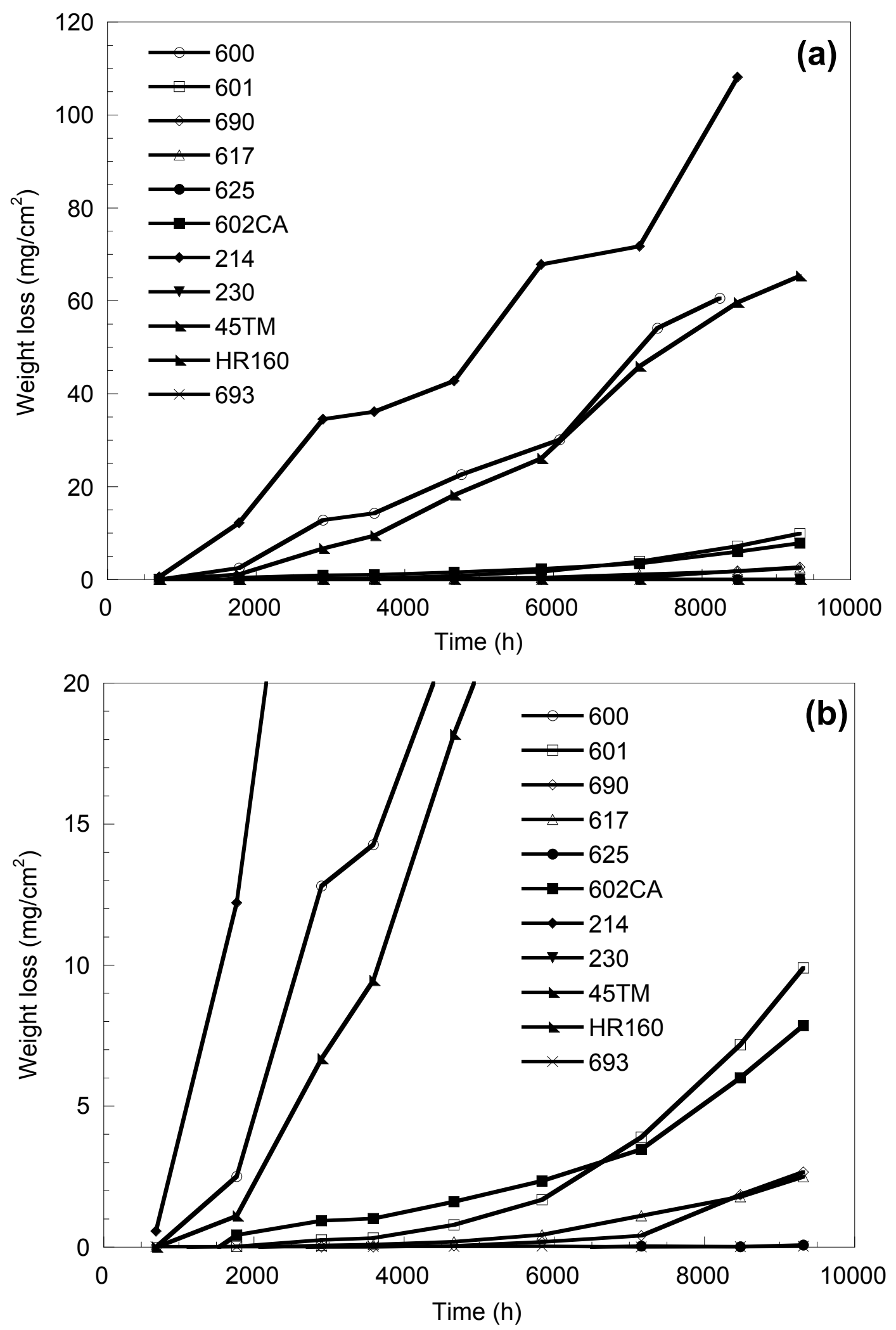

Figure 3.47. (a) Weight loss of Ni-based alloys after 9316-h exposure to Gas 21 (65.1\% $\mathrm{H}_{2}, 30 \% \mathrm{CO}, 0.94 \% \mathrm{H}_{2} \mathrm{O}, 4 \% \mathrm{CO}_{2}$ ) at $593^{\circ} \mathrm{C}$ and $1 \mathrm{~atm}$. (b) Magnified view. 
Although the weight loss of Alloy 601 is small, its pit depth is high (Fig. 3.48). Alloy 45TM also developed deep pits, whereas Alloy 600 and 214 developed shallow pits. Pits only appeared at the edge of Alloy 690 and 602CA. No pit was observed on Alloy 625, 230, HR160, and 693 after the 5839-h exposure.

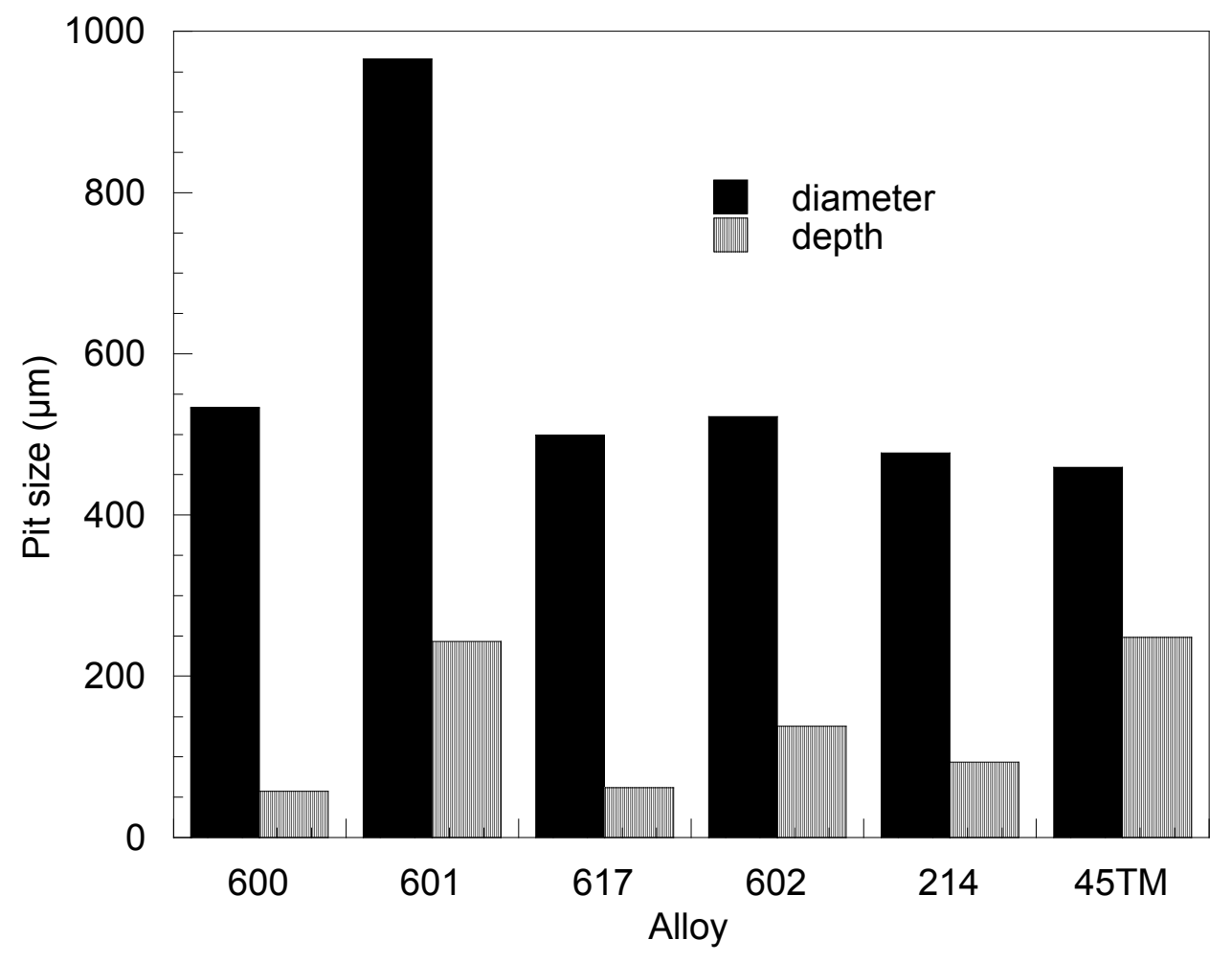

Figure 3.48. Pit size in Ni-based alloys after 5839-h exposure to Gas $21\left(65.1 \% \mathrm{H}_{2}\right.$, $30 \% \mathrm{CO}, 0.94 \% \mathrm{H}_{2} \mathrm{O}, 4 \% \mathrm{CO}_{2}$ ) at $593^{\circ} \mathrm{C}$ and $1 \mathrm{~atm}$. 


\section{ANALYSIS OF METAL DUSTING FAILURES}

Metal dusting degradation of structural metallic materials has been observed in the production of syngas, a step used in the manufacture of hydrogen, ammonia, methanol, and various liquid hydrocarbons. The failures are generally observed in the temperature range of $400-700^{\circ} \mathrm{C}$ in complex gas environments with high carbon activity $(>>1)$. Further, these systems operate at elevated pressures, which also exacerbate metal dusting degradation, since carbon activity increases with an increase in system pressure. During the course of this project, we examined two failed components from a hydrogen-production plant.

The analysis was performed on a pipe and a plate that were made of Alloy $800 \mathrm{HT}$. Figure 4.1 shows several holes on the pipe and a large hole $(\approx 10 \mathrm{~cm}$ in dia) on the plate, after the material was attacked by metal dusting corrosion. We used SEM and Raman scattering methods to analyze specimens cut from the two components. Figure 4.2 shows the cross section of the specimens.
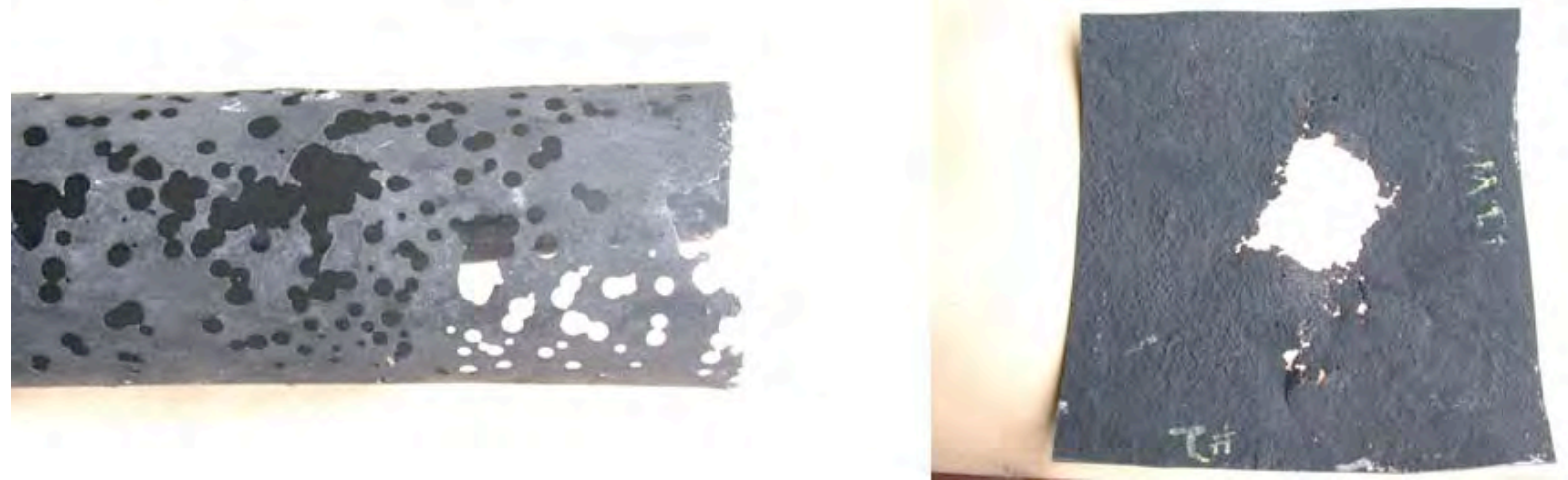

Figure 4.1. A pipe and a plate obtained from a syngas plant. Both components were attacked by metal dusting corrosion.

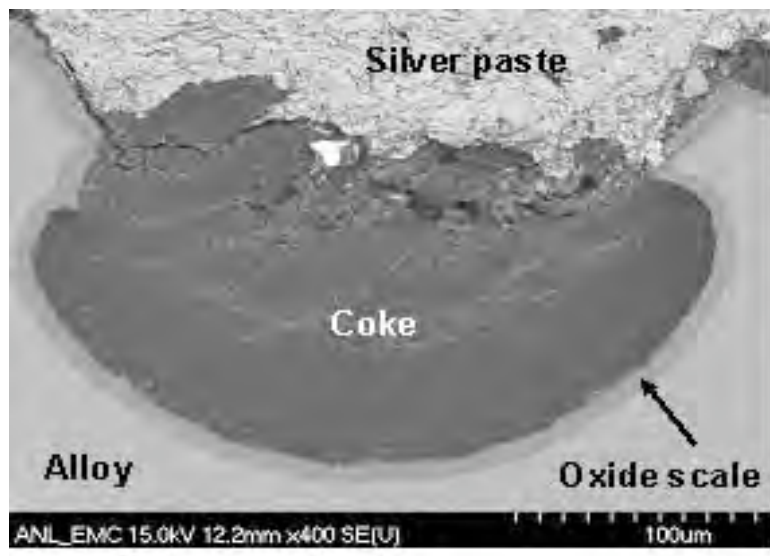

(a) Thick part of Alloy 800 pipe

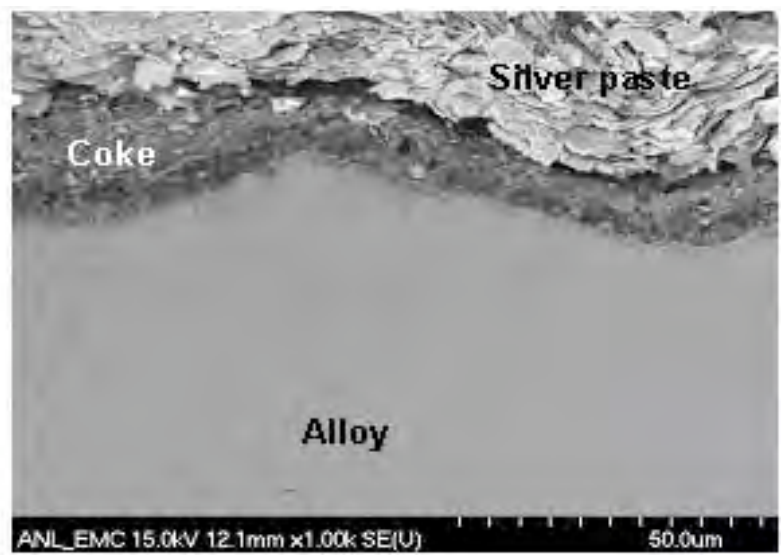

(b) Thin part of Alloy 800 pipe

Figure 4.2. Cross section of the Alloy $800 \mathrm{HT}$ pipe. SEM photomicrographs of (a) thick and (b) thin part of the pipe. Both parts were severely attacked by metal dusting. 
The pipe had a tightly adhering coke layer on the surface, which could not be removed by ultrasonic cleaning and acetone washing with a cotton tip. $A \approx 9 \mu \mathrm{m}$ oxide scale was observed on the surface of the thick part of the pipe. However, no such oxide scale was observed on the surface of the thinner part of the pipe, which was attacked severely by metal dusting. Therefore, the alloy in the thin part was directly exposed to high carbon activity gas without the protection of an oxide scale. Although metal dusting pits appeared on the surface of the thick part of the pipe, its corrosion rate was much lower than that of the thinner section because it was protected by the oxide scale.

Figure 4.3 shows EDX mapping of the cross section of the pipe sections. The oxygen content in the scale on the surface of the thick part is obviously higher than that inside the alloy and in coke. However, the thin part did not have a continuous oxide scale on the surface. Therefore, carbon can readily diffuse into alloys. EDX line scan results show that the $\mathrm{Fe} / \mathrm{Cr}$ ratio in the 9- $\mu \mathrm{m}$ oxide scale is higher than that in the alloy (Fig. 4.4). A solid solution $\mathrm{Fe}\left(\mathrm{Cr}_{1-\mathrm{x}} \mathrm{Fe}_{\mathrm{x}}\right)_{2} \mathrm{O}_{4}$ can form in the range $0 \leq \mathrm{x} \leq 1$. As shown in Fig. 4.5, $\mathrm{FeCr}_{2} \mathrm{O}_{4}$ is stable in the metal dusting environment, but $\mathrm{Fe}_{1.8} \mathrm{Cr}_{1.2} \mathrm{O}_{4}$ can react with high carbon activity gases, and the carbon deposition rate in $\mathrm{Fe}_{2.4} \mathrm{Cr}_{0.6} \mathrm{O}_{4}$ is much larger than that of $\mathrm{Fe}_{1.8} \mathrm{Cr}_{1.2} \mathrm{O}_{4}$. Therefore, spinel with a high iron content is susceptible to attack by high carbon activity gases. The average $\mathrm{Fe} / \mathrm{Cr}$ ratio for the oxide scale on the surface of Alloy 800 is 2.18, which is much higher than the 0.5 for $\mathrm{FeCr}_{2} \mathrm{O}_{4}$. Therefore, this oxide scale is not protective in the metal dusting environment.
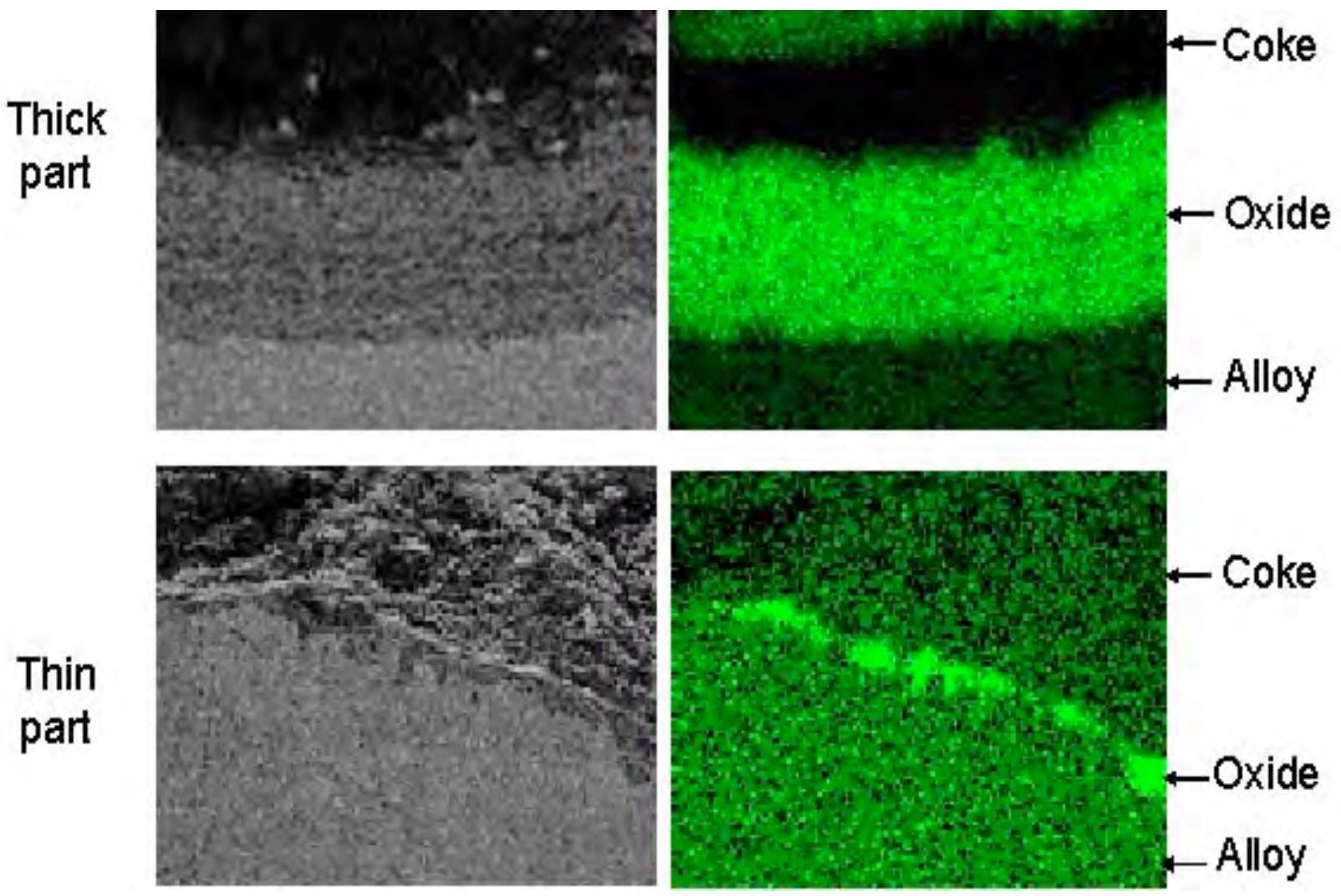

Figure 4.3. EDX map of the cross section of the pipe from a syngas plant. 


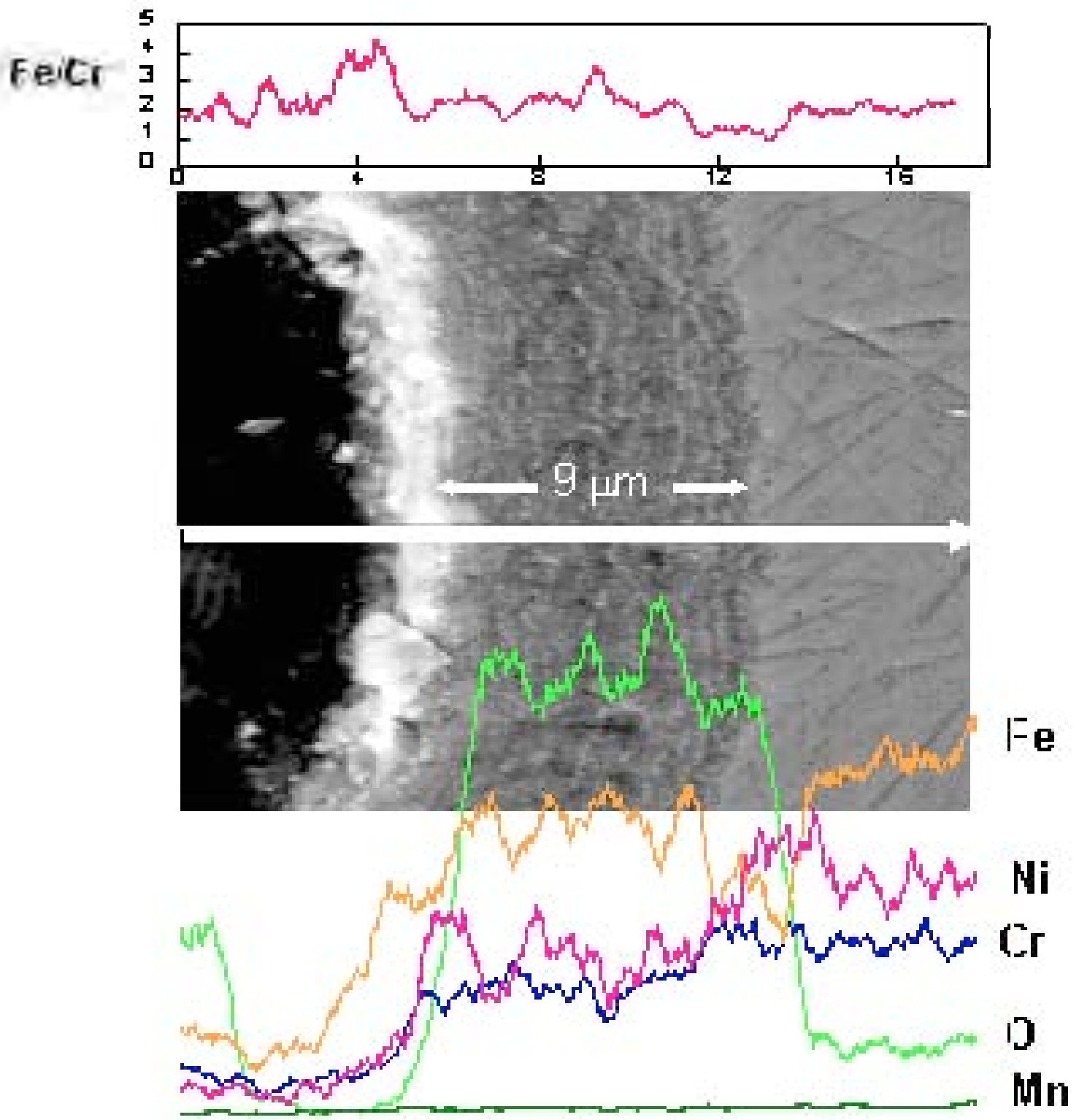

Figure 4.4. EDX line scanning of the cross section of the thick part of the pipe. Oxide scale indicated by $9 \mu \mathrm{m}$ and arrows. Alloy to the right. 


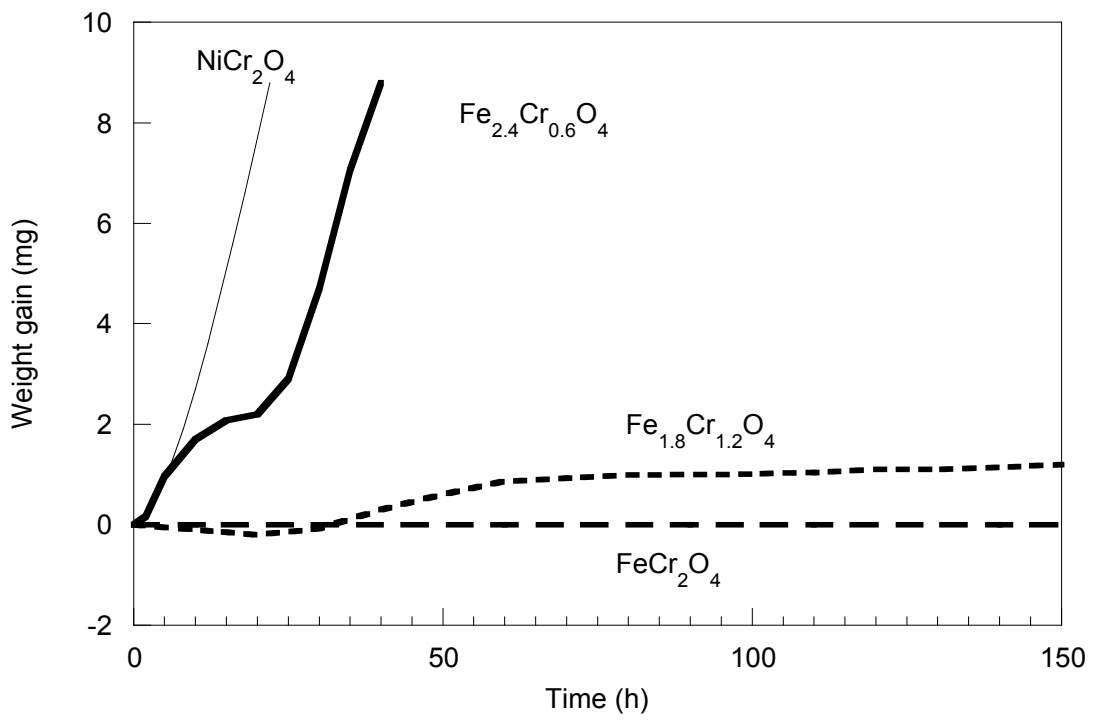

Figure 4.5. Weight change data for several spinels during exposure in Gas 2 (66.2\% $\left.\mathrm{H}_{2}-7.1 \% \mathrm{CO}_{2}-23 \% \mathrm{CO}-1.4 \% \mathrm{CH}_{4}-2.3 \% \mathrm{H}_{2} \mathrm{O}\right)$ at $593^{\circ} \mathrm{C}$.

Raman spectra show spinel as the primary phase in the oxide scale (peaks in Fig. 4.6). There is almost no $\mathrm{Cr}_{2} \mathrm{O}_{3}$ phase in the oxide scale. Previous study (Zeng and Natesan 2003) indicated that $\mathrm{Cr}_{2} \mathrm{O}_{3}$ is a better phase than spinel to resist metal dusting corrosion. Figure 4.7 shows carbon signal that was observed through the oxide scale on the Alloy 800 surface indicating that carbon can even penetrate through the oxide scale. The results from both SEM analysis of the cross section and Raman spectra of the plate surface are similar to those observed in the tube. There was almost no oxide scale on the surface of the thin part of the plate. An oxide scale formed on the surface of the thick part of the plate, but it contained a high-Fe/Cr-ratio spinel and no $\mathrm{Cr}_{2} \mathrm{O}_{3}$.

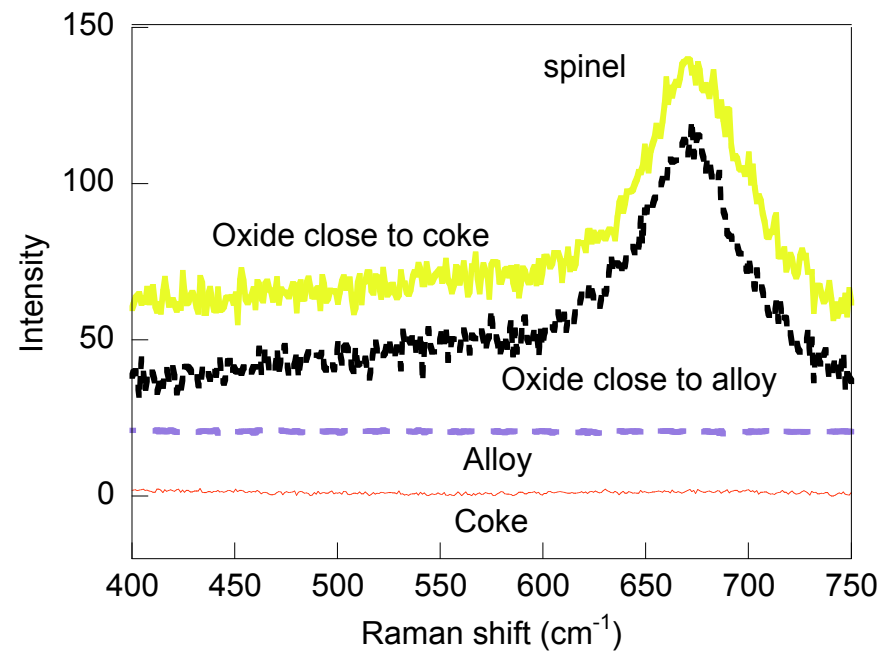

Figure 4.6. Spectra from the cross section of thick part of the pipe for Raman shift of $400-750 \mathrm{~cm}^{-1}$. 


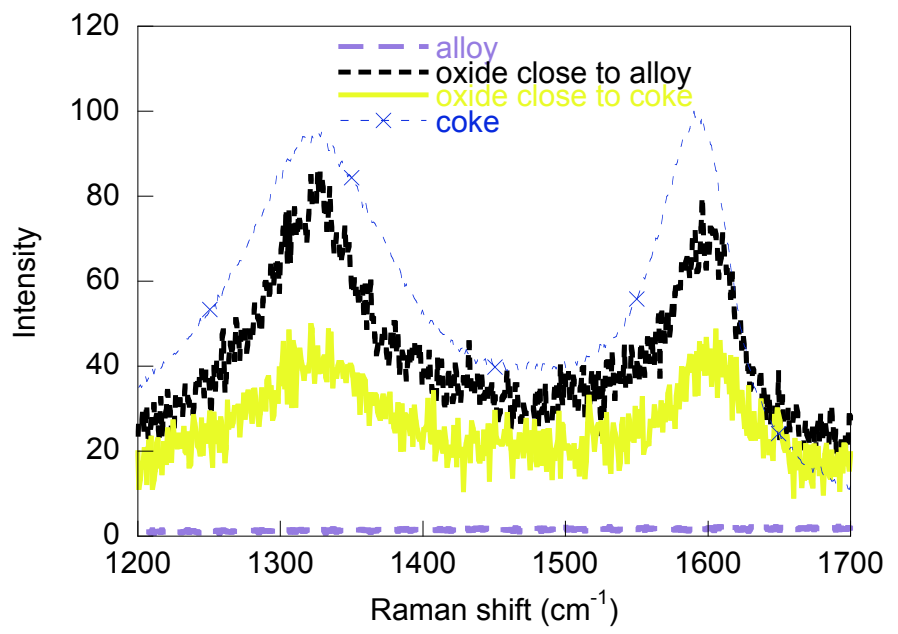

Figure 4.7. Spectra from the cross section of thick part of the pipe for Raman shift of $1200-1700 \mathrm{~cm}^{-1}$.

The phase compositions of $\mathrm{Ni}$-base alloys are different from the Fe-base alloys. Figure 4.8 shows the EDX mapping of the cross section of Alloy 45TM after 3700-h exposure to Gas 10 at $210 \mathrm{psi}$ and $593^{\circ} \mathrm{C}$. This alloy is not as good as other Ni-base alloys at resisting metal dusting corrosion. However, the Fe content in the oxide scale on the surface of Alloy 45TM is much lower $(\mathrm{Fe} / \mathrm{Cr}=0.2)$ than that in the oxide scale on the surface of Alloy $800(\mathrm{Fe} / \mathrm{Cr}=2.15)$. Therefore, the corrosion resistance of even a higher-iron containing Ni-base alloy (Alloy 45TM) is somewhat better than Alloy 800 .
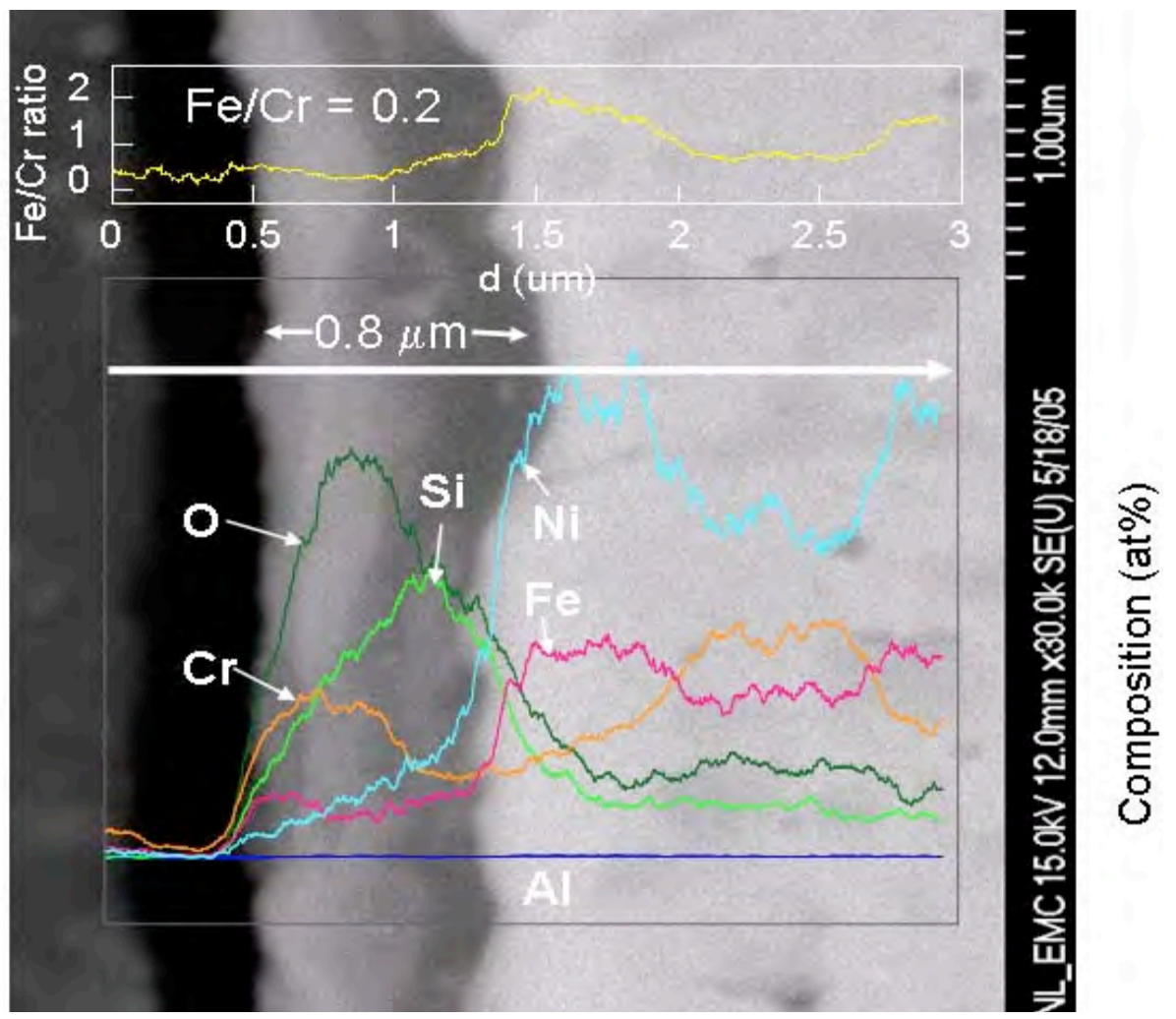

Figure 4.8. EDX line scanning of the cross section of Alloy 45TM after 3700-h exposure to Gas 10 at $593^{\circ} \mathrm{C}$ and $14.3 \mathrm{~atm}(210 \mathrm{psi})$. Oxide scale indicated by $0.8 \mu \mathrm{m}$ and arrows. 


\section{PERFORMANCE OF WELDMENTS}

During this report period, we initiated a metal dusting test on the weldments by exposing them to gas mixture 21 at a carbon activity of $\approx 104$ at $593^{\circ} \mathrm{C}$ and $1 \mathrm{~atm}$. Table 5.1 lists the specimens exposed in this experiment (Run 62). Figure 5.1 shows a macrophotograph of the weldments and corresponding base metals after 3114-h exposure. Figure 5.2 shows the weight loss data for the weldments and corresponding base alloys. The weight loss and pitting were observed on weldments W2, W3, and W7. Weight loss rate for W3 was highest among the weldments, and its base alloy (HR160) was also subjected to metal dusting, although the weight loss rate of HR160 is less than that of Alloy 601.

Table 5.1. Weldments of Ni-base alloys used in the study

\begin{tabular}{|c|c|c|}
\hline Weldment & Base alloy & Filler metal \\
\hline W1 & 602 CA & FM 602 \\
\hline W2 & 230 & $230 \mathrm{~W}$ \\
\hline W3 & HR160 & HR 160 \\
\hline W5 & 690 & FM52 \\
\hline W6 & 693 & 53MD \\
\hline W7 & 601 & 601 \\
\hline
\end{tabular}

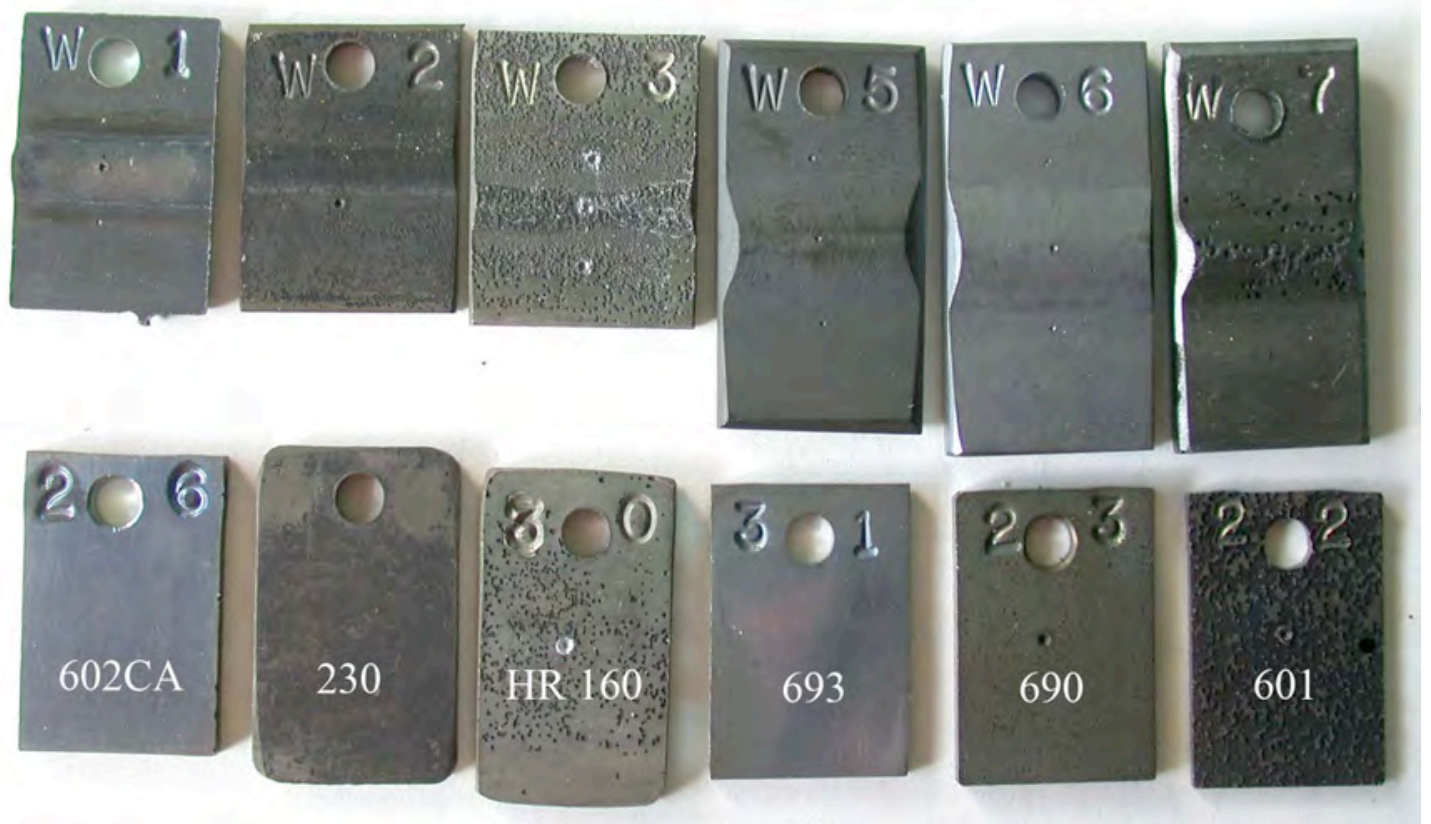

Figure 5.1. Macrophotograph of weldment and corresponding base metal specimens after $3114 \mathrm{~h}$ exposure at $593^{\circ} \mathrm{C}$ and $1 \mathrm{~atm}$ in a gas mixture with a carbon activity of 104 . 


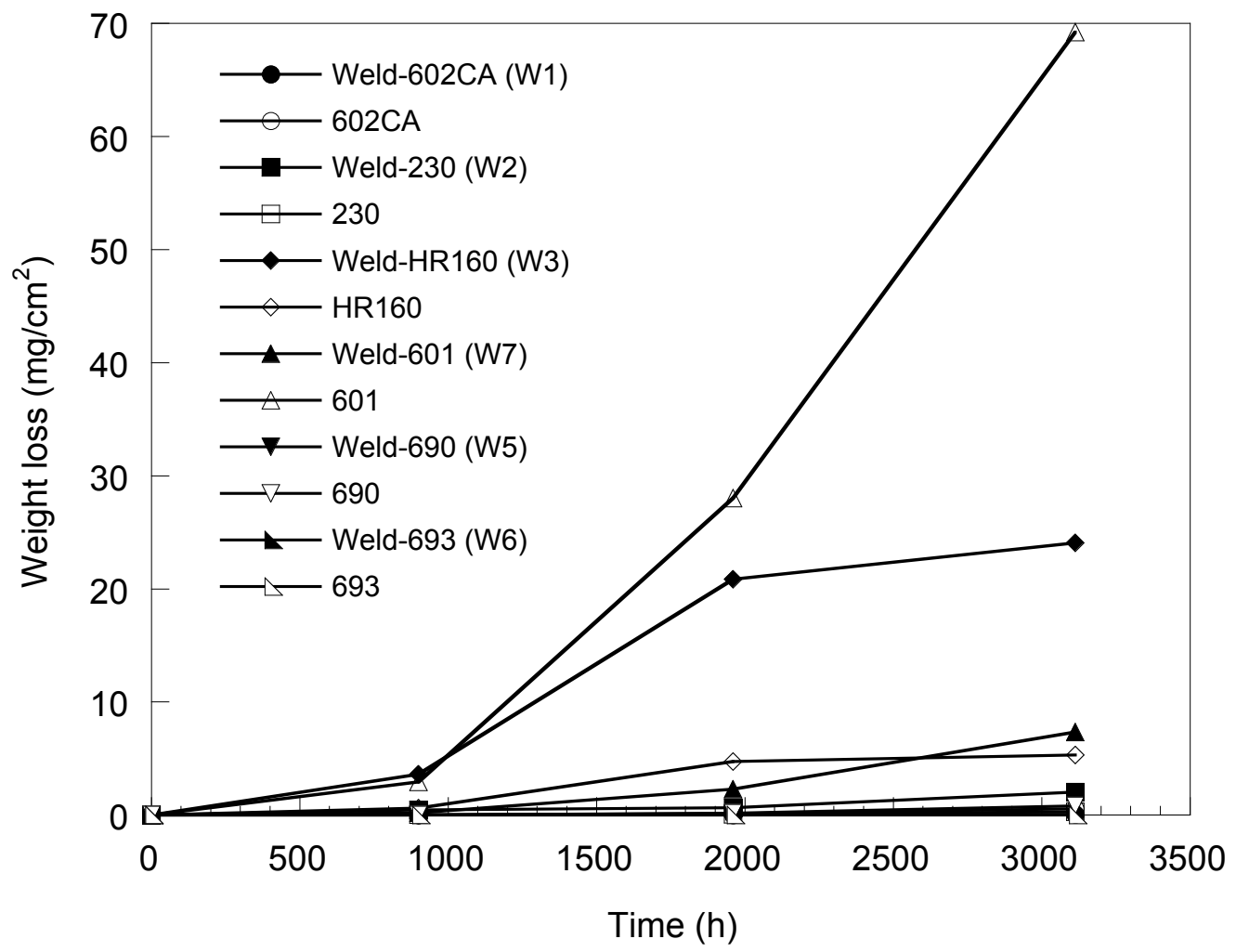

Figure 5.2. Weight loss data for weldment specimens and corresponding base alloys after $3114 \mathrm{~h}$ exposure at $593^{\circ} \mathrm{C}$ and $1 \mathrm{~atm}$ in a gas mixture with a carbon activity of 104 .

Figure 5.3 shows the 3D profile mapping of W3 across the weld area. Pits had coalesced along the boundary of the weld and base alloy. Weldment W7 showed pits predominantly in the weld area (Fig. 5.4), although the composition of both base and filler metals is the same. Figure 5.5 shows a photomicrograph of weldment W7 indicating pit development in the weld zone. Weldment exposures will continue, and analysis of the size, depth, and distribution of pits will be performed as specimens are retrieved from the exposure runs. It is also planned to initiate testing of the Fe-base alloy weldments under similar exposure conditions.
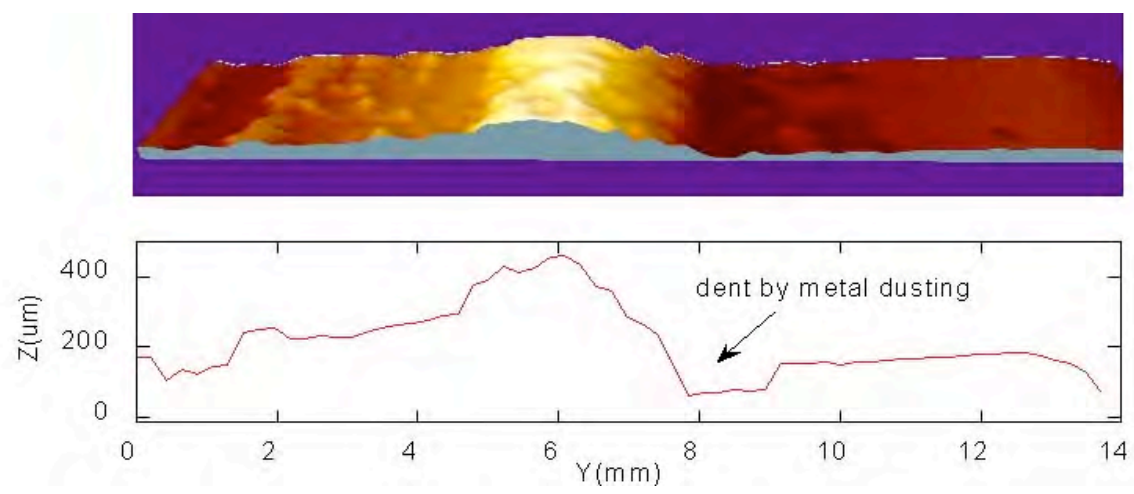

Figure 5.3. Three-dimension profile mapping of weld materials. Metal dusting pits had coalesced into a belt around the boundary of the weld and base alloy. 

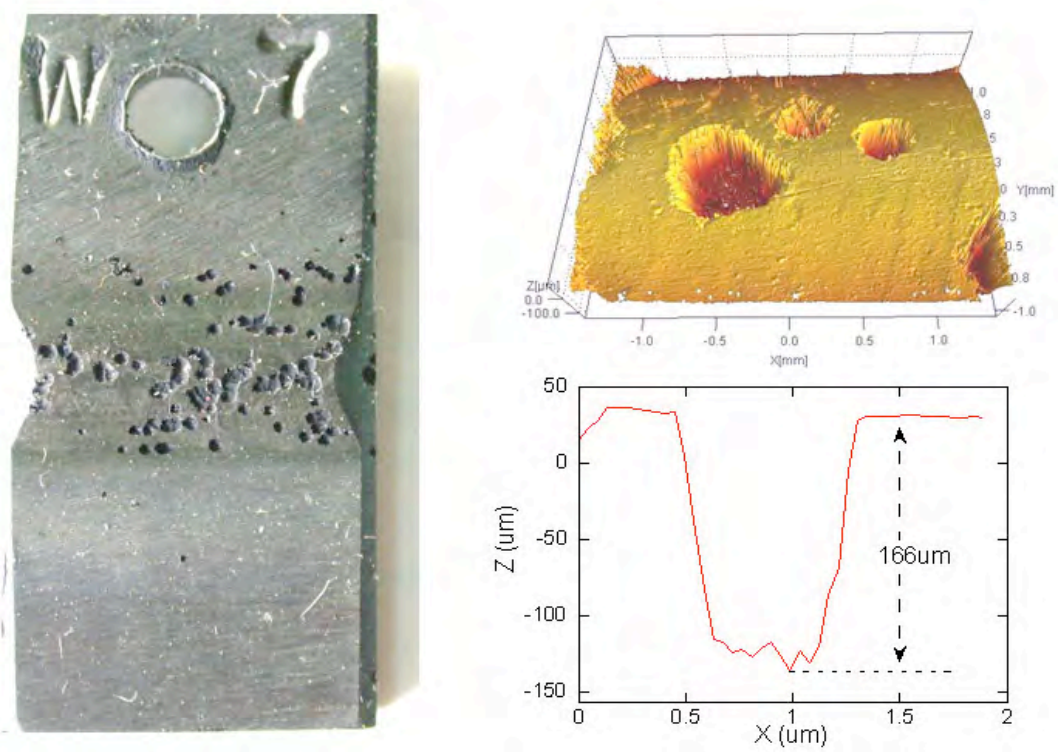

Figure 5.4. Left: Pits at the weld area of weldment W7. Right top: Profile of metal dusting pits at weld area. Right bottom: Depth of a metal dusting pit.

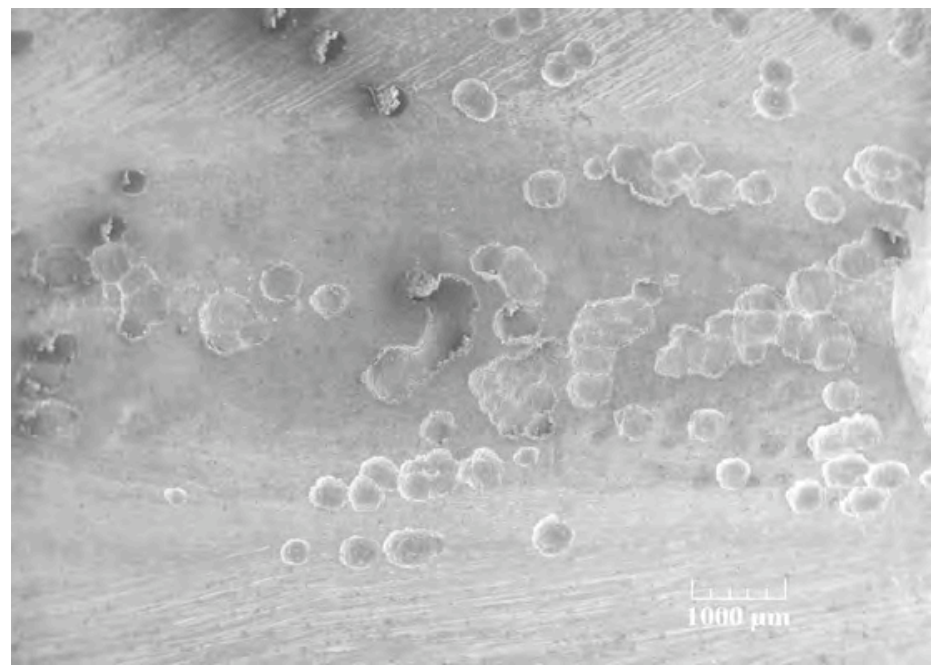

Figure 5.5. Photomicrograph of Weldment W7 showing pits in the weld zone. 


\section{SUMMARY}

The deposition of carbon from carbonaceous gaseous environments is a problemt in many chemical and petrochemical processes, such as reforming systems, syngas production systems, iron ore reduction plants, heat treatment, and others. One of the major consequences of carbon deposition is the degradation of structural materials by a phenomenon known as "metal dusting." An extensive program has been conducted, in recent years, at Argonne National Laboratory to establish the mechanisms for metal dusting degradation in metallic materials exposed to carbonbearing gaseous environments, to identify the key parameters that influence the onset of metal dusting and propagation of degradation, to establish the metal wastage under a variety of exposure conditions, to characterize the morphology of degradation using a wide variety of analytical techniques, and to assess the effect of alloy chemistry and the extent of metal dusting.

During the past year, substantial progress has been made in evaluating the performance of materials subjected to simulated metal dusting environments. We have procured and installed a MicroXam surface profiler for quantitative measurements of pit characteristics, in particular, pit depth. Several accomplishments can be identified from the study as:

- There are two major issues of importance in metal dusting. First is formation of carbon and subsequent deposition of carbon on metallic materials. Second is the initiation of metal dusting in the alloy and subsequent propagation of the degradation. The first is influenced by the $\mathrm{ac}$ in the gas mixture and the availability of the catalytic surface for carbon-producing reactions to proceed. There may be a threshold in ac (>>1) for carbon deposition. Metal dusting of the alloy in the reformer environments is determined by a competition between the oxide scale development and access of the virgin metal surface to the carbon deposit. In a 9700 $\mathrm{h}$ test (Run $59 \mathrm{HP})$ at $593^{\circ} \mathrm{C}$ and $14.3 \mathrm{~atm}(210 \mathrm{psi})$, we characterized the metal dusting performance of several $\mathrm{N}$-base alloys in terms of initiation and propagation of pits.

- By conducting long-term tests at 1 and 14.3 atm, while maintaining a carbon activity of $\approx 31$, we established that the time for initiation of metal dusting is substantially reduced at the higher pressure, even for Ni-base alloys,

- Based on a detailed analysis of pits (in several Ni-base alloys) as a function of exposure time, we correlated the growth in diameter of a single pit with the weight change observed for the alloys. We established that the alloys tested, except Alloy 214 , lose weight by localized pitting when exposed in metal dusting environments. Alloy 214 seemed to undergo uniform attack.

- We have also measured the pit density in several Ni-base alloys using scanning electron microscopy. Pit density for each alloy was found to be different. The 
results indicated higher pit density in Alloys 601 and 45TM when compared to that in Alloys 602CA and 693.

- Generally, the time for initiation of pits in Ni-base alloys is of the order of thousands of hours. However, the pit propagation rate is of major importance in assessing the viability of an alloy for any chemical process application. To expedite the initiation step and thereby emphasize pit propagation, we have developed a pre-pitting approach. We have used Alloy 800 and $9 \mathrm{Cr}$-1Mo steel as surrogate alloys to develop the pre-pitting approach, since these alloys have a short initiation time for pitting. Subsequently, we applied the approach to Ni-base alloys. The method has led to development of multiple specimens of each alloy with pits for further propagation study as a function of process variables such as temperature, system pressure, and gas chemistry.

- We have also developed an approach to identify the locations of pitting by an electrochemical copper deposition approach since the pit locations exhibit low resistance, leading to enhanced deposition of copper. Copper indicator experiments showed that there may be channels for carbon transfer into alloys. These channels can be located because their electrical resistance is much lower than that of the oxide scale.

- We have initiated tests on Ni-base alloys at a carbon activity of 100 at 1 and 30 atm system pressure. The environment in these tests being more aggressive, the time for pit initiation will be short. The emphasis in these tests is to quantify the pit propagation rates and correlate the data with alloy chemistry.

- We have also developed two approaches to mitigate metal dusting. In the first, we have developed alternative alloys by adjusting the composition of the alloy to minimize the outward transport of $\mathrm{Fe}$ from the substrate to the scale, thereby minimizing formation of detrimental spinel phase containing high concentrations of Fe. The second approach is to perform an intermediate oxidation step to stop or slow the growth of existing pits, thereby prolonging the service life of the material and components.

- We conducted a detailed analysis on two Alloy $800 \mathrm{HT}$ components that failed in a hydrogen reformer service. The results showed that the oxide scale on the alloy surface was predominantly $\mathrm{Fe}_{1+\mathrm{x}} \mathrm{Cr}_{2-\mathrm{x}} \mathrm{O}_{4}$ spinel phase with high $\mathrm{Fe}$ content, which has been shown to offer little resistance to metal dusting attack.

- We have procured weldment specimens of several Fe- and Ni-base alloys and have initiated study on metal dusting of Ni-base alloy weldments. The study will focus on the relative performance of the weld metal (if any), heat affected zones, and base metal upon exposure to metal dusting environments. 


\section{ACKNOWLEDGMENTS}

This work is sponsored by the U.S. Department of Energy, Office of Industrial Technologies, and Dr. Sara Dillich is the Program Manager for the project. D. L. Rink assisted with the experimental program, pit depth analysis, and scanning electron microscopy and EDX analysis. The authors acknowledge the members of the steering committee for valuable discussions during the course of this research. Haynes International, Sandvik Steel, Special Metals, Allegheny Ludlum, Krupp VDM, Rolled Alloys, and Outokumpu supplied alloy and weldment specimens of various alloys. The SEM analysis was performed in the Electron Microscopy Center, Materials Science Division, Argonne National Laboratory, Argonne, IL.

\section{REFERENCES}

Natesan, K., 2002, "Study of Metal Dusting Phenomenon and Development of Materials Resistant to Metal Dusting: Annual Report," Argonne National Laboratory Report, ANL02/05.

Natesan, K., and Z. Zeng, 2003, "Study of Metal Dusting Phenomenon and Development of Materials Resistant to Metal Dusting: Final Report," Argonne National Laboratory Report, ANL-03/33.

Natesan, K., Z. Zeng, V. A. Maroni, W. K. Soppet, and D. L. Rink, 2001, "Metal Dusting Research at Argonne National Laboratory," Proc. Intl. Workshop on Metal Dusting, Sept. 26-28, 2001, Argonne National Laboratory, Argonne, IL, p. 19.

Zeng, Z. and K. Natesan, 2003, Chem. Mater., 15, 872.

Zeng, Z., K. Natesan, and M. Grimsditch, 2004, Corrosion, 60, 632.

Zeng, Z., K. Natesan, and V. A. Maroni, 2002, Oxid. Met., 58, 147.

Zeng, Z., K. Natesan, and V. A. Maroni, 2001, "Study of Metal Dusting Mechanism in Iron Using Raman Spectroscopy and X-ray Diffraction," Proc. Intl. Workshop on Metal Dusting, Sept. 26-28, 2001, Argonne National Laboratory, Argonne, IL, p. 93. 
Argonne

Energy Technology Division

Argonne National Laboratory

9700 South Cass Avenue, Bldg. 212

Argonne, IL 60439-4838

www.anl.gov

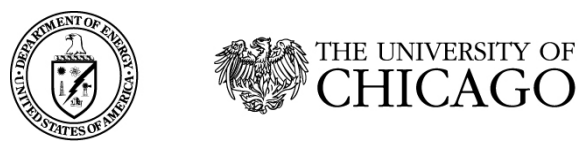

A U.S. Department of Energy laboratory managed by The University of Chicago 